\title{
Comparative Biology of Salticid Spiders at Rancho Grande, Venezuela. Part IV. An Analysis of Display.
}

\author{
JOCELYN CRANE. \\ Research Zoologist, Department of Tropical Research, \\ New York Zoological Society.
}

(Plate I; Text-figures 1-9).

[This is one of a series of papers resulting from the 45 th, 46 th and 47 th Expeditions of the Department of Tropical Research of the New York Zoological Society, made during 1945, 1946 and 1948 under the direction of Dr. William Beebe, with headquarters at Rancho Grande in the National Park of Aragua, Venezuela. The expeditions were made possible through the generous cooperation of the National Government of Venezuela and of the Creole Petroleum Corporation.

[The characteristics of the research area are in brief as follows: Rancho Grande is located in north-central Venezuela $\left(10^{\circ} 21^{\prime} \mathrm{N}\right.$. Lat., $67^{\circ} 41^{\prime}$ W. Long.), 80 kilometers west of Caracas, at an elevation of 1,100 meters in the undisturbed montane rain forest which covers this part of the Caribbean range of the Andes. Adjacent ecological zones include seasonal forest, savanna, thorn woodland, cactus scrub, the fresh-water lake of Valencia and various marine littoral zones. The Rancho Grande area is generally subtropical, being uniformly cool and damp throughout the year because of the prevalence of the mountain cloud cap. The dry season extends from January into April. The average humidity during the expeditions, including parts of both dry and wet seasons, was $92.4 \%$; the average temperature during the same period was $18^{\circ} \mathrm{C}$.; the average annual rainfall over a five-year period was $174 \mathrm{~cm}$. The flora is marked by an abundance of mosses, ferns and epiphytes of many kinds, as well as a few gigantic trees. For further details, see Beebe and Crane, Zoologica, Vol. 32, No. 5, 1947. Unless otherwise stated, the specimens discussed in the present paper were taken in the montane cloud forest zone, within a radius of one kilometer of Rancho Grande.]

\section{CONTENTS.}

I. Introduction

II. Purpose .....

III. Materials and Methods ........

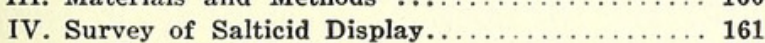

A. Form and Variety $\ldots \ldots \ldots \ldots \ldots \ldots \ldots \ldots \ldots \ldots \ldots \ldots \ldots \ldots$
B. Historical Review $\ldots \ldots \ldots \ldots \ldots \ldots \ldots \ldots$
C. Bases for Disagreements $\ldots \ldots \ldots \ldots \ldots \ldots$

C. Bases for Disagreements $\ldots \ldots \ldots \ldots \ldots \ldots$
D. Prognosis of Evolutionary Pattern $\ldots \ldots \ldots$
173

V. Factors in Display.................... 175

A. Factors of the Internal Releasing Mechanism 175

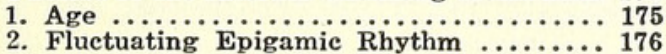

1 Contribution No. 858, Department of Tropical Research, New York Zoological Society.

This paper was awarded Honorable Mention in the A. Cressy Morrison Prize Competition of the New York Academy of Sciences for 1949 .

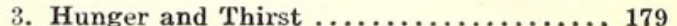

4. Fatigue and Overstimulation $\ldots \ldots \ldots \ldots \ldots \ldots \ldots$

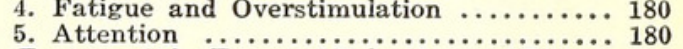

B. Factors of the External Releasing and Direeting Mechanisms .................... 180 1. Physical Environment ................ 180 2. Sensory Elements and Sign Stimuli ..... 181 a. Tactile Perceptions $\ldots \ldots \ldots \ldots \ldots \ldots 181$ i. Chementas i. Chemotaxis ............... 181 ii. Distance Chemoperception ...... 182 c. Vision ...................... 184 i. Vision as a Primary Stimulus..... 184

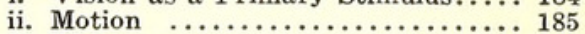
iii. Distance ................... 187 iv. Size $\ldots . . .189$ iv. Size ............................ 189 vi. Pattern, Intensity and Color........ 192

VI. Innate Releasing and Directive Mechanisms.... 199 A. Courtship ...................... 199 B. Threat Display .................. 200

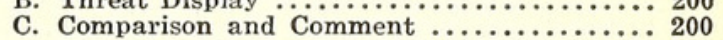

VII. Behavior Related to Display.............. 202 A. Displacement or Substitute Behavior ........ 202

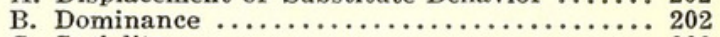

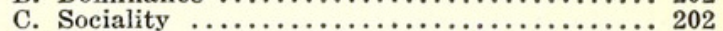

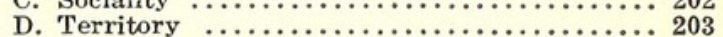

VIII. Functions of Display ............... 203

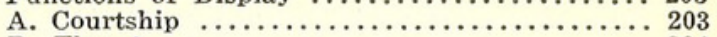

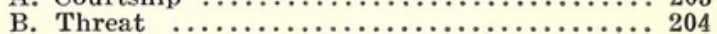

IX. Evolutionary Aspects of Display........... 205

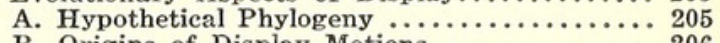

B. Origins of Display Motions ................ 206

C. Relation of Secondary Sexual Characters to Display . . . . . . . 208

D. Sexual Dimorphism and Display ........ 209

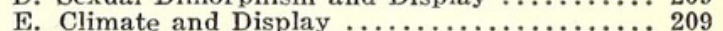

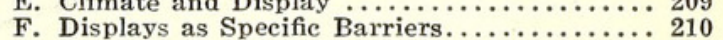

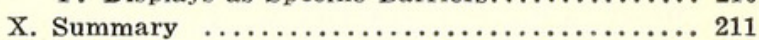

XI. References ................................

\section{INTRODUCTION.}

This is the fourth of a series of papers dealing with the salticid spiders of Rancho Grande, Venezuela. Part I (Crane, 1948.1) discussed the taxonomy and life histories of three species of Corythalia, Part II (1948.2) described methods of study and Part III (1949) dealt with systematics and behavior in eight new species of various groups of genera, as a basis for this and subsequent sections. The present paper on display, while an independent unit, will be followed by sections on comparative post-embryological development and on evolutionary trends, which must, to some extent, be anticipated in the present paper.

My deep appreciation goes to Dr. William Beebe for his continued advice, encouragement and patience during the progress of this study. Special thanks are due Miss 
Louise A. Moore and Mr. Douglas G. Boyden for their work on the drawings and diagrams, respectively.

\section{PURPOSE.}

The purpose of this paper is two-fold: first, to analyze the innate releasing mechanism of display behavior in salticids; second, through a comparison of display and related behavior in widely scattered genera, to shed light on evolutionary trends within the family.

\section{MATERIAL AND METHODS.}

The observational and experimental material in this paper has been drawn primarily from about fifteen species of salticid spiders which are common around Rancho Grande, Venezuela. They were carefully selected from among some thirty-five species in the same locality, in which display behavior was to some degree observed, on the following bases:

1. They represent a wide divergence of salticid forms, belonging to seven relatively well-defined groups of genera. These groups, although they have so far defied satisfactory divisions in keys to include all their borderline genera, are still rather generally recognized as composed of naturally related forms. For convenience, Petrunkevitch's $(1928,1939)$ practice of terming the groups "subfamilies" is followed, although their unequal values and the usual difficulties of salticid systematics are fully recognized. Since the tracing of a pattern of relationships is one of the purposes of this paper, groupings must be attempted. The genera chosen are relatively non-controversial, as are, in their broad outlines, the subfamilies to which they are referred; borderline cases have purposely been omitted. The selected forms are fairly typical members of the following subfamilies designated by Petrunkevitch: Marpissinae, Synagelinae, Dendryphantinae, Magoninae, Hyllinae and Plexippinae. The Lyssomanes group, however, in spite of its aberrant characters will be given only subfamilial status. These terms will be used throughout, in order to simplify correlation by future workers, in spite of questionable validity or priority in any of the old, type genera. Each subfamily corresponds to a group in Chickering's 1946 arrangement, based on Panamanian genera, except that in the present paper the plexippinids and hyllinids will be kept separate, largely in deference to basic behavior differences. From these limitations, it will be seen that the study cannot be expected to help in practical fashion in the determination of fine points of relationship among puzzling genera; rather, it is hoped only to clarify some of the broad outlines of the family's organization.

2. The second criterion of selection has been that each subfamily have a northern as well as neotropical distribution. This has a double advantage, since some comparable display behavior has in each case been already recorded and future comparisons will be facilitated.

3. In three genera, Sassacus, Phiale and Corythalia, intrageneric behavior patterns could be compared.

The thirteen species listed in Table I form the paper's foundation, in the sense that most of the observations and experiments were performed on them. Ten of them were described as new in Parts I and III of this study $(1948.1,1949)$; the remaining three are well known in the tropics. For further comparison, a few casual references will be made to the following Rancho Grande species which are systematically undetermined: Magoninae: Hypaeus sp., Dep't. of Tropical Research Cat. No. 45138; Hyllinae: Phiale sp., Cat. No. 481408; Plexippinae: Eustiromastix sp., Cat. No. 45110; Plexippinae: a genus, probably new, near Capidava, Cat. No. 4586.

In Table II an effort has been made to correlate the relevant observations made upon northern species of the same subfamilies by previous investigators. Complete spider display references to 1939 are given in Bonnet's bibliography (1945, p. 718). Kaston (1936) and Bristowe (1941) give excellent selected references on the subject.

The general methods of observation and experiment at Rancho Grande have already been recorded (Part II, 1948.2). Special information regarding particular experiments will be presented in the body of this paper. See also Pl. I, Fig. 2.

It remains to remark on the usage of several terms. The phrase "epigamic display" has been advocated by a number of behaviorists to replace "courtship," a word which has an undesirable historical burden of anthropomorphism. In the study of salticids, the choice is complicated by the wide range of distinctness of male-female, female-male and inter-male display; a general term seems necessary to cover the entire field. Again, "aposematic display" has been proposed to designate inter-male encounters; in the literature, however, this term is used so widely to cover displays against potential predators-a type of display which is not known to occur in salticids-that a more restricted name appears desirable. Therefore, for present purposes, the following terminology has been adopted: Epigamic display refers to special behavior of either sex which is normally used in any sexual situation, including encounters between males. Courtship applies to those forms of epigamic display which normally precede copulation. Threat display is used for all inter-male display, whether or not it is visually distinct from courtship, and whether or not occasional contact fighting occurs.

"Ornamentation" is used as a convenient term to cover special colors, patterns, tufts, brushes, etc., which, conspicuous to human eyes, are specializations possibly connected 
TABLE I.

\begin{tabular}{|c|c|c|}
\hline $\begin{array}{l}\text { Subfamily acc. to } \\
\text { Petrunkevitch (1939) }\end{array}$ & $\begin{array}{c}\text { Group acc. to } \\
\text { Chickering (1946) }\end{array}$ & Name \\
\hline Lyssomaninae & Lyssomaninae & Lyssomanes bradyspilus Crane, 1949 \\
\hline Marpissinae & Marpissa Group & Menemerus bivittatus (Dufour, 1831) \\
\hline Synagelinae & Zuniga Group & Semorina brachychelyne Crane, 1949 \\
\hline Dendryphantinae & Metaphidippus Group & Ashtabula furcillata Crane, 1949 \\
\hline Dendryphantinae & Metaphidippus Group & Sassacus flavicinctus Crane, 1949 \\
\hline Dendryphantinae & Metaphidippus Group & Sassacus ocellatus Crane, 1949 \\
\hline Magoninae & Amycus Group & Mago dentichelis Crane, 1949 \\
\hline Hyllinae & Phiale Group & Phiale dybowskii (Taczanowski, 1871) \\
\hline Hyllinae & Phiale Group & Phiale flammea Crane, 1949 \\
\hline Plexippinae & Phiale Group & Plexippus paykullii (Audouin, 1827) \\
\hline Plexippinae & Phiale Group & Corythalia chalcea Crane, 1948.1 \\
\hline Plexippinae & Phiale Group & Corythalia fulgipedia Crane, 1948.1 \\
\hline Plexippinae & Phiale Group & Corythalia xanthopa Crane, 1948.1 \\
\hline
\end{tabular}

with epigamic displays. It and similar words are put in quotation marks when it seems wise to emphasize their non-anthropomorphic use. The quotations will simultaneously act as reminders, as advocated by Korzybski (1948), of the every-day, inexact connotations of the terms; another of his safety devices, the frequent use of etc., is employed, not to disguise ignorance, but to emphasize the incomplete state of our knowledge.

The terms sign stimulus, releaser, director, innate releasing mechanism, stimulus configuration and heterogeneous summation are used with the meanings attached to them in Tinbergen's general discussion, in English, of social releasers (1948).

Throughout the present paper, the terms reaction and response are used interchangeably to indicate overt display behavior discernible to the human observer.

Kaston's (1948) nomenclature is followed in all references to species of salticids occurring in the United States.

\section{SURVEY OF SALTICID DISPLAY.}

\section{A. FORM AND VARIETY.}

The general habits and life histories of all salticids are similar and typical of many hunting spiders; they spin no snares, but stalk and leap upon their prey, which they eat promptly; the male copulates in the dorsal position; the female guards the egg cocoon until the emergence of the spiderlings. In the development of their eyes, however, salticids are unique even among long-sighted hunting spiders. In company with the latter, notably the lycosids, and correlated with the acute vision, the salticids have evolved a courtship display which is primarily visual. This is in contrast to the behavior of short-sighted forms, such as the web-spinning epeirids, in which courtship depends on senses other than vision.

As in all groups, there is considerable intra-family variation in details of behavior, particularly in the form and care of the cocoons, in jumping methods, in preferred ecological niches and in physiological tolerances of various kinds. A most important series of differences is based upon an apparently unreported correlation between visual acuity and chemical dependence on the one hand, and method of locomotion on the other. Because of its basic connection with display behavior, this subject will be considered in detail further on (p. 173).

The outstanding directions of development within the family are shown in the very remarkable variety of epigamic display patterns and in the apparently correlated ornamentation of the spiders. All salticids, before inserting the sperm-charged palps into the epigynum of the female, perform some sort of preliminary motions, the form of which, under natural conditions, is a fixed part of the behavior pattern for the species. These movements range from brief and simple elevations of the first legs to complicated and prolonged sequences involving most of the other appendages.

In some salticids there are clear visual distinctions between courtship and intermale threat display, which often employ not only distinctive motions but also different appendages. In each kind of epigamic display, when complete, there are always distinguishable two major stages. Specific display differences, as well as distinctions between courtship and threat, always lie principally in Stage I. Stage II, which immediately precedes either copulation or true fighting as the case may be, is very similar throughout the family; it consists in extending the first legs forward, parallel to each other and slightly elevated. (PI. I, Fig. 1).

Although salticid display is dominantly visual, the role of other senses is proving of considerable secondary importance. Unfortunately, because of the limitations of human sense organs and the lack of appropriate instruments, specific display descriptions must still be largely confined to the reporting of gross visual components. For instance, possible changes in chemical stimuli, which may be emitted in sequence during display, are still necessarily overlooked.

Table II presents correlated data on the displays recorded within the subfamilies 
TABLE II.

Comparative Display Data in Seven Subfamilies of Salticid Spiders.

Name

\section{Marpissa undata} (De Geer)

\section{Marpissa rumpfi Scop.}

\section{Menemerus bivittatus} (Dufour)

\section{Hyctia nivoyi Luc.}

Hyctia pikei Peckham

Salticus cingulatus Panz.

Salticus scenicus (Linn.)

Synageles venator Luc.

Semorina brachychelyne Crane

Gertschia noxiosa (Hentz)

Peckhamia picata (Hentz)
Display References

Courtship Posture (Stage I)

\section{MARPISSINAE}

Peckham, '89, p. 43; fig. ("Marptusa familiaris") (U.S.A.)

Bristowe, '29, p. 330352.

Bristowe, '41, p. 480; fig. (England)

Crane

(Unpublished observations) (Venezuela)

Berland, '27, p. 15; fig. Bristowe, '29, p. 329; fig. Bristowe, '41, p. 484 ; fig. (Europe)

Kaston, '48, p. 455; fig. (U.S.A.)

Bristowe, '29, p. 332.

(England)

Peckham, '89, p. 39. ("Epiblemum scenicum") Gerhardt, '21, p. 131. ("Epiblemum scenicum") Monterosso, '24, p. 1.

Bristowe, '29, p. 332.

Bristowe, ' 41 , p. 480 , 499 ; fig.

(Europe \& U.S.A.)

\section{Synagelinae}

Bristowe, '41, p. 485. (England)

Crane, '49, p. 37. (Venezuela)

Kaston, '48, p. 451; fig. (U.S.A.)

Peckham, '89, p. 43. Peckham, '90, p. 121 ; fig. (U.S.A.)
Carapace high.

1st \& 2nd legs raised slightly stretched laterally.

Abdomen pendent.

Carapace high.

1st legs raised vertically, parallel. Abdomen raised.

Carapace low.

1st legs raised slightly, stretched antero-laterally; 2nd legs ex tended forward.

Abdomen level.

1st legs stretched forward @ $45^{\circ}$; raised \& lowered.

Abdomen often bent sideways. (cf Dendryphantinae).

Carapace low.

1st legs raised vertically @ 00 $45^{\circ}$.

2nd legs extended forward.

Abdomen raised.

Similar to S. scenicus.

1st legs slightly raised, stretched laterally.

Chelicerae opened.

Palps stretched laterally.

1st leg's stretched forward, parallel. Abdomen wriggled or waved from side to side, sometimes raised a little.

1st legs stretched forward, @90 $\angle$, slightly raised.

Abdomen raised; tends to remain high with increasing excitement.

1st legs braced laterally.

Abdomen raised vertically \& swung from side to side.

Carapace high.

1 st legs on ground, bent, convex surface forward.

Abdomen raised vertically.

Spider sways from side to side. 
TABLE II (cont.)

Comparative Display Data in Seven Subfamilies of Salticid Spiders.

\begin{tabular}{l}
.hreat Posture \& Fighting \\
\hline \\
Jaws opened; pressed against \\
those of opponent. \\
Uusually ồ pay no attention to \\
each other; no distinctive mo- \\
tions; rarely courtship to mir- \\
ror image in closed vial.
\end{tabular}

Principal Apparent

Morphological

Adaptations to Display

\section{MARPISSINAE (cont.)}

Slight enlargement basal half of 1 st \& 2 nd leg's.

1st legs elongated, enlarged, darkened.

1st legs elongated, enlarged, darkened.

Runs; jumps only on prey or to cross gaps.

1st legs little used in walking. o vibrates pale palps.

1st legs elongated, enlarged, darkened.

1st legs elongated, enlarged, darkened.

Abdomen boldly striped.

Chelicerae elongated, enlarged, darkened.

1st legs slightly elongated.

Chelicerae elongated, enlarged, darkened.

1st legs slightly elongated.

SyNAGElinaE (cont.)

1st legs enlarged.

1st legs elongated, enlarged, darkened.

Abdomen dark with 2 dorsal white spots.

1st legs elongated, enlarged, darkened.

Abdomen dark with dorsal white bands.

1st legs elongated, enlarged, darkened.

Abdomen dark with dorsal white bands. 1st legs not used in walking, extended forward \& raised to clear ground.

Jerky walk; hops when pursued. (Crane obs. U.S.A.).
Runs; jumps only on prey or to cross gaps.

1st legs stretched to front, parallel; do not touch ground.

ㅇ vibrates palps.

Runs slowly, irregularly, like ant.

(Emerton, 1909). 
TABLE II.

Comparative Display Data in Seven Subfamilies of Salticid Spiders.

Name Display References Courtship Posture (Stage I)

\section{Marpissa undata}

(De Geer)

Marpissa numpfi
Scop.

Menemerus bivittatus (Dufour)

Hyctia nivoyi Luc.

Hyctia pikei Peckham

Salticus cingulatus Panz.

Salticus scenicus (Linn.)

Synageles venator Luc.

Semorina brachychelyne Crane

Gertschia noxiosa (Hentz)

Peckhamia picata (Hentz)

\section{MARPISSINAE} Peckham, ' 89 , p. 43 ; fig;; (U.S.A.)

Bristowe, '29, p. 330352. Bristowe, '41, p. 480; fig. (England)

Crane

(Unpublished observations) (Venezuela)

Berland, '27, p. 15; fig. Bristowe, '29, p. 329; fig. Bristowe, '41, p. 484; fig. (Europe)

Kaston, '48, p. 455; fig. (U.S.A.)

Bristowe, '29, p. 332.
(England)

Peckham, '89, p. 39. ("Epiblemum scenicum") Gerhardt, '21, p. 131 "Epiblemum scenicum") Bonterosso, '24, p. 1. Bristowe, '41, p. 480,499 ; fig. (Europe \& U.S.A.)

\section{SyNAGelinae}

Bristowe, '41, p. 485. (England)

Crane, '49, p. 37. (Venezuela) Kaston, ' 48, p. 451 ; fig.
(U.S.A.)

Peckham, '89, p. 43. Peckham, '90, p. 121 ; fig. (U.S.A.)
Carapace high.

1st \& 2nd legs raised slight stretched laterally.

Carapace high.

Carapace high. Jaws opened; pressed against 1st legs raised vertically, paralle
Abdomen raised.

Uusually $\hat{o} \hat{o}$ pay no attention to 1st legs raised slightly, stretched each other; no distinctive moantero-laterally; 2nd legs tended forward. Abdomen level.

1st legs stretched forward @ L $45^{\circ}$; raised \& lowered.

Abdomen often bent sideways. Dendryphantinae).

Carapace low.

1 st legs raised vertically @ $L$ $45^{\circ}$.

2nd legs extended forward.

Abdomen raised.

Similar to S. scenicus.

1st legs slightly raised, stretche laterally.

wider and palps not stretched
to

(No mirror display. Crane obs.
U.S.A.)

1st legs stretched forward, paralle. side to side, sometimes raised little.

1st legs stretched forward, @ 90 $\angle$, slightly raised.

Abdomen raised; tends to remain high with increasing excitemen

1st legs braced laterally.
Abdomen raised vertically \& swun from side to side.

Carapace high.

1st legs on ground, bent, convex sU face forward.

Abdomen raised vertically.

Spider sways from side to side.
TABLE II (cont.)

Comparative Display Data in Seven Subfamilies of Salticid Spiders.

\begin{tabular}{lll}
\hline Threat Posture \& Fighting & $\begin{array}{l}\text { Principal Apparent } \\
\text { Morphological } \\
\text { Adaptations to Display }\end{array} \quad$ Locomotion \& Remarks \\
\hline
\end{tabular}

MARPISSINAE (cont.)

Slight enlargement basal half of 1 st \& 2 nd legs.

1st legs elongated, enlarged, darkened.

1st legs elongated, enlarged, darkened.

tions; rarely courtship to mirror image in closed vial. darkened.

1st legs elongated, enlarged, darkened.

Abdomen boldly striped.

Chelicerae elongated, enlarged, darkened.

1 st legs slightly elongated.

Chelicerae elongated, en-

larged, darkened.

1st legs slightly elongated.

\section{SyNAgELiNAE (cont.)}

1st legs enlarged.

1st legs elongated, enlarged, darkened.

Apparently no inter-male display. No mirror display.
Abdomen dark
white spots.

1st legs elongated, enlarged,

darkened. white bands.

1st legs elongated, enlarged,

darkened. white bands.
Runs; jumps only on prey or

to cross gaps.
1st legs little used in walking. o vibrates pale palps.

1st legs not used in walking, extended forward \& raised to clear ground. Jerky walk; hops when pur-
sued. (Crane obs. U.S.A.).
Runs; jumps only on prey or

to cross gaps.
1 st legs stretched to front, parallel; do not touch

round.

o vibrates palps.

Runs slowly, irregularly, like ant

Emerton, 1909). 
TABLE II. (cont.)

Comparative Display Data in Seven Subfamilies of Salticid Spiders.

Name

Display References

Courtship Posture (Stage I)

\section{LYSSOMANINAE}

Lyssomanes bradyspilus Crane

Crane, '49, p. 34; see also Text-fig. 8, this paper. (Venezuela)

\section{DENDRYPHANTINAE}

Ashtabula furcillata Crane

Crane, '49, p. 41; fig.

(Venezuela)

Peckham, '89, p. 49; fig.

("Icius mitratus")

(U.S.A.)

Icius elegans (Hentz)

Peckham, 89, p. 46.

("Dendryphantes elegans") (U.S.A.)

Sassacus ocellatus Crane

Crane, '49, p. 45.

(Venezuela)

Crane, '49, p. 41.

(Venezuela)

assacus flavicinctus

Crane

Metaphidippus protervus (Walck.) and/or

M. galathea (Walck.)

Paraphidippus marginatus (Walck.)

Peckham, '89, p. 45; fig. ("Dendryphantes capitatus") (U.S.A.)

Peckham, '89, p. 50; fig. ("Philaeus militaris")
Carapace high, occasionally bobbed

No legs raised; 1 st 3 prs. brace forward.

Palps sometimes tap ground.

Abdomen pendent, twitched.

Prolonged posing in this position as-

Rate of retinal motions within AMI are accelerated.

Carapace high.

1st legs stretched laterally, wave up \& down.

Palps jerk; later are quiet.

Abdomen turned to side.

Carapace high.

1st legs stretched laterally, held a right $\&$ to body.

Abdomen twisted to side.

1st legs waved "in way that remind one of a wind-mill". Later, re volves on tip-toe.

Carapace scarcely elevated.

1 st legs stretched up \& out at righ $\leqslant$ to each other.

Chelicerae closed.

Palps vibrated occasionally.

Abdomen sometimes twisted slightl to side, held motionless.

Carapace moderately high.

1 st legs stretched up at wide $\leqslant t$ each other.

Chelicerae stretched sideways, bu closed.

Palps stretched sideways.

Abdomen trailed inconspicuousl from side to side.

Later: Carapace \& abdomen slowl rocked from side to side.

Carapace low.

1st legs stretched forward, close $t$ ground, slightly curved with tip turned up.

Palps given circular movement.

Later, lies on side, legs still extend ed. (U.S.A.) 1st leg's raised, curved toward eacl other, tips nearly meeting.

Palps moved up and down. 
TABLE II (cont.)

Comparative Display Data in Seven Subfamilies of Salticid Spiders.

Threat Posture \& Fighting

Principal Apparent

Morphological

Adaptations to Display

\section{LYSSOMANINAE (cont.)}

Threat display rarely induced; posture as in courtship, but no bobbing, no abdominal twitching, no acceleration of retinal motions.

Fighting \& mirror display absent.

Apparently no inter-male display. No mirror display.

Same as courtship.

Chases rivals away.

Stage I: Similar to courtship, except chelicerae partly unsheathed, \& no distinct abdominal twisting.

Stage II: Actual fighting, 1st legs raised vertically; chelicerae wide open; palps extended laterally. Clinching frequent, with occasional injury; no deaths seen.

Stage I: Like courtship except no rocking.

Stage II: (Rare). Chelicerae unsheathed, extended forward; 1 st legs raised vertically; clinching; no injuries seen.

Occasional mirror display.

Distinct from courtship. 1st legs raised. Sparring, chasing \& clinching without injury.

Distinct from courtship.

1st legs raised.

Palps vibrated.

Abdomen dragged to either side.

Chasing and clinching without injury.
Distal portion of black retina contrasts with green surroundings.

Chelicerae elongated but not specially displayed.

\section{DENDRYPHANTINAE (cont.)}

1st legs elongated, enlarged, darkened, fringed.

Abdomen with lateral white stripe bounded by iridescence.

1st legs elongated, fringed.

Abdomen with lateral white stripe bounded by darker.

Carapace with frontal tufts. 1st legs elongated; tibia fringed, black-spotted.

Both sexes covered with iridescent scales.

1st legs elongated, enlarged, darkened, with white scales.

Chelicerae elongate, enlarged darkened.

Clypeus with white band.

Abdomen with large, subdistal, white-barred black spots.

1st legs elongated, enlarged, darkened.

Chelicerae elongate, enlarged, darkened.

Clypeus with yellow band.

1st legs elongated, enlarged. White markings on dark palps \& clypeus.

1st legs elongated, enlarged. Chelicerae elongated.
Locomotion \& Remarks

Runs in short spurts. Jumps only in final pounce on prey.

Palps pendent, pat ground during pauses.

1st legs take part in locomotion.

o sags to side when watching display; muscular activity in eyes increase as in $\hat{\delta}$.

Runs; jumps only on prey or to cross gaps.

1st legs unused in progress, held forward, they \& palps tap ground; waved in air in pauses.

ㅇ vibrates palps.

१ "indifferent"; sometimes attacks $\hat{o}$.

ㅇ irritable, prone to attack; later raises abdomen or turns it sideways.

Runs; jumps only to catch prey \& cross gaps.

1st legs held forward, scarcely touch ground; these \& palps wave in air \& tap ground, during pauses.

우 once did weak mutual display.

Runs; jumps occasionally when pursued, as well as to catch prey \& cross gaps.

Palpates ground \& waves 1 st legs less than $S$. ocellatus.
Runs, but hops freely when pursued, as well as to catch prey to cross gaps.

Palps often jerk.

1st legs not waved. Take some part in walking.

(Crane obs. U.S.A.)

ôㅇํ guard immature 우우 until molt. 
TABLE II. (cont.)

Comparative Display Data in Seven Subfamilies of Salticid Spiders.

\begin{tabular}{lll}
\hline \hline Name & Display References $\quad$ Courtship Posture (Stage I)
\end{tabular}

Ashtabula furcillata Crane

Hentzia mitrata (Hentz)

Icius elegans (Hentz)

Sassacus ocellatus Crane

Sassacus flavicinctus Crane

Metaphidippus protervus $M$. galathea (Walck.)

Paraphidippus marginatus (Walck.)

\section{LYSSOMANINAE}

Crane, '49, p. 34; see also Text-fig. 8, this paper.
(Venezuela)

\section{DendRyPHaNTINaE} Crane, '49, p. 41; fig. (Venezuela)

\section{Peckham, '89, p. 49; fig.} ("Icius m.S.A.)

Peckham, 89, p. 46. ("Dendryphantes elegans") Crane, '49, p. 45

Crane, '49, p. 41 (Venezuela)

Peckham, '89, p. 45; fig. ("Dendryphantes capitatus")

Peckham, '89, p. 50; fig. ("Philaeus militaris")

TABLE II (cont.)

Comparative Display Data in Seven Subfamilies of Salticid Spiders.

Threat Posture \& Fighting

Carapace high, occasionally bobbed o legs raised; 1st 3 prs. brace forward.

Palps sometimes tap ground. Abdomen pendent, twitched.

asRate of retinal motions within AMB are accelerated.

Carapace high

st legs stretched laterall, ingrertly no inter-male disup \& down.

Palps jerk; later are quiet.
Abdomen turned to side.

Carapace high

Same as courtship.

1st legs stretched laterally, held at Chases rivals away.

Abmen twisted to

1st legs waved "in way that reminds volves on tip-toe.

Carapace scarcely elevated. st legs stretched up \& out at rig Chelicerae closed.

Palps vibrated occasionally. Palps vibrated occasionally

to side, held motionless.

Carapace moderately high 1 st legs stretched up at wide $\measuredangle$

each other.
Chelicerae stretched sideways, closed.

Palps stretched sideways.

Abdomen trailed inconspicuousls from side to side.

Later: Carapace \& abdomen

Carapace low.

st legs stretched forward, close ground, slightly curved with th ground, sli posture as in courtship, but n Later, lies on side, legs still ex ed.

1st legs raised, curved toward other, tips nearly meetin.
Palps moved up and down.

Principal Apparent

Adaptations to Display

Threat display rarely induced; obbing, no abdominal twitch ing, no

motions. \& mirror display absent.

play, No mirror display.

Lyssomaninae (cont.)

Distal portion of black retina contrasts with green surndings.

Chelicerae elongated but not specially displayed.

\section{DENDRYPHANTINAE (cont.)}

1st legs elongated, enlarged, darkened, fringed.

Abdomen with lateral white cence.

1st legs elongated, fringed. Abdomen with lateral white
stripe bounded by darker.

Carapace with frontal tufts. 1st legs elongated; tibia fringed, black-spotted. Both sexes covered with iridescent scales.

1st legs elongated, enlarged, darkened, with white scales. Chelicerae elongate, enlarged darkened.

age 1: Similar to courts except chelicerae partly unsheathed, \& no distinct abdominal twisting.

age II: Actual fighting, 1st legs raised vertically; chelicerae wide open; palps exfrequent, with occasional injury; no deaths seen.

stage I: Like courtship except no rocking.

tage II: (Rare). Chelicerae unsheathed, extended forward; 1st legs raised vertically; clinching; no injuries seen.

ccasional mirror display.

Distinct from courtship. 1st legs raised. Sparring, chasing \& clinching without injury.

Distinct from courtship.

Palps vibised.

Abdomen dragged to either side. Chasing and elinching without dypeus with white band.

dith large, subspots.

1st legs elongated, enlarged, darkened.

Chelicerae elongate, en-

larged, darkened.

Clypeus with yellow band.

1st legs elongated, enlarged. palps \& clypeus.

1st legs elongated, enlarged. Chelicerae elongated.
Locomotion \& Remarks

Runs in short spurts. Jumps only in final pounce on prey, Palps pendent, pat ground during pauses.

1st legs take part in locomo-

tion.
sags to side when watching display; muscular activity in eyes increase as in $\delta$.

Runs; jumps only on prey or to cross gaps.

progress, held forward, they \& palps tap ground; waved in air in pauses.

$q$ vibrates palps.

"indifferent"; sometimes attacks $\hat{\delta}$.

irritable, prone to attack later raises abdomen or turns it sideways.

Runs; jumps only to eatch prey \& cross gaps.

1st le ly touch ground; these \& palps wave in air \& tap palps during pauses.

once did weak mutual display.

Runs; jumps occasionally when pursued, as well as to catch prey \& cross gaps. Palpates ground \& waves 1 st . ocellatus.

Runs, but hops freely when pursued, as well as to catch prey to cross gaps.

Palps often jerk.

1st legs not waved. Take some part in walking.

(Crane obs. U.S.A.)

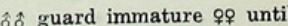
molt. 
TABLE II. (cont.)

Comparative Display Data in Seven Subfamilies of Salticid Spiders.

Name

Phidippus audax (Hentz)

Phidippus clarus

Keyserling

Phidippus purpuratus Keyserling

\section{Phidippus whitmanii} Peckham

Philaeus chrysops Poda

Phiale flammea Crane
Display References

Courtship Posture (Stage I)
Kaston, '36, p. 121; fig. (U.S.A.)

Peckham, '89, p. 44. ("Phidippus rufus")

(U.S.A.) (U.S.A.)

\section{DENDRYPHANTINAE (cont.)}

("Phidippus morsitans") Kaston, '36, p. 120; fig. (U.S.A.)
Kaston, '36, p. 118; fig.

Carapace moderately high.

1st legs raised in 2 jerks, stretcher obliquely out at $\angle$ of $45^{\circ}$ t ground; later waved alternately Palps raised and lowered rapidl. when close to ․

Carapace moderately high.

1st legs stretched out, the femu: obliquely up, other segment: paralleling ground.

Palps sometimes widely spread.

Abdomen now \& then moved from side to side.

Carapace high.

1st legs stretched out, held highe] than in clarus \& audax; waved.

Palps held wide apart, parallel with each other, occasionally drummec on ground.

Abdomen dropped.

Carapace high.

1st legs stretched forward \& up crossed at tips.

Palps held wide apart, parallel with 2nd legs.

Abdomen dropped.

Sways during advance.

\section{HyLLINAE}

Bristowe, '29, p. 333.

Bristowe, '41, p. 480 .

(England)

Homann, '28, p. 249; fig.

("E. blanchardi")

(Germany)

Berland, '14, p. 116.

Thomas, '29, p. 267.

Bonnet,' '33, p. 139; fig.

(France)

Crane, '49, p. 48.

(Venezuela)
Some waving of 1 st legs \& twitching of abdomen, but tends to leap on o with almost no display.

Carapace high.

1st legs raised \& waved up \& down Palps vibrated.

Abdomen slightly elevated.

Courtship sometimes almost absent. Leaps on of suddenly.

Carapace high.

1st legs raised at $45^{\circ} \angle$ to each other \& ground.

Palps vibrated irregularly.

Abdomen lowered.

Carapace rocked from side to side.

Later, sinks low, 1st legs stretched to front. 
TABLE II (cont.)

Comparative Display Data in Seven Subfamilies of Salticid Spiders.

hreat Posture \& Fighting
ike courtship, until opponents
close; then chelicerae \& fangs
opened wide; some o fighting.

s in $P$. audax.

\section{Principal Apparent}

Morphological Adaptations to Display

\section{DENDRYPHANTINAE (cont.)}

1st legs elongated, enlarged, with white fringes and scales.

Palps with white scales.

1st legs elongated, enlarged, lightly fringed.

Palps with white band.

1st legs elongated, enlarged, heavily fringed.

Clypeus with white fringe.

1st legs elongated, enlarged, heavily fringed.

\section{HyLuinae (cont.)}

1st legs elongated, enlarged, darkened; palps pale, whitehaired.

1st legs elongated, darkened with light tufts \& scales.

1st legs elongated, darkened. Clypeus \& palps with buffy yellow bands against black.
Both sexes savage, prone to eat mate.

\section{Locomotion \& Remarks}

iffers from courtship in quiet palps \& absence of low stage. t close quarters, chelicerae open, 1st legs spread widely, often touch opponent's; no injuries.

isplays freely to mirror.

Hopping well developed.

Excellent visual acuity; hops skilfully when pursued.

Berland \& Thomas saw frequent leg-waving when spiders were alone in field and in clean boxes; Bonnet saw waving only before 우․

Basically a runner although jumps readily over gaps; 1st legs little used in walking, habitually waved during pauses; true also of 우 $\&$ young.

우 raises 1st legs \& vibrates palps during display. 
TABLE II. (cont.)

Comparative Display Data in Seven Subfamilies of Salticid Spiders.
TABLE II (cont.)

Comparative Display Data in Seven Subfamilies of Salticid Spiders.

Name Display References $\quad$ Courtship Posture (Stage I)

\section{DENDRYPHANTINAE (cont.)}

Phidippus audax (Hentz) Peckham, '89, p. 45. ("Phidippus morsitans") (U.S.A.)

Kaston, '36, p. 118; fig. (U.S.A.)

Kaston, '36, p. 121; fig. (U.S.A.)

Keyserling

Phidippus whitmani Peckham

Evarcha falcata B].

Philaeus chrysops Poda

Peckham, '89, p. 44 ("Phidippus rufus")

\section{HYLLINAE}

Bristowe, '29, p. 333. Bristowe, '41, p. 480 .

(England)

Homann, '28, p. 249; fig.

("E. blanchardi")

(Germany)

Berland, '14, p. 116

Thomas, '29, p. 267

Bonnet,'33, p. 139; fig.

(France)

Crane, '49, p. 48.
Carapace moderately high.

st legs raised in 2 jerks, stretc obliquely out at $\angle$ of $45^{\circ}$ ground; later waved alternatel Palps raised and lowered rapid
when close to $\circ$.

Carapace moderately high.

st legs stretched out, the femv obliquely up, oth

Palps sometimes widely spread.

Abdomen now \& then moved side to side.

Carapace high

1st legs stretched out, held highe than in clarus \& audax; waved.

Palps held wide apart, parallel wit each other, occasionally drumme on ground.

Abdomen dropped.

Carapace high

1st legs stretched forward \& up crossed at tips.

Palps held wide apart, parallel wit

bdomen dropped.

Sways during advance.

(Venezuela)
Some waving of 1 st legs \& twitching o with almost no display.

Carapace high.

1st legs raised \& waved up \& down. Palps vibrated.

Abdomen slightly elevated.

Courtship sometimes almost absent Leaps on 9 suddenly.

Carapace high. \& ground.

Palps vibrated irregularly.

Abdomen lowered.

Carapace rowered.

Larer sinks low, 1st legs stretched

to front.
Principal Apparent

Morphological
Adaptations to Display

Locomotion \& Remarks

reat Posture \& Fighting

DENDRYPHANTINAE (cont.)

1st legs elongated, enlarged, with white fringes and

Palps with

Like courtship, until opponents close; then chelicerae \& fangs

in P. audax.

1st legs elongated, enlarged, lightly fringed.

Palps with white band.

1st legs elongated, enlarged, heavily fringed.

Clypeus with white fringe.

1st legs elongated, enlarged, heavily fringed.

\section{HyLuinae (cont.)}

1st legs elongated, enlarged, darkened;palps pale, whitehaired.

1st legs elongated, darkened with light tufts \& scales.

fifers from courtship in quiet palps \& absence of low stage. close quarters, chelicerae open, 1st legs spread widely, often touch opponent's;

splays freely to mirror.
Both sexes savage, prone to

eat mate.

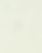


TABLE II. (cont.)

Comparative Display Data in Seven Subfamilies of Salticid Spiders.

Name

Display References

Courtship Posture (Stage I)

\section{Plexippinae}

Plexippus paykullii Aud. Crane (unpublished obs.); Pl. I, fig. 1, this paper. (Venezuela)

Eustiromastix sp.

Crane (unpublished obs.). (Venezuela)

Berland, '23, p. 206.

Berland, '27, p. 15; fig. (France)

Crane, '48.1, p. 35 ; figs. (also, see footnote, this paper, $p$. 183).

(Venezuela)

Corythalia xanthopa
Crane
Corythalia fulgipedia Crane
Crane, '48.1, p. 28; figs. (Venezuela)
Carapace very high.

1st legs stretched forward, up \& out at varying wide $k$, higher witl excitement; no waving.

Palps quiet.

Abdomen pendent.

Prolonged posing in display posi tion.

Carapace high.

1st legs raised antero-laterally @ L of $45^{\circ}$ to ground; sometime jerked, \& raised higher.

Palps vibrate.

Abdomen horizontal.

Some posing in display position.

3rd legs wave.

Carapace moderately high.

Palps hanging, motionless.

Abdomen slightly below horizontal

Stage Ia: Side-to-side rocking, al feet on ground.

Stage Ib: 1st legs stretched for ward, straight, parallel @ $45^{\circ}$ to ground.

No posing in display position.
Crane, '48.1, p. 21; figs. (Venezuela)
Carapace moderately high.

Palps hanging, motionless.

Abdomen about horizontal.

3rd legs stretched out, waved up $\delta$ down in unison above the hori zontal.

No posing in display position.

Carapace progressively lowered.

Palps jerked in unison.

Abdomen about horizontal.

1st, 2nd, \& 3rd legs stretched far ou to sides, the 3rd legs being slight ly intermittently raised \& vi brated up \& down in unison witl body.

No posing in display position. 


\section{TABLE II (cont.)}

Comparative Display Data in Seven Subfamilies of Salticid Spiders.

Threat Posture \& Fighting

Principal Apparent of clypeus.

abdomen pendent

and, 3rd \& 4th legs off ground, raised successively higher.

Prolonged posing. No fighting. Displays freely to mirror.

Distinct from courtship, although same legs used.

Differs in waving 3rd legs below horizontal, often in an arch; prolonged posing.

Palps flexed \& stiff.

No fighting.

Displays freely to mirror.

Distinct from courtship, although similar in very first phase, \& same legs used throughout. Whereas in courtship carapace sinks lower, in threat it rises higher. At peak, all legs are drawn close in \& stretch up. 2nd tarsi leave ground \& 3rd legs are raised slightly; body rocks from side to side; posing with 3rd legs arched frequent. Palps jerked at beginning, later flexed \& stiff.

No fighting.

Displays freely to mirror.
Morphological

Adaptations to Display

\section{Plexippinae (cont.)}

1st legs elongated, enlarged, darkened.

White clypeus band against black.

1st legs slightly longer, thicker, blacker than others.

3rd legs elongated, compressed, fringed.

Palps \& clypeus with yellow bands.

2nd, 3rd \& 4th legs fringed, compressed, with iridescent patches; 3rd \& 4th legs elongated.

Locomotion \& Remarks

Hops often even during ordinary progress.

ㅇ completely passive.

Hops often even during ordinary progress.

1st legs take active part in walking.

Palps quiet.

o extremely savage both before \& after mating; often kills ô.

Performs display motions even when alone in clean boxes.

Ordinary progress consists largely of hopping.

1st legs take active part in walking.

Palps quiet.

o not aggressive; when watching display, sits high with braced legs until receptive, then crouches.

1st, 2nd \& 3rd legs fringed, compressed, with iridescent patches; 3rd legs elongated.

Locomotion as in xanthopa.

우 sometimes aggressive, may do some form of reciprocal display.

Locomotion as in xanthopa. o more aggressive than most salticids, although not seen to injure $\hat{o}$; when stimulated performs rough, reciprocal display. st, 2nd \& 3rd legs fringed, patches strongly developed; 3rd legs elongated.

Palps with white patches. 
TABLE II. (cont.)

Comparative Display Data in Seven Subfamilies of Salticid Spiders.

\begin{tabular}{lll}
\hline Name & Display References $\quad$ Courtship Posture (Stage I)
\end{tabular}

Plexippus paykullii Aud.

\section{PlexipPINAe}

rane (unpublished obs.); Pl. I, fig. 1, this paper. (Venezuela)

Eustiromastix sp.

Crane (unpublished obs.) (Venezuela)

Saitis barbipes Sim. Corythalia xanthopa

Corythalia chalcea Crane Crane, '48.1, p. 21; figs.
(Venezuela)

Berland, '23, p. 206 Berland, '27, p. 15; fig. (France)

Crane, '48.1, p. 35 ; figs. (also, 183) (Venezuela)
Carapace very high. at varying wide 4 higher excitement; no waving. Palps quiet.

Abdomen pendent.

Prolonged posing in display pos tion.

Carapace high.

Crane, '48.1, p. 28; figs. (Venezuela)

TABLE II (cont.)

Comparative Display Data in Seven Subfamilies of Salticid Spiders. legs raised antero-laterally $\angle$ of $45^{\circ}$ to ground; someti jerked, \& raise

Abdomen horizontal.

Some posing in display position

3rd legs wave.

Carapace moderately high.

Palps hanging, motionless.

Stage Ia: Side-to-side rocking, all

feet on ground.

Stage Ib: 1st legs stretched for ward, straight, parallel @ L $5^{\circ}$ to ground.

No posing in display position.

Carapace moderately high. Palps hanging, motionless. Abdomen about horizontal.

3rd legs stretched out, waved up down in unison above the hor zontal.

No posing in display position. threat similar to early courtship but abdomen lowered \& palps quiet.

mirror display, sometimes ending in attack.

Same as courtship.

mpletely distinct from courtship.

Palps motionless, flexed, their vellow scales continuing band of clypeus.

\section{Abdomen pendent.}

2nd, 3rd \& 4th legs off ground, raised successively higher. No fighting

Distinct from courtship, although same legs used.

hers in waving 3 rd legs below horizontal, often in an arch; palps flexed \& stiff.

No fighting.

Displays freely to mirror.

Carapace progressively lowered. Palps jerked in unison.

Abdomen about horizontal. st, 2nd, \& 3rd legs stretched far to sides, the 3rd legs being \& y intermittently raised \& body.

No posing in display position.

stinct from courtship, although similar in very first phase, \& same legs used throughout. Whereas in courtship carapace higs lower, in threat it rises drawn. At peak, all legs are 2nd tarsi in \& stretch up legs are raised slightly \& 3rd

Principal Apparent
Morphological
Adaptations to Display

Adaptations to Display

Locomotion \& Remarks

arcely developed; rarely, brief

Carapace very high

Plexippinae (cont.)

White clypeus band against rocks from side to side; body with 3rd legs arched frequent. alps jerked at beginning, later flexed \& stiff.

Displays freel

plays freely to mirror. 1st legs elongated, enlarged, darkened. black.

1st legs slightly longer, thicker, blacker than others.

rd legs elongated, compressed, fringed.

Palps \& clypeus with yellow

nd, 3rd \& 4th legs fringed compressed, with iridescent elongated.

1st, 2nd \& 3rd legs fringed compressed, with iridescent patches; 3rd legs elongated.

Hops often even during ordinary progress.

completely passive.

Hops often even during ordinary progress.

active part in walking.

o extremely savage both before \& after mating; often kills $\hat{\text { s. }}$.

Performs display motions even when alone in clean boxes.

Ordinary progress consists largely of hopping.

1st legs take active part in walking.

q not aggressive; when watching display, sits high with then crouches.

Locomotion as in xanthopa. sometimes aggressive, may do some form of reciprocal display.

1st, 2nd \& 3rd legs fringed compressed, with iridescen patches strongly developed; 3rd legs elongated. Palps with white patches.
Locomotion as in xanthopa. although not seen to injure $\hat{\delta}$; when stimulated performs rough, reciprocal display. o more aggressive than most 
TABLE II. (cont.)

Comparative Display Data in Seven Subfamilies of Salticid Spiders.

Name

Display References

Courtship Posture (Stage I)

Mago dentichelis Crane

Crane, '49, p. 48; fig.

(Venezuela)

\section{MAGONINAE}

Maevia vittata (Hentz)

Peckham, '89, p. 54; fig.

("Astia vittata")

(Wisconsin, U.S.A.)

Painter, '13, p. 625.

(Connecticut, U.S.A.)

Ballus depressus Walk.

Bristowe, '31, p. 1409; fig.

Bristowe, '41, p. 484 ; fig. (England)
Displays of the 2 forms differ.

Gray form: Carapace high; 1 st leg raised, waved, palps stretche sideways; abdomen down; later whole body low, 1st \& 2nd leg forward, tips touching; palp forward. (Peckham, Wisc.).

Low stage precedes high stage (Painter, Conn.).

Black, tufted form: Carapace ver: high; 1st legs raised \& waved, 0 held high in pose.

(Peckham \& Painter).

Carapace slightly raised.

1st legs stretched sideways slightly forward; waved alter nately up and down or held is pose.

2nd tarsi touch ground, far out $\delta$ slightly forward.

Abdomen sometimes vibrated.

All legs on ground, drawn in, sway body from side to side. under consideration in this paper. Text-fig. 1 and Table III will give some idea of the variety of display motions throughout the family. All displays unite at least several of the listed movements, and many involve all of the major headings except that of retinal motion, which so far appears to operate as part of the signal mechanism only in Lyssomanes.

No less varied are the forms of "ornamentation" in the family; these occur too often on displayed appendages to be explained only by chance mutations, metabolic processes, other behavior patterns, etc. They include many specializations of size, shape, hair concentration, scalation and pigmentation, several forms usually occurring in a single spider. For example, the first legs, which always enter at least into Stage II courtships, are often elongated, thickened and much darker than the others; in addition, the palps, which frequently vibrate during display, in many species show patches of shiny white scales. Again, in Corythalia xanthopa, the fourth legs, elevated only in threat display, are prominantly fringed; in the related C. chalcea, in which they never leave the ground, fringes are absent. Many other examples occur in the literature, of which the Peckham's original series are among the best $(1889,1890)$. The striking point is that any appendage specially exhibited in epigamic display usually shows some differentiation which is to human eyes conspicuous.

However, two other obvious points must be kept in mind. First, not all parts active in display are so ornamented; an example is the brown abdomen of Semorina, relieved only with small, pale inconstant spots. Second, not all parts conspicuously ornamented (again, to human eyes) play any demonstrable part whatsoever in display. Examples are the bright scarlet abdomen of Phiale flammea and the striking carapace bands of various Phiale and Corythalia.

\section{B. Historical Review.}

The history of the study of salticid display reflects the changing ideas of evolutionists. The Peckhams pioneered both in the recording and explanation of epigamic display and of the apparently correlated ornamentation $(1889,1890)$. According to them, the phenomena were due to direct Darwinian sexual selection; the females, consciously or unconsciously, were affected by the performances, colors and beauty of the males, selecting the most handsome or at least the most striking. Male battles were initiated both for simple possession of a mate and as sham contests for the females' edification. The Peck- 
TABLE II. (cont.)

Comparative Display Data in Seven Subfamilies of Salticid Spiders.

\begin{tabular}{|c|c|c|}
\hline hreat Posture \& Fighting & $\begin{array}{l}\text { Principal Apparent } \\
\text { Morphological } \\
\text { Adaptations to Display }\end{array}$ & Locomotion \& Remarks \\
\hline & MAGONINAE (cont.) & \\
\hline $\begin{array}{l}\text { Vave 1st legs at each other but } \\
\text { "quarrels . . harmless" } \\
\text { (Peckham). } \\
\text { isplays to mirror. }\end{array}$ & $\begin{array}{l}\text { Tufted form is black anteri- } \\
\text { orly, has cephalic tufts. }\end{array}$ & $\begin{array}{l}\text { Peckham \& Painter disagree } \\
\text { on selection value of di- } \\
\text { morphism. } \\
\text { o } \text { irritable; fight each other. }\end{array}$ \\
\hline
\end{tabular}

tage I: Similar to courtship. tage II: 1st legs waved higher, almost meet overhead; when lowered, 1st \& 2nd tarsi rub together. Rarely, chelicerae opened and knocked repeatedly against opponent's; no injuries.

Displays to mirror. 1st \& 2nd legs enlarged, blackened.

1st legs enlarged, partly blackened.
5 other Venezuelan magoninids use all legs actively in walking, hop freely during ordinary locomotion.

All include rubbing of 1 st \& 2nd tarsi in display.

ㅇ usually extends 1st legs during courtship.

우 vibrates light palps. hams disagreed strongly with Wallace (1878, 1889), who attributed both performance and ornamentation to the greater vigor of the male, especially during the breeding season. Montgomery (1910) in general held Wallace's views; furthermore, he thought the displays originated in self-defense movements, which were combined with external evidence of physiological excitement. Berland $(1923,1927)$ attributed the behavior altogether to the exceptional physiological activity of the breeding season and its correlated excitement.

Bristowe (1941 et ante) has held the view that courtship in spiders in general has two fairly distinct functions, namely recognition and stimulation. Recognition he holds to be particularly important, since in spiders the female is not only carnivorous but often much larger than the male. Inter-male display and fighting he attributes essentially to mistaken identity: "It, would appear from what has been said above that the battles, which are preceded by normal courtship reactions, are the outcome of frustrated instinct, and are modifications of courting procedure brought about as a result of the different reception experienced at the hands of another male to that of a female." (1929, p. 352). He believes that display arose from the groping and chemotaxing motions of primitive spiders, which have been modified by signs of sexual excitement, such as twitching of the abdomen. He points out that a male which produces a striking pigment spot easily visible to the female during his approach has a better chance to survive than has an individual less easily identified.

Savory agrees with Bristowe, except that he considers the division between "recognition"-for which he prefers the term "realization"-and stimulation invalid. He gives the following summary of his views on spider courtship: "If we may venture to summarize in a few words the results of so complex an activity as courtship, we may say that courtship is a chain of related instinctive actions, in which the reproductive urge suppresses the normal habits of self-protection and selfnourishment, and is accompanied internally by the physiological changes necessary to make the subsequent union possible." (1928, p. 221).

Gerhardt, who has recorded numerous spider pairings, has been most interested in copulation methods, showing that the various positions assumed by the male shed light on phylogeny. In salticids the copulation position is invariably dorsal and similar throughout the family. He has made few observations on the courtship phases of reproduction.

There has been as great discrepancy in 
TABLE II. (cont.)

Comparative Display Data in Seven Subfamilies of Salticid Spiders.
TABLE II. (cont.)

Comparative Display Data in Seven Subfamilies of Salticid Spiders.

Name Display References $\quad$ Courtship Posture (Stage I)

Peckham, '89, p. 54; fig. ("Astia vittata")

(Wisconsin, U.S.A.)

(Connecticut, U.S.A.
Displays of the 2 forms differ. Gray form: Carapace high; 1 st raised, waved, palps stretc sideways; abdomen down; whole body low, 1st \& 2nd forward, tips touching; forward. (Peckham, Wisc.). Low stage precedes high sta (Painter, Conn.)

Black, tufted form: Carapace ver high; 1st legs raised \& waved, held high in pose.

Carapace slightly raised.

1st legs stretched sideways nately up and down or held pose.

2nd tarsi touch ground, far out slightly forward.

Abdomen sometimes vibrated.

All legs on ground, drawn in, sways body from side to side.
I: Similar to courtship. Stage II: 1st legs waved higher, almost meet overhead; when
lowered, 1 st \& 2 nd tarsi rub together. Rarely, chelicerae sgainst opponent's; no inju-

ries,
Displays to mirror.

ist legs at each other but

(Peckham)

plays to mirror.

rincipal Apparent

Morphological

Adaptations to Display

Locomotion \& Remarks

\section{MAGONINAE (cont.)}

Tufted form is black anteri-

orly, has cephalic tufts.

\section{Peckham \& Painter disagree on selection \\ ९ irritable; fight each other.}

1st \& 2nd legs enlarged, blackened.

blackened.
5 other Venezuelan magoninids use all legs actively in ordinary locomotion.

All include rubbing of 1 st \& 2nd tarsi in display.

usually extends 1 st legs during courtship.

ㄴobrates light palps. nder consideration in this paper. Text-fig. 1 and Table III will give some idea of the variety of display motions throughout the family. All displays unite at least several of the listed movements, and many involve all of the major headings except that of retinal motion, which so far appears to op. erate as part of the signal mechanism only in Lyssomanes.

No less varied are the forms of "ornamentation" in the family; these occur too often on displayed appendages to be explained only by chance mutations, metabolic processes, other behavior patterns, etc. They include many specializations of size, shape. hair concentration, scalation and pigmentation, several forms usually occurring in a single spider. For example, the first legs which always enter at least into Stage II courtships, are often elongated, thickenec and much darker than the others; in ad dition, the palps, which frequently vibrat during display, in many species show patche of shiny white onthali xanthopa, the fourth legs, elevated only ir threat display, are prominantly fringed; in the related $C$. chalcea, in which they never leave the ground, fringes are absent. Many other examples occur in the literature, of which the Peckham's original series are among the best $(1889,1890)$. The striking point is that any appendage specially exhibited in epigamic display usually show some differentiation which is to human eves conspicuous.

However, two other obvious points must be kept in mind. First, not all parts activ in display are so ornamented; an example is the brown abdomen of Semorina, relieved only with small, pale inconstant spots. Second, not all parts conspicuously ornamented (again, to human eyes) play any demonagain, to human eyes) play any demonstrable part whatsoever in display. Examples fle the bright scarlet abdomen of Phial fammea and the striking carapace band of various Phiale and Corythalia.

\section{B. Historical Review.}

The history of the study of salticid display reflects the changing ideas of evolutionists. The Peckhams pioneered both in the recording and explanation of epigamic display and of the apparently correlated ormamentation (1) apparently correlated ornamentatione $(1889,1890)$. According to them, the phe nomena were due to direct Darwinian sexual selection; the females, consciously or unconsciously, were affected by the performances, colors and beauty of the males, selecting the most handsome or at least the most striking. Male battles were initiated both for simple possession of a mate and as sham contests for the females' edification. The Peck- hams disagreed strongly with Wallace (1878, 1889), who attributed both performance and ornamentation to the greater vigor of the male, especially during the breeding season. Montgomery (1910) in general held Walace's views; furthermore, he thought the displays originated in self-defense movements, which were combined with external evidence of physiological excitement. Berland $(1923,1927)$ attributed the behavior al ogether to the exceptional physiological actforeptional physiological actexcitement. Bristowe

Bristowe (1941 et ante) has held the view that courtship in spiders in general has two fairly distinct functions, namely recognition and stimulation. Recognition he holds to be particularly important, since in spiders the emale is not only carnivorous but often much larger than the male. Inter-male display and fighting he attribute. Inter-male display and dentity: "It, wutes essentially to mistaken een 1 , would appear from what has receded above that the battles, which are the out by normal courtship reactions, are modificome of frustrated instinct, and are modifications of courting procedure brought as a result of the different reception thatienced at the hands of another male to the a female." (1929, p. 352). He believes hat display arose from the groping and chemotaxing motions of primitive spiders, which have been modified by signs of sexual excitement, such as twitching of the abdomen. He points out that a male which produces a striking pigment spot easily visible to the female during his approach has a better chance to survive than has an individual less easily identified.

Savory agrees with Bristowe, except that he considers the division between "recognition"-for which he prefers the term "realization"- and stimulation invalid. He gives the following summary of his views on spider the following summary of his views on spider courtship: "If we may venture to summarize in a few words the results of so complex an activity as courtship, we may say that courtship is a chain of related instinctive actions, in which the reproductive urge suppresses the normal habits of self-protection and selfnourishment, and is accompanied internally by the physiological changes necessary to make the subsequent union possible." (1928, p. 221).

Gerhardt, who has recorded numerous spider pairings, has been most interested in copulation methods, showing that the various positions assumed by the male shed light on phylogeny. In salticids the copulation position is invariably dorsal and similar throughout the family. He has made few observations on the courtship phases of reproduction.

There has been as great discrepancy in 
views regarding the senses involved in salticid display, as in those concerning its origin and functions. The Peckhams (1894) concluded that sight was essential, both for recognition and as stimulus for display; Petrunkevitch (1910) agreed. Montgomery (1910) apparently saw a salticid court after merely touching a female. Berland (1914, 1923, 1927) thought smell must be involved in locating the female though sight was needed to stimulate courtship. Bristowe and Locket (1926) and Bristowe (1929, 1941) thought that both sight and chemotaxis (referred to as "smell" in the earlier papers) were involved. Savory (1928, p. 215), after speaking of inter-male courtships, of the courting of immature individuals and those of other species, sometimes through glass, says in regard to spider courtship in general: "It is clear, therefore, that the stimulus which initiates the male's performance is vague, rather than definite and specific. It may act upon the sense of sight, of smell, or of touch, but the appearance or the scent of the female does not seem to be readily distinguishable from that of the male."

The most recent group of observers have concluded, along with the Peckhams and Petrunkevitch, that sight alone among salticids is the only adequate and necessary stimulus for salticid display; these workers include Homann (1928), Bonnet (1933), Heil (1936) and Kaston (1936). The latter gives a detailed review of previous work, followed by a report and discussion of observations and experiments of his own; these were conducted on thomisids, pisaurids, lycosids and salticids. His salticid examples are distributed among four Connecticut species of the genus Phidippus (Dendryphantinæ). His conclusions, which include his results with that genus, are as follows (p. 152): “On the basis of a large number of observations and experiments with the males of 19 species from 4 families of vagabond spiders, it is pointed out that the senses involved in courtship may vary with the species. There is no evidence that a sense of smell is used in sex recognition by any spiders. At least this sense plays no part in initiating courtship activity in the male. There is no evidence that Attid males can 'recognize' the females by any sense other than sight. At any rate, it appears that the visual stimulus is the only one that suffices to incite courship in this family."

\section{BASES For DisAGREements.}

The disagreements and uncertainties among previous investigators appear to have been due principally to the following causes:

1. Although all observers have realized that display stimuli among the various families differed, and were roughly dependent on the development of vision, yet it does not seem to have been clear that there are large differences within the family, at least in salticids, in the relative importance of the senses. On these sensory differences depend many differences in behavior.

2. Systematic attention does not seem to have been paid to the fluctuating physiological states of individual spiders.

3 . The early experiments, as usual throughout the history of biological science, were not properly organized to ensure the testing of only one stimulus or characteristic at a time.

4. In later work, the compound natures of such concepts as "visual stimuli" do not seem to have been taken fully into account.

5. The recent concepts of innate releasing and directive mechanisms, as developed by Lorenz, Tinbergen, and their co-workers, do not appear to have been applied to spiders.

6. Certain motions involving sensory perception, such as waving of the first legs, have perhaps occasionally been mistaken for epigamic display.

\section{TABLE III.}

\section{Principal Motions Reported in Salticid} Display Literature.

1. General manoeuvers, involving spider as a whole.
a. Tacking.
b. Direct approach.
c. Leaping.
d. Sidling.
e. Semi-circling and circling.
f. Posing.
g. Crawling.
h. Elevation of carapace.
i. Rocking motions.
j. Bouncing motions.

2. Retinal motions within antero-median eyes.

3. Palp motions.

a. Vibrations, jerks, rotations; synchronized or alternate.

b. Flexion or extension in special attitudes.

c. Palpation of female or opponent.

4. Chelicerae motions.

a. Lateral extension of basal segment.

b. Extension of distal segment.

c. Clinching.

d. Biting.

5. First leg motions.

a. Elevation and extension forward, up or out, and to any intermediate degree.

b. Vibrations, waves, jerks, rotations; synchronized or alternate.

6. Second leg motions.

a. Extension forward, to rub second tarsus against first.

b. Elevation to form portion of fan-type display.

7. Third and fourth leg motions: Elevation and extension to various degrees, sometimes forming part of fan-type display involving all legs.

8. Abdominal motions.

a. Depression, when carapace is raised.

b. Twitching or vibration; vertical or horizontal.

c. Twisting or bending to side.

d. Elevation. 


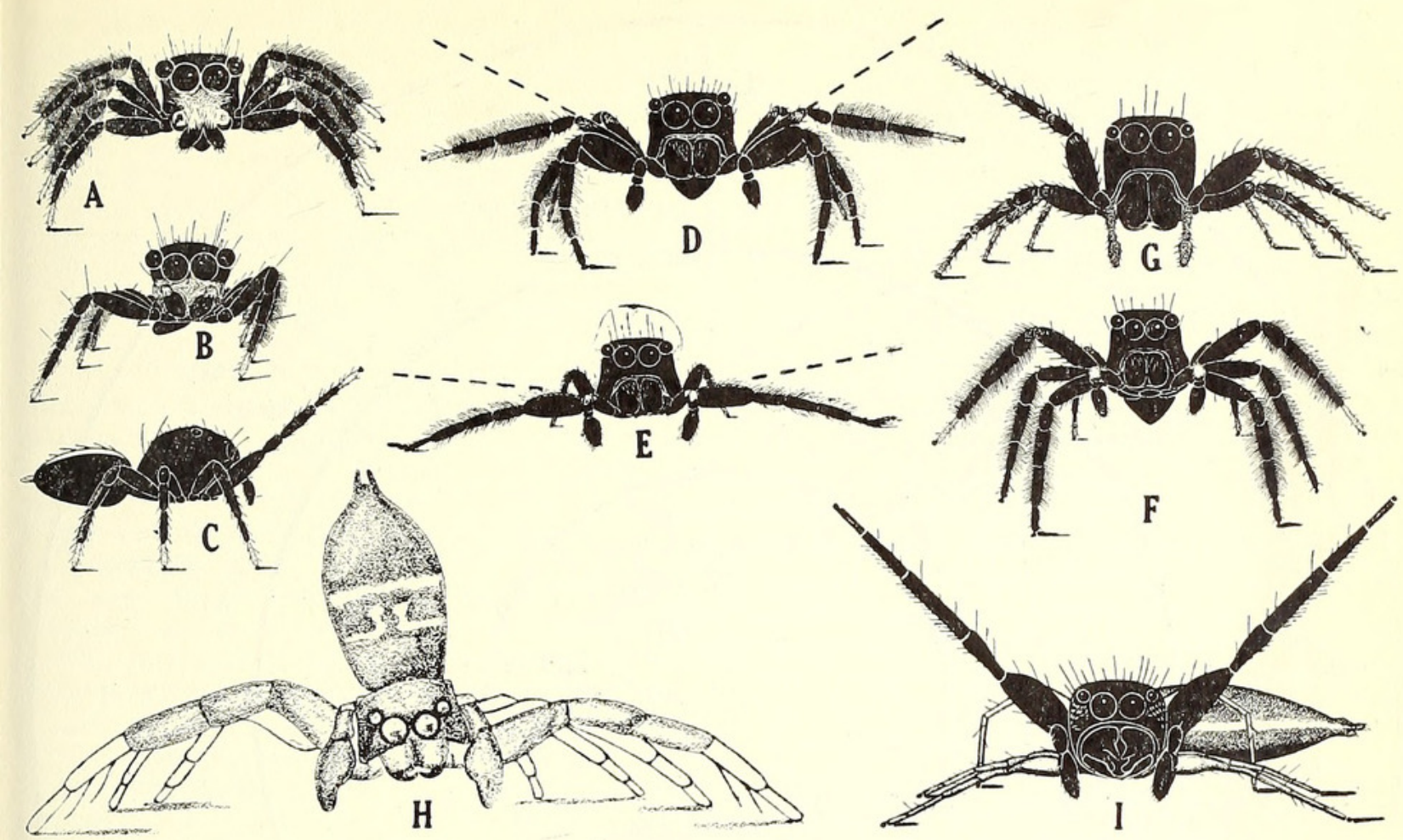

TEXT-FIG. 1. Examples of display motions in salticid spiders. A-F, Subfamily Plexippinae; G, Magoninae; H, Synagelinae; I, Dendryphantinae. A, Corythalia xanthopa, threat; B, C, same, courtship; D, C. chalcea, threat (dotted lines indicate peak position of legs during courtship); E, C. fulgipedia, threat; F, same, courtship; $\mathbf{G}$, Mago dentichelis, courtship; H. Gertschia noxiosa, courtship (from Connecticut, U. S. A.; similar to that of the Venezuelan genus Semorina) ; I, Ashtabula furcillata, courtship. H, after Kaston, 1948; others reprinted from Parts I and III.

7. The great range of development of threat display within this single family does not appear to have been recognized, since the days of the Peckhams' scattered remarks on the subject.

\section{Prognosis of Evolutionary Pattern.}

In order to bring into perspective the material in the following pages, it is necessary to anticipate some of the conclusions reached not only in this paper but in future sections of the series on post-embryology and general evolutionary trends.

1. Correlation of Jumping with Sensory Development. The genera studied at Rancho Grande showed great variety in the frequency of jumping in the course of normal, unexcited progress. Taking into consideration their behavior in other fields, notably display, it seems certain that this variety is based on differences in the dependence on various senses. In some forms more dependence is placed on chemical senses and less on vision. Evidence is presented later showing that these chemical senses include both chemotaxis and a distance chemoperception appearing very similar in its operation to the vertebrate sense of smell. In other forms, vision seems both more acute and more farsighted, while the chemical senses are relegated to relative unimportance. Experiments have not yet been performed at Rancho Grande on variations in visual acuity, al- though several experimenters, notably Homann (1928) and Heil (1936), present modern data on visual perceptions in species of the subfamilies Marpissinæ and Hyllinæ.

A few minutes' observation of unconfined salticids of selected genera will, I think, give convincing empiric support of the hypothesis. For example, in Ashtabula the progress is "a scurrying run, the first legs held flat and low, straight in front of the body; both they and the palps palpate the surface almost constantly during progress. During pauses the first legs are usully elevated, and they and the palps jerked rapidly up and down." (Part III, 1949, p. 41). These "runners," as salticids of similar habits will be called, never resort to hopping or jumping except in crossing gaps in the surface and in the final stages of prey capture. In contrast to other kinds, they are more easily observed in glass-covered dishes than when permitted to run freely on a table (cf. Part II, p. 143). Their comparatively poor vision and their dependence on chemotaxis, or near-chemotaxis, make their exploration of a new environment a highly "restless" and "nervous"-appearing proceeding, as they race to and fro.

In strong contrast is the behavior of an almost completely vision-dependent salticid, such as a Corythalia. When allowed to drop on an unfamiliar surface, he tends to pivot almost where he is placed while he looks all around ; finally he moves off, without haste or 


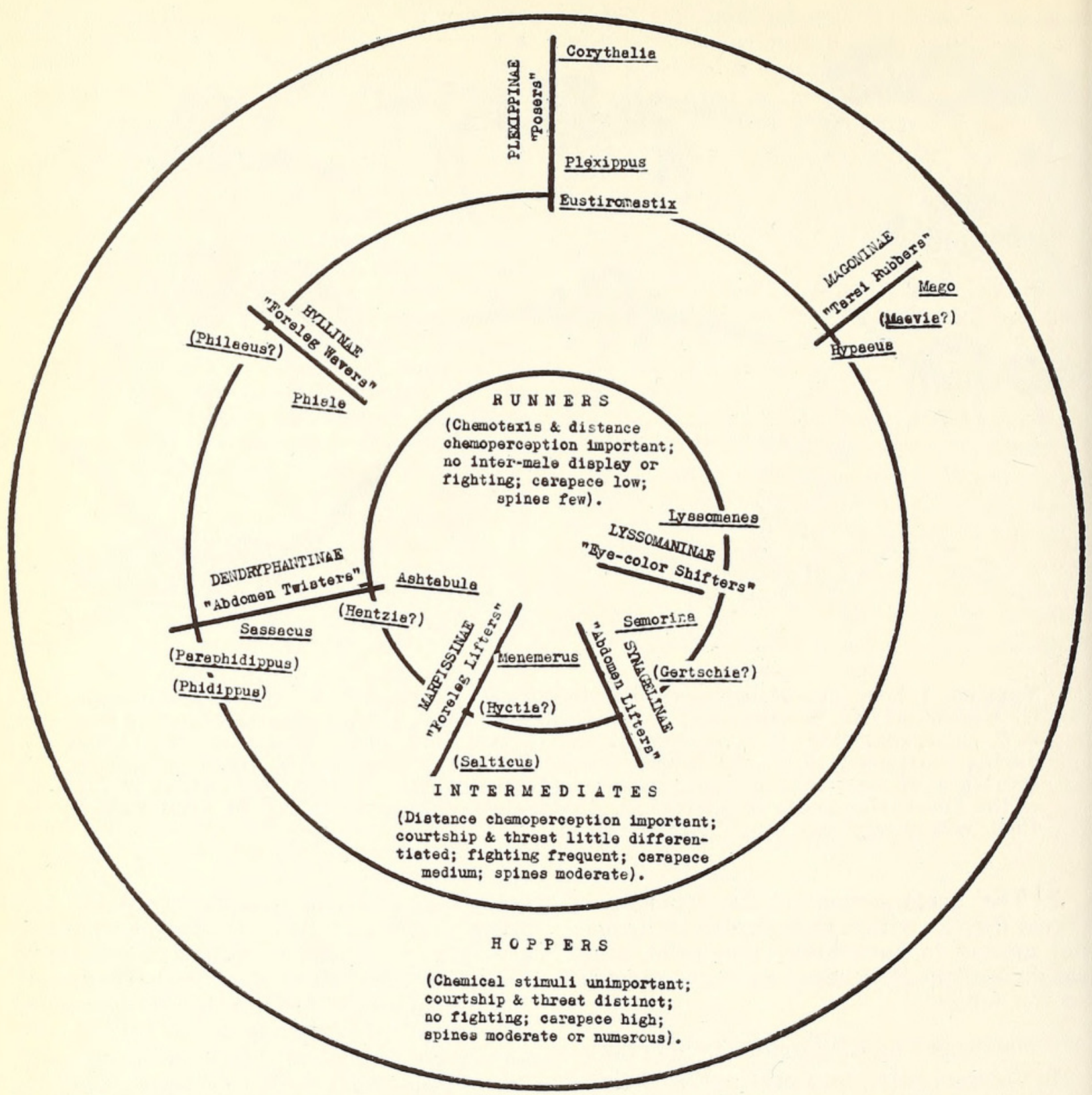

TexT-FIG. 2. Tentative basis for a hypothetical phylogeny in salticids. See text (pp. 205 and 175) for explanation; cf. Table II. Non-Venezuelan genera are enclosed in parentheses; those not observed alive by the author are followed by a question mark. The characteristics ("foreleg lifters" etc.) under each subfamily indicate the most generally present display distinction; it usually is not found in every genus, and occurs sporadically in other subfamilies as well; cf. Lorenz (1941) on the phylogeny of display in ducks.

visible agitation, in a series of short runs and hops, interspersed with pauses for further observation. His palps, usually motionless, are held quite clear of the ground; his first legs are used as much in walking as all the others. To the human observer, in an anthropomorphic moment, the contrast in "poise" between a chemotaxis-dependent and a strongly vision-dependent salticid is ludicrous. When startled or pursued he hops almost altogether. In the future, salticids progressing in the Corythalia fashion will be called "hoppers."

Phiale is a good example of an intermediate stage, in which hopping is moderate and eyesight obviously keen. Considerable dependence appears to be placed on distance chemoperception, however, although not on chemotaxis. The specially sensitive first legs and palps are often carried up, in normal progress, and during the pauses they are waved up and down, without touching the ground; it seems certain that they are receiving sense impressions which, by definition, are not chemotactic.

Characteristics of locomotion, where known, are included in Table II.

2. Preliminary View of Evolutionary Pattern. It is generally agreed that the salticids are more specialized than the lycosids, particularly in regard to the development of vision. In this characteristic, indeed, they lead all other families. It seems likely, therefore, that the salticids in which vision is 
best developed are those farthest from the primitive stock. This hypothesis is supported by evidence from a number of other fields, although the pattern of specialization, as shown even in these few present-day genera, is far from a simple "family tree." As in all other groups, salticids having many primitive characteristics may be extremely specialized in a few directions.

Briefly summarized, the hypothetical pattern may be stated as follows:

The evidence in regard to salticid evolution-based on post-embryology, external morphology, ornamentation, locomotion. general habits and epigamic display-all points to a radiative type of development. Many forms with primitive characteristics still survive. Each subfamily so far studied in any detail includes genera ranging through at least two stages (Text-fig. 2).

The first, most primitive stage includes species with low carapaces (Text-fig. 3), low visual acuity, high dependence on chemotactic stimuli, locomotion of the running type, courtship simple and threat display absent.

The second stage is characterized by intermediate carapaces, visual acuity, hopping proficiency and courtship development; by depending on distance chemoperception rather than on chemotaxis; and, especially, by the presence of threat display which is based on the mistaking of males for females, and is undifferentiated from courtship except that it often ends in true fighting.

The third and most specialized stage is represented by species with high carapaces, extreme visual acuity, chemical perceptions of minimized importance, locomotion consisting principally of hops, courtship often complex but sometimes secondarily simplified, and threat display separate from courtship and altogether ritualistic.

I realize keenly the extremely small number of forms investigated at Rancho Grande in relation to the large size of the family. However, published records, in so far as they can be analyzed from modern points-of-view, and my own sporadic observations in other localities, appear to lend support to the hypothesis. It seems that the basic framework will prove to have validty.

\section{FACTORS IN DISPLAY.}

The releasing and directive mechanisms of salticid display have proved much more varied and their interrelationships more complex than was expected. Although all epigamic display is fundamentally visual in this family, chemoperception is important in certain phases; simple adulthood is not the only physiological essential for performing or responding to display; vision itself must be divided into perceptions of motion, distance, size, form, intensity, pattern and color for an approach to understanding display stimuli.

In the following pages an attempt is made to isolate and evalute these factors, giving

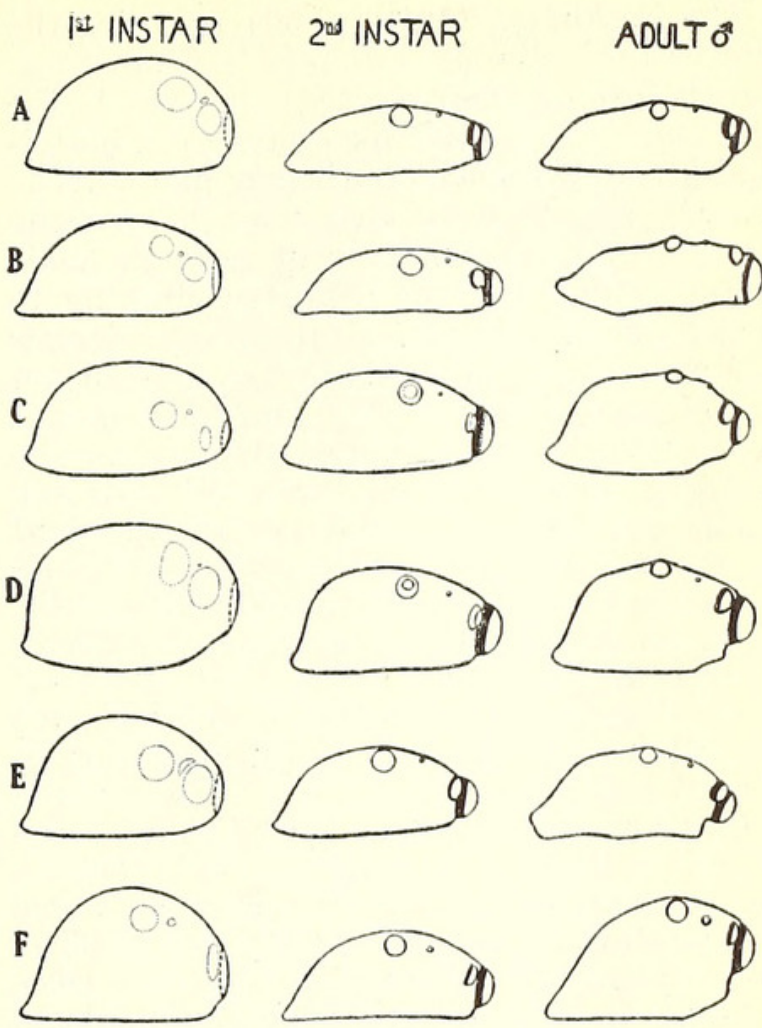

TEXT-FIG. 3. Change of carapace proportions with growth in representative genera of salticids. Left column, 1st instar; center column, 2nd instar; right column, adult male. A, Menemerus bivittatus; B, Semorino megachelyne; C, Sassacus flavicinctus; D, Mago dentichelis; E, Phiale flammea; F, Corythalia chalcea.

in each case a summary of the observations and experimental results upon which the conclusions are based. Because of space limitations, it is impossible to publish full details of field and laboratory data; however, descriptions of especially illustrative observations and experiments are quoted now and then directly from the original notes. Laboratory procedures have already been described (Part II, 1948.2). Reference to Text-fig. 6 will help clarify the relationships of display elements during the course of this analysis; in the subsequent section on innate releasing mechanisms, beginning on p. 199, these factors are viewed as closely integrated, mutually dependent series of stimuli activating, controlling and directing both courtship and threat.

\section{A. Factors OF The Internal RELEASing MECHANISM.}

1. Age. In general, no sexual interest appears between the sexes until both are adult. Exceptions occur when a mature male in a particularly responsive state briefly courts a pre-adult female of similar appearance to the adult; such displays never pass beyond Stage I. A number of workers have reported behavior of this kind and I have seen it in various genera, always of the hopper type, especially in Corythalia. Very rarely juvenile individuals perform abortive displays; examples will be given below. 
The Peckhams (1889, p. 50) recorded the interesting case of Philaeus militaris (= Paraphidippus marginatus) in which the adult males actually kept guard over individual preadult females until they molted. The nearest approach to this seen at Rancho Grande was the behavior of a single male C. fulgipedia. He was captured clinging to the outside of a cocoon, within which a female was molting to the adult instar. He did not even wait for her to dry and harden, but raced through the briefest display as she emerged, and mated. She was still soft and weak, and gave no resistance or apparent response at all. The eggs appeared on schedule, some two months later, and were fertile. This was an exception to the general behavior pattern of the genus.

Similarly, mature males rarely display to juvenile males except in reinforced experimental situations.

During experiments on display sign stimuli with $C$. xanthopa and $C$. chalcea, several cases of display behavior were noted in immature individuals of both sexes. They were exceptions, however, to the rule. Once a preadult (6th instar) male chalcea leapt repeatedly on a dead, mounted adult male, when the latter was appropriately moved. $\mathrm{He}$ then gave a medium complete threat display, through the fan stage with stiffened palps, following this with a Stage I courtship, and ending with a clumsy attempt to mate, approaching atypically from the rear. When a normal adult male was presented to him, without a rest period, the young one at once gave a complete threat display; when the adult responded in kind, the other retreated. When a preadult female was presented to the young one, she attacked him, whereupon he retreated, turned and courted briefly, Stage I. This sequence with the female happened four times, she charging him each time.

A single case of display in a 5 th (pre-preadult) instar chalcea was recorded. This individual did a moderately complete threat display (through the arch phase) to two different adult males, punctuating them with retreats. One of the adults responded with threat. There was no courting or other reaction to females.

Preadult females of both xanthopa and chalcea gave incipient threat displays on a number of occasions, to adult displaying males, alternating the rudimentary fan-pose with the usual abortive attacks and retreats. In each case, it was clearly rudimentary threat, not ccurtship. These motions were never made in the presence of potential prey or predators, even of similar size.

Display is usually delayed, however, even after the final molt has taken place. Corythalia males normally do not display to each other or to a female until at least two days thereafter. One exceptional xanthopa did his first threat displays on the third and sixth days, but did not court at all until the seventh and then only a rudimentary Stage I; full threat and courtship were not attained until the tenth day. Although freshly molted females are both attractive and receptive, they normally do not emerge from their cocoons for two or three days. Judging by the responses of males, female xanthopa do not attain their maximum attractiveness until about the fifth day.

The age at which males and females lose interest in display varies with the species. After two months in the adult stage, unmated $C$. fulgipedia males usually cease to initiate display in threat or courtship, and do not respond to threats of other males. However, one example, reared from the egg, three months after the final molt briefly courted an aged female who had completed molting more than six months before. Unmated males of $C$. xanthopa are in their adult prime less than a month; for several weeks thereafter they may respond to stimulus situations which are both complete and reinforced, but never to the extent of carrying a courtship beyond Stage I. An exception was a 32-day-adult male which mated with a 33-day-adult female, after a courtship of 13 minutes; the usual courting period for the species is three to five minutes. Their healthy brood was reared through several instars.

Unmated females of fulgipedia remain attractive to males and will accept them at least four months after the final molt, even though they have, at the usual time (about two months after molting), started laying the customary successive clutches of eggs. Females of xanthopa start losing both their responsiveness to display and their attractiveness after about three weeks, although the eggs in this species are not laid until about the fortieth day after molting.

No Rancho Grande female, in spite of repeated attempts on a number of well-distributed genera, was ever found to mate more than once, when more than a few hours had intervened; usually, also, she lost most of her attractiveness. However, there are a number of recorded northern observations of repeated salticid matings by both males and females (e.g., Peckham, 1889, p. 38). Rancho Grande males, as in the north, copulated readily at least several times in Corythalia, Phiale and Menemerus; other genera were not investigated, nor were such aspects as the duration of fertility and the effect of copulation on subsequent display initiation and duration.

2. Fluctuating Epigamic Rhythm. Not only is the period of display and acceptance at Rancho Grande limited to moderately young adults of both sexes and to unmated females, but there is also a definite fluctuation in both sexes from day to day in sexual aggressiveness and receptivity. Such fluctuations are of course well known, and are in fact the rule in higher vertebrates. Hints of it have also been detected in fiddler crabs (Crane, 1941 , p. 153 ff.), but it does not seem to have been much investigated in invertebrates. 
In all salticids under special observation at Rancho Grande, it was noted repeatedly that young, vigorous adults of either sex varied daily in behavior. Those which were particularly lively in display or responsiveness on one day might, on the next, be altogether unresponsive to sexual situations, although their general health and activity seemed unimpaired. These individuals had not been allowed to mate on the preceding day, nor had there been a break in the feeding routine, or noticeable changes in other conditions such as moisture or general weather. A day or more later, they might recover all their previous epigamic energy.

This phenomenon was specially investigated in more than twenty adult Corythalia xanthopa males of varying ages. About half of them passed the final molt in the laboratory, so that their exact length of adulthood was known. None of this group was allowed to mate. All were kept under conditions as similar as possible, although all twenty were not observed simultaneously, but in small, overlapping groups. All were tested for various periods up to 43 days with stimuli of such proven efficacy that they came to be termed "standard stimuli" for the species. They consisted of a particular, normal male, dried and mounted in semi-threat stance (see p. 169), a mirror image, young and older adult females, and live normal males.

In the case of low-threshold males, various unnatural or incomplete stimuli were also presented. The mounted specimens and mirror were each presented in a series of up to a dozen successive jerking approaches to the tested male, after his attention had been caught by the stimulus. The quickness of response (if any) was taken into account when determining his sexual tone, because, obviously, a stimulus which drew a response only on repetition was reinforced by summation. Again, the "startle" element of repeated presentations of the same stimulus in quick succession, rather than continuously, was important in drawing responses from low-tone individuals; hence all handcontrolled stimuli, for the sake of uniformity, were presented in this fashion: the mount or mirror was lifted high in the air for an instant after each approach to the spider. The working of the law of heterogeneous summation (Tinbergen, 1948, p. 35) was minimized by always working with a group in every test period; each individual could thus be tested with one stimulus followed by a rest, yet with a minimum wastage of experimental time. The same general rules were followed in all salticid testing (see also, Part II, p. 143).

In the course of the work, the fluctuating internal drive appeared divisible into four major degrees of sexual tone, with the following characteristics:

A-Tone. Internal drive strong, that is, male with low epigamic threshold. Only minimal stimulus needed for maximal response, which follows promptly and appropriately to all normal stimuli and to many deficient stimulus situations as well. Display follows through swiftly into Stage II in courting receptive young females; old females courted with considerable persistence. Responses continued during a prolonged test-period. No "vacuum responses," however, have ever

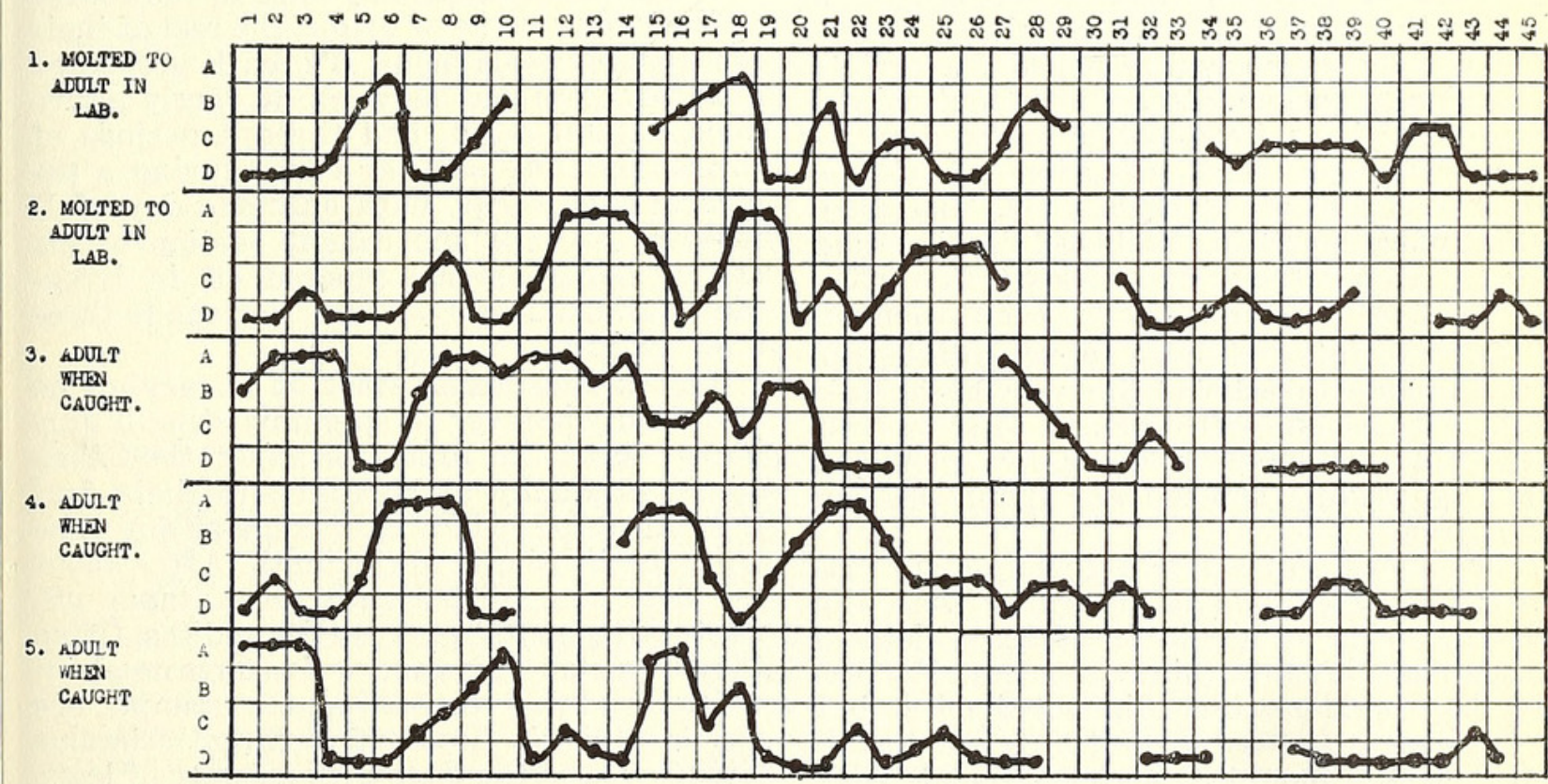

TExT-FIG. 4. Daily fluctuation of epigamic threshold in five male Corythalia xanthopa. Spiders of A tone are most responsive to epigamic stimuli, those of D tone unresponsive. The tone was determined by the individual's response to three standard stimuli: his own mirror image, a particular dead male mounted in a semi-threat position, and a young, living female. See p. 177. Blanks in the graphs indicate days when observations were not made. 
been observed, in this or any other salticid; that is, no display is performed without some external stimulation.

B-Tone. Internal drive moderate, the epigamic threshold being moderately low. Maximal stimulus needed for normal response; either threat or courtship or both may be elicited, but only through summation, though display is eventually complete. Courtship of a young female may be energetically performed throughout its entire course, but older females attract little or no attention. All courtships are likely to die out in the middle, when the male, instead of following up the female during her normal, periodic retreats, simply circles around her previous resting place, palpating the ground in the manner of less specialized, runner-type salticids. Again, the male sometimes gives atypical responses, leaping briefly at the threat stimulus before performing threat display, or even courting it; equally briefly and rarely, he may threaten a female. He may or may not respond to one or two slightly incomplete stimulus situations. Invariably ceases to respond in a test period after relatively few stimuli have been presented.

$\mathrm{C}$-Tone. Internal drive weak, the epigamic threshold being moderately high. Maximal stimulus needed for minimal response. Male responds either to normal threat or normal courtship stimuli, but not both; summative threat stimuli more often draw a response even than young females. No courtship is ever followed through to completion, and the palpating of the female's resting place is pronounced, the male spending much of his attention on one of her former positions, even though she is at the moment sitting in full view, and facing him, only an inch away. Leaping at threat stimuli is frequent and, unlike the case in B-tone spiders, is rarely followed by the normal response. Incomplete stimulus situations attract no attention, except, sometimes, brief notice followed by escape behavior. The attention of C-tone spiders is difficult to attract and hold, they often move about in "restless" fashion, and always stop responding quickly, often after only one or two stimuli have been presented.

D-Tone. Internal drive impercentible, the the epigamic threshold being very high. Male does not respond with display to stimuli of any kind, although other daily activities, such as feeding and moving about, are unimnaired.

The above four states naturally merge into one another, and in recording the daily changes of tone, it was found convenient to recognize plus and minus degrees. For example, a spider which did not display, but nevertheless showed enough interest to follow a jerked mount or a young female with with his eyes (through the twisting of his carapace), was counted D-plus.

Typical examples of daily fluctuations are shown in Text-fig. 4. Text-fig. 5 diagrams the degree of influence on each other of spiders of various tones.

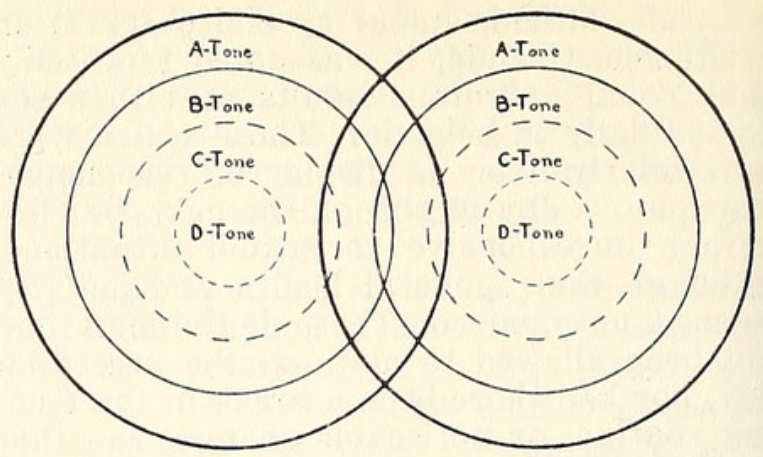

TEXT-FIG. 5. Diagram showing mutual influence of salticids of various epigamic tones. For example, even an A-tone spider never draws a display response from one of $\mathrm{D}$ tone, although he himself displays readily toward individuals of any tone and either sex; B- or C-tone spiders may respond to the displays of an individual of higher tone, but rarely initiate it themselves. The boundaries between tones should not be regarded as hard and fast lines. See pp. 176-179. In salticids, courtships are rarely completed in the field, or threat displays energetically prosecuted, except by spiders of A tone, that is, of the lowest epigamic threshold. This is in contrast to the condition in some vertebrates, where the behavior of a correspondingly low-threshold individual is not regarded as typical (cf. Part II, 1948.2 , p. 143, and Tinbergen, 1948, p. 39).

The one result that emerged clearly from the records was the complete lack of a definite rhythm in xanthopa. In general, however, individuals in their prime remained from one to four days in A-tone, then dropped within 24 hours to C or D; they remained at these high-threshold levels from one to three days, and then climbed back to B-plus or A in about 48 hours. Some spiders attained A-tone only once in the course of their four weeks of prime, the rest of their top display levels being B's, with prolonged $\mathrm{C}$ and $\mathrm{D}$ stretches between. A rarely active male, caught adult, had three A-periods of three, four and one day each, during a period of two weeks, with only one day of $D$ intervening; the subsequent portion of his active display prime tapered off in irregularly alternating B's and C's of one to three days each.

Just-molted males start at D, paying no attention whatever to epigamic stimuli during at least the first two days; they then climb, gradually or abruptly, to their first $B$ or $A$ period, which may come at any time from the third day to the tenth. After about the 28th day, display responses taper off, fluctuating gently between C's and D's. Often they flow along for four or five days on about a C-minus level, responding, for example, one day to a single, summative threat stimulus situation, and the next with a series of leaps only to the same stimulus, but with the addition of a few abortive rocks to a young female.

That the above phenomena are not the results of laboratory conditions is proved by the fact that a number of males were tested 
in the field, before capture, and their behavior was found to correspond to that immediately afterwards in the laboratory; also, these and other males were taken, as adults, in all four phases, some young, judging by their future plotted curves, some old. Their behavior curves differed in no wise from those of males reared through at least one molt in the laboratory, except that in general the wild-caught adults tended to hit and hold A-tone oftener and longer.

Although males of other genera and species were not tested systematically, there is no doubt but that they do have periods similar to those of xanthopa. Females, too, show noticeable behavior fluctuations, both in general aggressiveness and in reciprocal display, although their periods were not studied. One C. chalcea, for example, was especially prone during several days to do a particular type of jiggling in mutual display; I never saw it in another of her species, and it soon dropped from her usual behavior, reappearing only sporadically. Although she was exposed to the display of a number of males during and after this time, she was not allowed to mate for another two weeks, when the process went off perfectly normally.

3. Hunger and Thirst. Hunger, as might be expected, was an important factor in the behavior of females, since a hungry female was usually far more aggressive and needed far longer courting than one which was well-fed. However, in no genus except $E u$ stiromastix have I ever seen a female try seriously to kill a male, although occasionally she will leap at him. Moderate hunger in males lowers their epigamic tone only

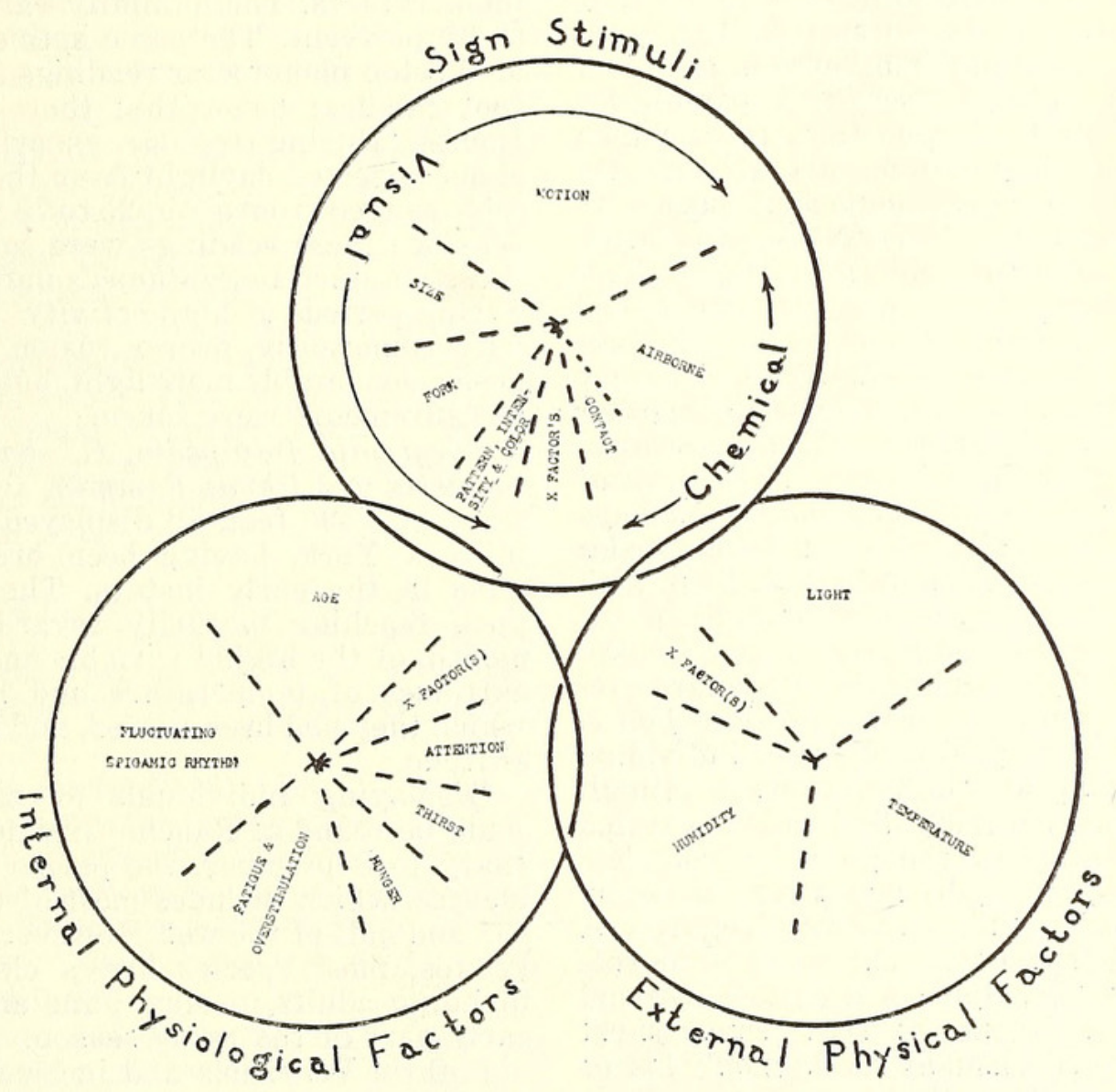

TEXT-FIG. 6. Factors of the innate releasing mechanism in salticid display. The circles are represented as loosely interlocking to indicate the interdependence of the three groups of factors. Similarly, the spokes are not continued to the circumference in order to show the mutual influence of the sections. Finally, the spokes are represented as broken lines, to emphasize the variability and instability of their relative importance; this varies not only throughout the family, but even in the same spider under different conditions. For example, among the Synagelinae, the chemical factors are more important than among the Plexippinae, while the same sections are of still different relative value in the end-forms of the Dendryphantinae. The sizes of the sections, therefore, are merely a guide to their average apparent importance within the family. The term "X-factor (s)" is included in each circle to emphasize the incomplete state of our knowledge. "Distance" is omitted from among the sign stimuli since it seems to be more of a compound factor in display than do the others, based largely on apparent size, on chemical stimuli or their absence, and on physiological conditions; perception of distance and depth does exist however (see Homann, 1928; Heil, 1936). Tactile factors are omitted since they do not release display in salticids, although they are important in the final display stages. The sign stimuli circle applies to courtship; for threat display, the chemical factors should be eliminated. 
slightly-from B-minus to C-plus, for example. In all the experimental work, no spiders were tested without having been fed at most 48 hours previously.

Thirst cannot of course properly be separated from the external factor of humidity, although spiders do drink water as needed. Salticids that for some days had been kept without special moisture in the laboratory went into silk shelters, if they did not die first, became semi-torpid and did not react to display stimuli; this behavior is doubtless equivalent to aestivation in the field.

4. Fatigue and Overstimulation. These two factors have not been properly distinguished. Actual physical fatigue, however, sometimes appeared clearly involved during experiments. Often initially restless individuals, even of hopper-type genera, were tested which raced about the table before settling down to attending to stimuli; they often had even to be pursued to the floor; afterwards, even when otherwise of A- or B-tone, they always reacted to stimuli for a shorter length of time than those which responded without preliminary activity. On the other hand, overstimulation appears to be a better term for the cessation of reaction that takes place in spiders at the peak of their internal drive, when they have had practically no exercise but have been presented with a succession of stimuli. In every individual the moment is reached, as in other animals, when no further response is drawn, no matter what the stimulus. The length of reaction time is highly variable; $C$. xanthopa is, however, as typical as any: A-tone males may be tested for around half an hour with only minimum pauses between stimuli (about three minutes). When a large group is used (the customary experimental procedure) responses may spread over three or four hours, the long rotation period allowing individual rests of 10 to 30 minutes between stimuli presentations. An individual which is tested in the morning to the point of complete non-response is usually again responsive by mid-afternoon; full recovery (regardless, that is, of internal drive changes) is the rule by the next day. Spiders with low internal drive, e.g., of C-tone, have extremely short response periods, usually totaling only five or ten minutes; often there is only a single response, regardless of length of rest between stimuli.

5. Attention. This factor is quite distinct from the others, and a sine quo non of display. Although spiders with strong drive undeniably are more easy to stimulate with display situations than weak-drive individuals, all vary irrespective of sexual tone in the amount of time needed to attract their attention to a stimulus. Sometimes they are so restless when first put on the table that their only motive appears to be to get somewhere else; some minutes pass before they seem suddenly to "wake up" with an almost literal jerk and "notice" the stimulus, which may have been equally close in front of them many times before. This applies to both threat and courtship stimuli. The same is true of a spider engaged with one display stimulus, or with food, when another and, at the moment stronger, situation is presented.

\section{B. Factors of the External Releasing AND DiRECTIVE MECHANISM.}

1. Physical Environment. The effect of the physical environment has not been precisely analyzed in regard to exact tolerances and requirements of temperature, humidity, light and altitude. However, the following facts have been determined:

Corythalia xanthopa in the Rancho Grande laboratory displayed readily at temperatures between $65^{\circ}$ and $80^{\circ}$ Fahr., the extremes tested. As has been noted by others, responses were somewhat accelerated at the higher temperatures. The humidity varied from 50 to 95 per cent. The same species displayed at Weston photometer readings as low as 0.8 foot candles; below that there was no response. During regular experimental sessions, reflected daylight from the laboratory table ranged from about 25 to 75 foot candles, Weston; these readings were comparable to those obtained in xanthopa's natural habitat during periods of high activity. Menemerus, with apparently poorer vision, seemed to need considerably more light, but no accurate measurements were taken.

Corythalia fulgipedia, C. chalcea, Eustiromastix and Phiale flammea, although captured at 3,500 feet, all displayed at sea level in New York, having been brought there alive in the early instars. They displayed upon reaching maturity regardless of the month, of the highly variable and unnatural extremes of temperature and humidity in which they had been reared, and of the lower altitude.

Displaying individuals of most species could be found at Rancho Grande from February to September, the period of our residences, which includes most of the dry season and half of the wet. However, as in other groups, most species had a clear peak of breeding adults in May, June and July, the early part of the rainy season.

Both in Venezuela and in New York, spiders displayed under extremely unnatural conditions, with no time whatever needed for adjustment, short of their being literally frozen, deeply chloroformed, dried out or far overheated. That is, if the spider were not injured physically beyond recovery, if he remained capable of primary activitiesmoving freely, catching prey and spinning a shelter-he could and did display when in a period of moderate or strong drive and when properly stimulated. All salticids observed displayed as readily in a glass container or on a table top as in their own forest environment, and in every case the pattern of display behavior in captivity was identical with that recorded in the field. The only exception was that, rarely, captive 
Corythalia males, in close quarters under hot lights, occasionally injured each other in actual fights; ordinarily, aggressive behavior was confined to highly ritualized threat display.

In the field, salticids invariably disappeared under leaves and therefore presumably did not display, both during every shower beyond a drizzle and during all hours of intense heat, drought or baking sunlight. Display during the night in the laboratory was successfully stimulated in A- or B-tone Corythalia and Phiale which were forced out of their shelters and provided with adequate light. Hence an innate diurnal rhythm does not appear to exist in these forms.

In brief, the only external physical requirements for display appear to be tolerable conditions of temperature and humidity, along with adequate light (sun, photoflood or mazda). In Corythalia at least, this illumination is less than that sufficient for comfortable reading by a human being.

2. Sensory Elements and Sign Stimuli. The sign stimuli (or perceptual signs) considered here are those external signals which are involved in releasing or directing epigamic display in salticids. They are unexpectedly complex, especially in courtship, in which they customarily involve compound tactile, chemoperceptual and visual stimuli. Of them all, only two or three combinations of a few visual stimulus-elements can be termed primary releasers, since no salticid displayed at Rancho Grande unless the antero-median eyes were photopically stimulated.

Reference to Table II and Text-fig. 2 will be helpful in maintaining orientation in regard to the various displays and the presumed degree of specialization of species discussed.

a. Tactile Perceptions. Although in many web-spinning spiders tactile perceptions are of great importance in courtship, in salticids their role is confined to advanced Stage II, where the stimuli are probably mingled with chemotactic stimuli. They will be discussed together on p. 182.

b. Chemoperception. For many years a possible "sense of smell," as earlier observers called it, in spiders has been the subject of extended experiment and considerable controversy. In their studies of courtship in various spiders, modern workers, particularly Kaston (1936) and Bristowe (1941), have drawn necessary and precise distinctions between contact chemoperception and distance chemoperception.

In contact chemoperception, conveniently called chemotaxis, the spider must actually touch the female herself, her silk or exuviae, or at least her trail, in order to receive a sensory chemical impression. This sense, both authors agree, often enters into spider courtship, although it is not always essential for the stimulation of display, and, in their experiments, was not necessary in salticids.
The Rancho Grande results were in agreement with these conclusions.

On the other hand, in courtship stimuli involving distance chemoperception, a spider would have to react to volatile, airborne particles given off by a female, her silk or exuviae, or her trail. Such stimuli have not been found by these authors to take any part in stimulating courtship display in any spiders which they have studied, nor do they consider that evidence has yet been brought forward which necessitates the operation of such a sense in spider courtship. Here the Rancho Grande results differ; it seems necessary to postulate the use as a secondary sign stimulus in courtship of a sense analogous to smell.

The two aspects of chemoperception-contact and distance-will now be considered in reference to the Rancho Grande salticids.

i. Chemotaxis. In some other groups of spiders, all with vision less well developed than in salticids, chemotaxis is a primary releaser of courtship, with or without sight of the female. In salticids this is certainly not the case. Kaston, reexamining the situation in 1936 ( pp. 129-130), concluded that it was not essential in two species of Phidippus, and Bristowe (1941 et ante) agreed. Similarly, at Rancho Grande, when chemotaxis was positively eliminated from the stimulus situation, in every genus tested A-tone males displayed without chemotaxis. Contrariwise, no individual ever displayed on the stimulus of chemotaxis alone, although excitement over chemotactic stimuli was often shown. The tested forms were the following: Menemerus, Semorina brachychelyne, Ashtabula, Sassacus (2 spp.), Phiale (2 spp.), Plexippus and Corythalia (3 spp.).

However, in all of the numerous observations and experiments, variations were very obvious in the minor exercise of chemotaxis. These were present on all levelsgeneric, specific and individual. When chemotaxis was allowed, the initiation of display in all the runner genera (Menemerus, Semorina, Ashtabula) was definitely expedited, although that of the hopper and intermediate forms (e. g., Corythalia, Phiale) was apparently not affected in the case of A-tone spiders. However, many individuals in all genera, when of B-tone, initiated display only when chemotaxis was included in the stimulus situation.

Salticids of all conditions, except those of D-tone, and in all genera, but particularly among the runners, often paid great attention to the recent resting places of females, tapping them with palps and forelegs and revolving round and round the area. All B-tone or tiring spiders tended to break off display and palpate at length her just-vacated resting spot even as the aroused female sat and watched only an inch or two away; sometimes, absorbed in these palpations, a male allowed a prospective mate to wander completely out of sight; this reaction was noted 
most frequently in the hopper genus Corythalia.

In the runners there was more of a tendency to follow a trail, by intermittent palpation of the ground, over which the female had passed. In Sassacus ocellatus, Phiale and Corythalia, there were no tendencies to trailfollowing chemotaxis at all; once a female had attracted his attention, a male often followed her zigzag or curving retreat by taking the most efficient short-cuts, whether or not display had been initiated.

The latter half of Stage II is so similar and well known throughout the family that it will not be specially treated here. It begins with the male climbing over the female, patting her carapace with palps and first legs, and follows through to the twisting of the abdomen and successive insertion of the palps into the epigynum, usually after some palpation of its surface. Here it will only be pointed out that chemotactic as well as purely tactile perceptions are probably involved.

Chemotactic perceptions are also not necessarily eliminated from the stimuli which continue to lower the female's threshold during the same period. Her final resistance is probably broken down by the stimulating action of the patting motions; however, since her chemotactic receptors appear to be scattered over her entire body, as well as concentrated on the appendages (Kaston, $1936 \&$ ref.), they very likely are stimulated at this time.

Except in the advanced stage noted above, chemotaxis certainly plays no important part in the acceptance of a male by a female. Since she usually retreats a number of times during normal courtship, she infrequently crosses a male's trail during display in the field. It is true that some individual males have a tendency to circle the female completely during display. Also, females of Phiale and Menemerus have often been seen to palpate a male's recent resting place, while he is still displaying. Nevertheless, on open table tops in more than 20 experimental situations and in uncounted casual observations, involving all the experimental genera, males were accepted without the females once crossing their trail.

I can find no evidence whatever that chemotaxis plays any part in inter-ale display; I have never seen a male palpate the surface or show apparent excitement of any kind when placed on the spot recently vacated by another male, even when both have been or are displaying to each other. However, a male Menemerus, a typical runner, could be induced to display to his mirror image only by corking him in a clean glass vial and holding the mirror against the glass end. After a few minutes, display sometimes took place in A-tone individuals, each presumably activated by his own strongly reinforced chemical stimuli. This experiment was performed on six different males; the display was indistinguishable from Stage I of courtship and was always of very brief duration.

The occasional males in various genera that enter upon Stage II of threat, when the first legs of each opponent touch, practically always finish the encounter at this point with no damage done to either. The fangs are very rarely unsheathed during these moments. Chemotaxis, or, rather, the absence of the female chemotactic stimulus, may be involved here.

ii. Distance Chemoperception. The apparent part played in display by a sense analogous to olfaction will now be discussed. The majority of previous experiments concerned with it have dealt with the reactions of spiders to essential oils, chiefly of an apparently irritating nature. It has been pointed out several times (e.g., Kaston, 1936, p. 146) that sensitivity to these stimuli does not necessarily indicate possession of a true olfactory sense. Such a sense has, however, been proved to occur in a number of terrestrial invertebrates, including moths, beetles and bees. The only aspect directly concerned in the present display study is the part, if any, taken by a sense analogous to odor perception.

If such a sense exists, the necessary affectors do not, of course, necessarily consist of volatile particles; they need only be airborne and, presumably, invisible to human eyes. It is regrettable but natural that we human beings, as visually dominated organisms, should tend to be impressed with and to study chiefly visually or at least aurally dominated displays in animals. Moths and other nocturnal creatures, both vertebrate and invertebrate, may, for all we know, give off in epigamic display regular symphonies of smells in a rhythmic succession. More difficult to imagine, but perhaps easier to check, is the following possibility: Females of certain animals, at the peak of physiological readiness, may actually radiate certain wavelengths invisible to us. These may be either infrared or ultraviolet, using those terms in their broadest sense. An alternative possibility is that these frequencies may be reflected rather than radiated. The emission, of whichever type, would doubtless be under hormonal control, and would have some signal values for males. It would not necessarily of course be perceived visually. In that connection may be mentioned the old, recurrent speculations on possible wave-perceptive functions of insect antennae. The claims of some investigators that blind-folded human beings respond muscularly to red light is another related topic (See Birren, 1938, ref.).

Toward the proof or disproof of the possibility of such emissions, not one jot of experimental proof is offered here. The subject is mentioned only because of its potential connection with salticid display, and in the hope of stimulating investigation. If found valid, it would explain one or more aspects of 
animal display which at present are inexplicable. The proving of the perception of special frequencies would solve puzzles in certain fiddler crabs and birds, for example. In each of these cases, males appear instantly to distinguish receptive females of their own kind from non-receptive ones in some fashion which does not appear to depend either on her behavior or on her emission of any recognized sensory signal (see Beebe, 1928, p. 64; Crane, 1941, p. 157; and Armstrong, 1947, p. 340 \& ref.).

It is true that the operation of scent has not yet been eliminated under experimental conditions in the above instances. Since the published work on crabs, however, many field examples have been seen where the particularly stimulating female crab was several yards to leeward in a stiff wind; the poor olfactory development in birds is well known. According to Kettlewell (1946), however, moths have not yet been proved ever to approach females with the wind, the contrary evidence of earlier experiments having been due to incomplete observations.

In view of its highly controversial aspect, therefore, this present speculation may be on the order of postulating improbable sunken continents in order to explain an inconvenient distribution of fauna, flora or culture. Nevertheless, it is set down in the hope that adequate instruments will soon be developed capable of testing the possibility. Proofs of the use of supersonic signals by bats (Hartridge, 1945) and the perception of polarization of light by bees (von Frisch, 1949; Thorpe, 1949) are suggestive recent results of research in unusual directions. In our own future researches and experiments we certainly intend to take such possibilities into account.

In regard to salticid spiders, however, it seems that the phenomena described below can be most simply and adequately explained by postulating the action of typical, airborne, volatile, chemical particles acting upon appropriate receptors. They will be so considered in this paper.

The work at Rancho Grande seems to point conclusively to the existence of such a chemical sense. It appears likely that it is merely a further development of chemotaxis, in that the affectors, and perhaps the receptors, are basically similar or identical. This sense plays an important secondary role in courtship.

The evidence for this conclusion is based chiefly on the following observation: Young, living, unmated, adult females at Rancho Grande were in general markedly more successful in drawing courtship display from males than were females in other categories.

Their superior attraction was noted in more than 25 species, in fact, in all material plentiful enough to yield comparative observations; these included all the Rancho Grande forms discussed in this paper. The Peckhams (1894, p. 251) attributed a similar observa- tion to the fact that females about to lay eggs were so heavy that they tended to move about less, and that it was the lack of movement which made them relatively unattractive. In the basic experiments at Rancho Grande, this factor was eliminated by chloroforming the subjects. They were then presented alternately as motionless, or uniformly moving stimuli on L-mounts. Chemotaxis was ruled out as previously described (Part II, pp. 143 and 144). The males were allowed only front views on a plane surface, to avoid the visual variables of large vs. small abdomens, or fresh vs. rubbed patterns. The effects of summation were guarded against, as usual. For experimental purposes, a female was counted as "young" when she had been adult for less than two weeks, "old" when more than four.

The general results, in this and other genera, were as follows: A-tone males, when given a choice, almost always devoted their attention to a young female, although an old or mated individual was usually courted energetically if no other was available. B-tone and C-tone males, as well as all near-senile males, showed no courtship display response at all to any but young females. A-tone males often courted a young female which was chloroformed, placed on a mount and held motionless; males of the same tone rarely took any notice of an old or mated individual similarly presented. Dead, thoroughly dried females of all ages either drew no reaction when motionless, or, when appropriately moved, occasionally drew confused threat display. Finally, although certain paper models of $C$. xanthopa males successfully drew threat display, models of females were never successful.

Special test situations, involving $C$. xanthopa ${ }^{2}$ and Phiale, gave the following results which are pertinent:

The abdomen of a young adult female xanthopa had been painted black for another experiment on the tenth day after her molt. After repeated intermittent chloroforming, she died about five o'clock one afternoon. At that time, when crumpled, motionless and of atypical coloring, she readily drew display from several males. Chemotaxis had, as usual, been eliminated from the test situation. By seven o'clock the next morning, although she was not yet stiff, she had lost attraction for three A-tone males to the extent that, although some attention was paid her when she was jerkily moved, no display whatever was drawn. The normally colored abdomen of a chloroformed female, adult for fourteen days, was then cut off from the cephalothorax

2 The published description of $C$. xanthopa display (Part I, p. 36) erroneously states that rocking precedes threat as well as courtship; further observation showed that this as well as courtship; further observation showed that this reinforcement of chemical stimuli. Normally, rocking does not occur in threat display. See Table II, this paper, for synopsis of threat and courtship distinctions. Also, the threat display figured (l.c., Text-fig. $14 \mathrm{C}$ ) represents a moderate phase; in the held even higher, well tarsi leave the ground. 
and placed on the mount $10 \mathrm{~mm}$. from the dead female. Two males now displayed promptly to the black corpse, following through to attempted mating with it, disregarding completely the normally colored, detached abdomen.

The detached abdomen was then rubbed over a dried, mounted male, which had heretofore always drawn prompt threat display. It drew brief, confused display, with both threat and courting elements, from a male which had threatened it a few moments before, and threatened standard stimuli immediately after (without a rest period). During the test, however, he followed the confused display with a leap at the mount and finished with an abortive attempt to mate.

On another occasion, a male xanthopa was threatening a dried male mount. Another freshly detached abdomen of a young female was hidden under a tiny paper tent, $5 \mathrm{~mm}$. to the left of the displaying male which in turn was $50 \mathrm{~mm}$. from the mount. The male stopped threat display, went into a courtship stance and rocked. When the mount was removed, there was no further reaction.

A xanthopa male paid no attention to a scrap of black cloth alone on a mount, or to the same cloth with a young female underneath it, with or without motion of the mount. Then a large, dried Eustiromastix male was given a yellow clypeal band similar to that of xanthopa, and placed on another mount. This stimulus drew prompt threat display when the mount was moved. The piece of cloth was then placed in a heap under the Eustiromastix. Threat again followed. However, when the chloroformed female was once more hidden beneath the cloth and the whole placed under the Eustiromastix, the test male paid swift attention without display, then vibrated the palps, took a courtship stance, and, finally, after one or two rocks, leapt on top of the Eustiromastix and tried to mate with it. This involved such a violent attempt to twist the stiff abdomen that the whole structure toppled over. With a changed sequence of stimuli, the same series was presented to two other males, with similar results, except that the courtship response died out before mating attempts.

Young females of both Corythalia and Phiale, when painted to resemble males, drew unmixed courtship, not threat, although old painted females drew mixed display (p. 194).

When female epigyna of Menemerus, Phiale and Corythalia, in a total of six individuals, were sealed with paraffin, no diminution in attraction was noted; the attractive substances are probably secreted rather generally by body and appendages; the experiments of Kaston (1936) and others on nonsalticids support this idea.

It should be mentioned incidentally that young adult females have a stronger odor to human noses than either males or older females, at least in Menemerus and all three species of Corythalia. In a series of tests on Corythalia, the odor of young females was the only one perceptible to two of five observers; the other three people in every case considered the young female's odor strongest, but indistinguishable in quality from that of males or other females. The latter seemed stronger than the males'. No generic or specific differences were detected, during casual tests with various genera. The terms used in attempts to describe the salticid odors included "spicy," "pungent," and "faintly antiseptic."

Further incidental data, by no means to be regarded as actual evidence for distance chemoperception, include the different methods of using palps and first legs in the various genera (Table II). This seems to be in accord with the various degrees of reliance on contact and distance chemoperception.

The chemoreceptors (including those of chemotaxis and the distance chemoreceptors, whether or not they are distinct), have been shown to be generally distributed on the spider, but concentrated near the tips of the palpi and first legs (Kaston, 1936 and ref.). With this view the Rancho Grande experiments agree. Females without palps or without first legs readily accepted males in Menemerus and Corythalia. When both palps and first legs were removed, reaction time was slowed in Menemerus but not in Corythalia. Males similarly handicapped displayed right through to mating attempts. When use of the first legs was the essential part of display, spiders without them would suddenly leap at the female after a prolonged period of attention. This response was specially noted in Menemerus. Reaction time was decidedly slowed in handicapped males in initiating courtship, but not in responding to any of the threat stimuli, including the mirror and painted mounts. It was much slower in mutilated runners of the genus Menemerus than in the hopper genus Corythalia.

In summary, the following conclusions appear valid. At Rancho Grande, distance (airborne) chemoperception is a positive factor in courtship, but not in threat display. A strong, invisible stimulus is given off by young females, serves as a secondary sign stimulus for releasing courtship and is surpassed in importance only by the male's ability to use his antero-median eyes. It appears to have little directive value. When courtship and threat are distinct, the addition of airborne chemical stimuli from a young female to a stimulus configuration tends to change threat to courtship.

\section{b. Vision.}

i. Vision as a primary stimulus to display. Use of the AME (antero-median eyes) by the male is the only single, sine qua non of display. The investigators who have experimented with the reactions of blinded male salticids agree that they will not display when the eyes are completely covered, no matter what other stimuli (e.g., contact and airborne chemical stimuli) are present. Apparent excitement eaused by other stimuli 
has sometimes, however, been observed. The species previously tested are well distributed among a number of subfamilies: Dendryphantes elegans, Saitis pulex, Phidippus rufus and Astia vittata (Peckham, 1894, p. 248) ; Evarcha blancardi (Homann, 1928, p. 254); Aelurillus v-insignatus (Bristowe, 1929 , p. 343) ; Phidippus clarus, P. audax (Kaston, 1936, p. 131). Homann confined some of his blinding experiments to the AME, finding that display failed to occur as completely as when spiders were totally blinded.

The present experiments support and extend these previous conclusions. Two males each of Corythalia xanthopa, $C$. chalcea and Menemerus bivatattus, all of A-tone, were used. In one of each pair all eyes except the AME were painted, as described in Part II (1948.2, p. 144); in the other, only the AME were covered. After the spiders had apparently recovered from the chloroform (the minimum time allowance was one hour), standard test stimuli (p. 177) were presented on three successive days, unless a positive response was obtained earlier. Regardless of all-negative responses, the paint was then removed and, in tests counted as successful, positive responses obtained to at least one of the standard stimuli within one hour.

In each species, the males with the AME uncovered performed complete display (both threat and courtship, in the case of Corythalia) within the allotted period, although their reaction time in general appeared a little slowed. In contrast, those with the AME painted never displayed at all. The latter did, however, show some awareness of moving objects, including females, by shifts in position and slight "following" with the eyes at distances of half an inch or less. This note is typical: "X64 male sat quiet, although he ran and jumped when prodded. Took no notice of X34 female, as she watched him only one-half inch away; although she actually brushed against him several times, even his palps hung quiet. Later he moved off, crossing her trail and very recent resting place without pausing. Finally, when she jumped past him, he did turn toward her; the stimulus, however, could have been a vibration of her jump, rather than either a chemical or visual stimulus. Even in the same vial with her, with all her chemical stimuli reinforced, there was no reaction."

The most interesting result, from the viewpoint of phylogeny, was that Menemerus, which appears to depend more on chemotaxis and distance chemoperception and less on vision than Corythalia, was decidedly less handicapped by the loss of the AME. He moved around much more actively, and palpated the females' resting places in apparent excitement. No attempt was made by either genus to pursue prey without the use of the AME.

The AME of a single young female $C$. xanthopa were covered. Just before the operation she had allowed a male to reach an advanced Stage II, when the pair was purposely separated..After painting, she refused him and four other actively displaying males which subsequently displayed to her, two or three in succession, on four successive days. One male, on the third day, reached Stage II repeatedly, ". . . but at the least touch, or before, she moved off. Male was very persistent. She did not turn to keep him in view; her palps hung motionless. Since he circled her time after time in displaying, as usual, she crossed his trail frequently during her retreats. She never once assumed the raisedcarapace stance so many xanthopa females temporarily adopt when attention is gained. He persisted for twenty minutes, then gave up. I cleaned her eyes, introduced the same male within half an hour, and they were mating five minutes later." (Field lab. note.)

No other female blinding experiments were completed through the final stage of obtaining positive mating responses after the AME were uncovered. However, all the indirect evidence-in the observations of others and in my own-points to the usual necessity for the female to see the male before allowing mating to take place.

In summary, use of the AME, and of the AME only, is a prime requisite in salticid courtship.

ii. Motion. It seems well established that at least some salticids will not only leap on motionless prey, but will display to a motionless female (e.g., Peckham, 1894, pp. 243248; Heil, 1936, p. 10). Nevertheless, the present study showed that movement is the most important single element in the visual sign stimulus pattern, in both courtship and threat display, in all the salticids tested. Although display was occasionally obtained by a motionless spider, the courtship response always occurred under the following conditions: first, the stimulus was a female; second, the displaying male was of A-tone with exceptionally low threshold; third, the motionlessness of the stimulus was the only unusual factor in the situation. On other experimental occasions in which the above conditions were fulfilled, however, only negative responses were drawn. Table IV gives test data and results of pertinent experiments.

In many (certainly more than twenty) unrecorded, casual observations, a normal spider, which was sitting quietly when the male to be tested was introduced, would not draw a display until it moved, even though the two spiders were close together and the test male, judging by his actionshis turning, or moving toward the stimulus -had certainly become aware of the stimulus.

In more than 300 tests on 10 species, in which the stimulus was in some way unnatural, no positive response was ever obtained until the stimulus was moved. Many times the slightest, brief, manual twitching of the cardboard mount was enough of an 
TABLE IV.

Responses of Males to Motionless Females.

Series A. Conditions. Male of A-tone; normal female chloroformed, placed on cardboard mount in approximately natural position; chemotaxis, but not distance chemoperception, eliminated (i.e., fresh sheet of paper on open table used for each test); same female in experimental session drew display from same male both before test (followed by rest) and immediately after. Exposure of each male to stimulus consisted in allowing him to drop near, or run toward, female, chivvying him gently with brush if necessary, to ensure her being in his direct line of vision. Even in negative responses, attention was often gained, even extending to feeling of the female with palps and legs, although display was not released.

\begin{tabular}{|c|c|c|c|c|}
\hline Species. & $\begin{array}{c}\text { No. of } \\
\text { Individuals. }\end{array}$ & $\begin{array}{l}\text { No. of } \\
\text { Tests. }\end{array}$ & $\begin{array}{l}\text { Negative } \\
\text { Responses. }\end{array}$ & $\begin{array}{c}\text { Positive } \\
\text { Responses. }\end{array}$ \\
\hline $\begin{array}{l}\text { Menemerus } \\
\text { bivittatus }\end{array}$ & 5 & 7 & 6 & 1 \\
\hline $\begin{array}{l}\text { Semorina } \\
\quad \text { brachychelyne }\end{array}$ & 1 & 2 & 2 & 0 \\
\hline $\begin{array}{l}\text { Sassacus } \\
\text { flavicinctus }\end{array}$ & 2 & 2 & 2 & 0 \\
\hline $\begin{array}{l}\text { Phiale } \\
\text { dybowskii }\end{array}$ & 1 & 5 & 0 & 5 \\
\hline $\begin{array}{l}\text { Phiale } \\
\quad \text { flammea }\end{array}$ & 2 & 3 & 0 & 3 \\
\hline $\begin{array}{l}\text { Corythalia } \\
\text { chalcea }\end{array}$ & 1 & 1 & 0 & 1 \\
\hline $\begin{array}{l}\text { Corythalia } \\
\text { xanthopa }\end{array}$ & 4 & 12 & 11 & $\begin{array}{c}1 \\
\text { (delayed) }\end{array}$ \\
\hline Total & 16 & 32 & 21 & 11 \\
\hline
\end{tabular}

Series B. Chemotaxis permitted. Conditions as in A, but males permitted to cross repeatedly trails of the now motionless females.

\begin{tabular}{l|c|c|c|c}
\hline \hline \multicolumn{1}{c|}{ Species. } & $\begin{array}{c}\text { No. of } \\
\text { Individuals. }\end{array}$ & $\begin{array}{c}\text { No. of } \\
\text { Tests. }\end{array}$ & $\begin{array}{c}\text { Negative } \\
\text { Responses. }\end{array}$ & $\begin{array}{c}\text { Positive } \\
\text { Responses. }\end{array}$ \\
\cline { 2 - 5 } $\begin{array}{c}\text { Menemerus } \\
\text { bivittatus }\end{array}$ & 4 & 9 & 8 & 1 \\
$\begin{array}{c}\text { Sassacus } \\
\text { flavicinctus } \\
\begin{array}{c}\text { Corythalia } \\
\text { xanthopa }\end{array}\end{array}$ & 2 & 2 & 2 & 0 \\
\hline \hline
\end{tabular}

Series C. Elimination of Distance Chemoperception and Motion, Conditions as in A, but female isolated in glass vial. No tests completed, since males did not display even when the stimulus female regained consciousness and moved naturally. However, in spite of the imperfect conclusions, it is worth recording that not one positive response was drawn in a total of more than 20 tests involving the same species listed in Series A. The enclosing of tested males, rather than stimulus females, would not have given significant results, since the effect of possible self-stimulation through crossing of their own tracks or responding to their own distance chemical stimuli, would not be eliminated. Similarly, mirror responses automatically involved sight of the males' own motions (however slight).

Series D. Alteration of Female Appearance. Conditions as in A, but female painted or upsidedown. More than 25 tests, using stimuli which gave positive responses when moved, were all negative when motionless. See pp. 191 and 193 for tested species; all were given motion response tests in the same session. No stimulus which was unsuccessful when moved drew display when motionless.

Series $E$. Use of Models. No motionless model, even when successful in motion, drew a positive response. See p. 190. Test individuals were given motion-response tests in the same session. 
addition to the stimulus situation to draw a prompt display.

This manual jerking of the mount of a chloroformed or fresh dead female was as effective as the female's own motions in drawing display. Her further motion was not essential, once the male had initiated display; it is, however, customary in normal courtship for even A-tone females to turn and twist and, especially, to retreat a few inches at least once or twice during courtship.

Also, the finer motions of females during male display almost certainly have value. In various species-in $C$. xanthopa, for example -females early in courtship brace themselves high in a position similar to a prethreat stance in males. Just before or after the beginning of the male's Stage II, they crouch low. Again, in very many species, the females vibrate the palps rapidly during the early stages of courtship. Finally, in a few species, notably $C$. fulgipedia and Sassacus ocellatus among Rancho Grande examples, excited females often make weak copies of the males' motions, with occasional individual quirks of their own. None of these female motions ever proved to be in the least necessary either to release or to direct male display. There seems no question, however, but that they have minor directive value, and the female's eventual, crouching quiescence, as in other animal groups, certainly acts as a positive factor in permitting the continuation of Stage II. Also, it is this crucial point which in intermediate genera largely determines the continuation of display as Stage II courtship or as contact threat or actual fighting. In final summary, however, the function of female posture and motion changes is minor: in no genus which I have observed closely does the release of Stage II depend, in lock-and-key fashion, on any motion, or cessation of motion, in the female.

From the female's viewpoint, the sight of a male making appropriate courting motions is essential for acceptance. Exactly what constitutes, for each species "appropriate motion" is, however a completely unsolved question of obvious evolutionary interest. Since no method has yet been devised of testing this aspect, only the following general remarks may be made.

Little or no notice is taken of motionless males, although occasionally an A-tone female will approach or even touch one, without any attempt to injure or eat him (cf. behavior toward a partly blinded male, p. 185). No male was ever allowed to mate without complete courtship for the species, although sometimes the whole display was raced through in less than a minute, with no repetitions of stages, where both individuals were of high tone. In the occasional instances where males, because of low tone or a confusing experimental factor, omitted display and leapt directly on the female, she invariably drove him off or escaped.

Many males of high tone court females of similar-appearing or closely related species.
These females are often attentive for long periods and make no effort to attack or retreat. It is usually the female that withdraws, often before Stage II is reached. It has yet to be determined how much her withdrawal depends on the, for her, "incorrect" pattern of male motion, and how much on the unsatisfactory character of other elements in the stimulus configuration.

In the release of inter-male threat display, motion is usually essential. Once a $C$. xanthopa, of especially high A-tone, did perform threat to a chloroformed male; this, however, was the only exception in more than 25 trials on different species. Those males which react to their mirror images will very rarely display unless the mirror is moved jerkily forward.

One more point should be emphasized in regard to motion in general. The positive responses to motionless stimuli, of whatever nature, usually occur when the test spider is dropped suddenly near the stimulus. It seems likely that the visual effect to the spider may be similar to that obtained when the stimulus is moving-roughly analogous to a human passenger's confusion when one of two parallel trains starts to move.

To sum up: Male display is sometimes released in the presence of motionless females. In these cases, however, the males are of extremely high epigamic tone (Aplus), the females of unaltered appearance, and the general external conditions propitious. Therefore, although movement of the stimulus is not a primary releaser for courtship, it is an important secondary releaser, and, doubtless, a director as well. Appropriate motion of the male is essential for acceptance by females. The response to motion does not appear to vary with the degree of specialization within the family.

iii. Distance. The distance at which salticids perceive their prey and mates, and at which they start display, has been measured for a variety of species (e.g. Peckham, 1894, p. 242; Homann, 1928, p. 247 ff.). In this study it is pertinent to add the following remarks and conclusions.

Corythalia xanthopa, which averages around $4.3 \mathrm{~mm}$. in length, is typical of moderately small species at an advanced stage of visual evolution. Males will come to a state of attention and approach a female on the same level, from a maximum distance of ten inches, but the usual limit of attention (as distinct from display) is not more than six inches for courtship, much less for threat. Neither courtship nor threat usually takes place at more than three inches, and usually at 1.5 to two inches. At the resumption of an interrupted series, however, it may start at 3.5 to four inches. Stage II, in courtship or threat, starts at less than one inch, usually at about half an inch. $C$. chalcea and fulgipedia, which have apparently equal visual dependence with xanthopa, are both somewhat larger than the latter; in correlation 


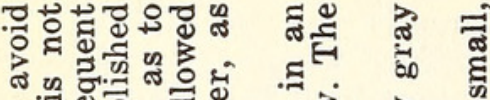
ค ๓ द्व

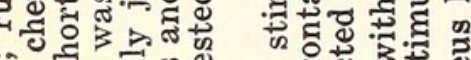
ช... \%

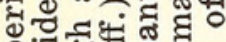

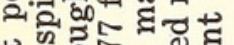

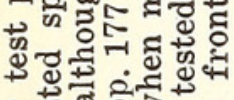

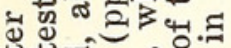
范 政,

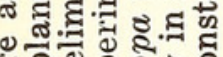
क⿺辶一

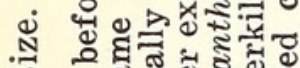

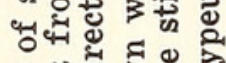

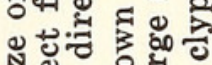

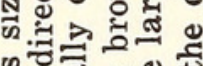

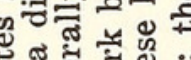
⿶凵

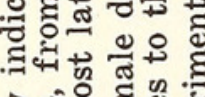

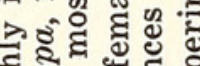

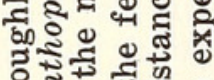
空 용 在诰

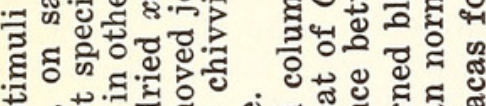
no 0 ㄴ.

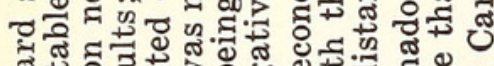
고으.

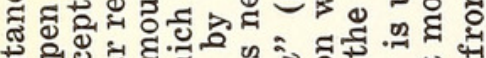
要

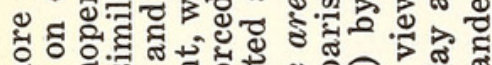

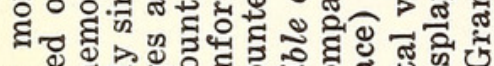

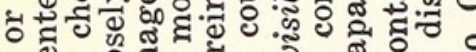

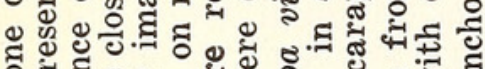
政 8. 0.0 ฆ 胥

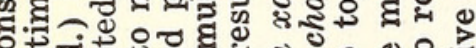
叫

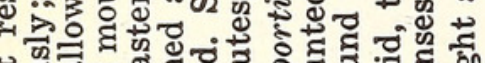
충

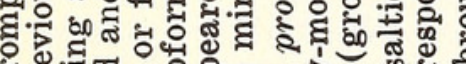

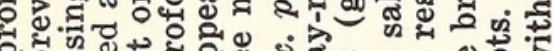
ع 20 ข กี

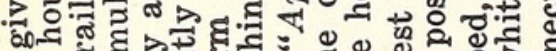
政 额

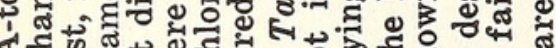
政

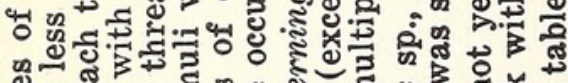
of

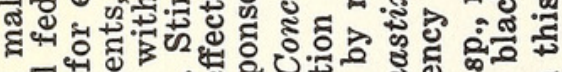

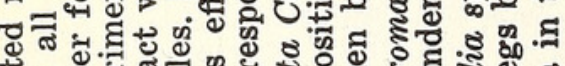
4.

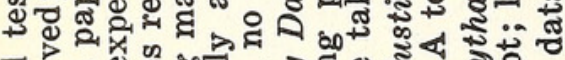

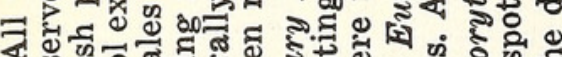
ขొ

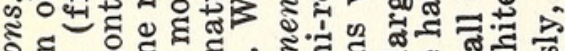

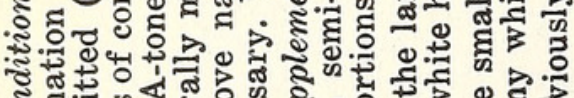
5

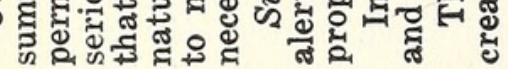

\begin{tabular}{|c|c|c|}
\hline 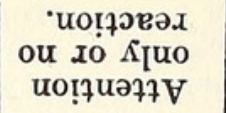 & कू NaHO & $\infty \pi$ \\
\hline 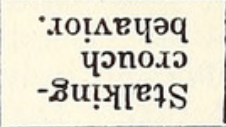 & & $\approx$ \\
\hline 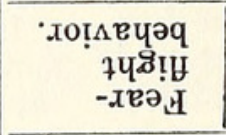 & a a d a d & \\
\hline 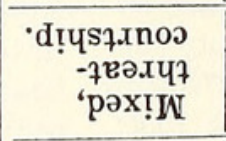 & -1 & - \\
\hline 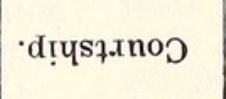 & ه & ar \\
\hline 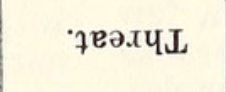 & $\sim \infty$ & बत \\
\hline 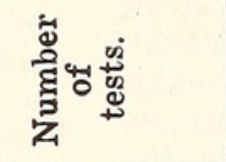 & 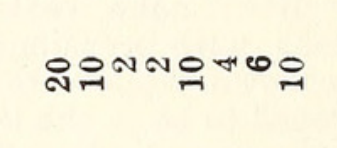 & 100000 \\
\hline 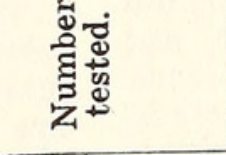 & 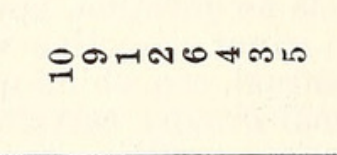 & 100000 \\
\hline 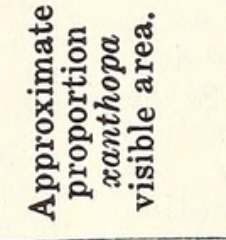 & 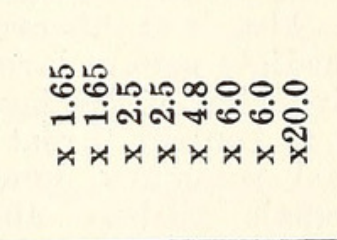 & 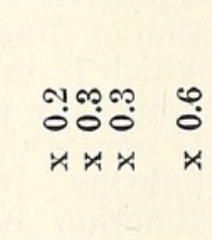 \\
\hline 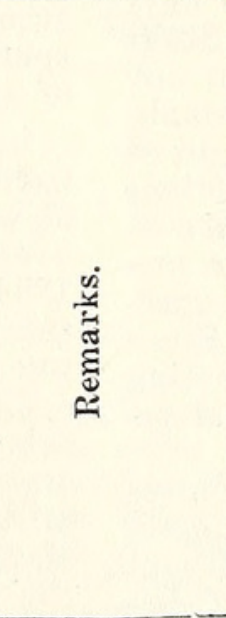 & 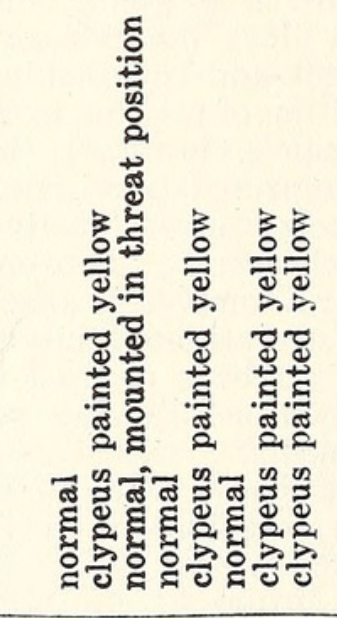 & 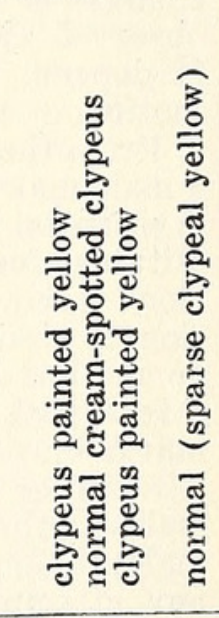 \\
\hline 产 & 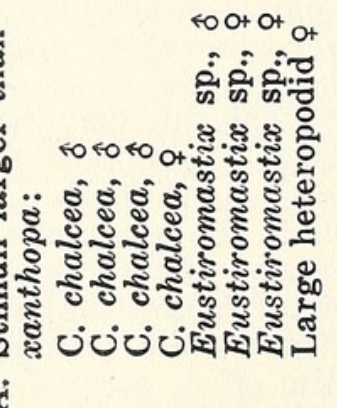 & 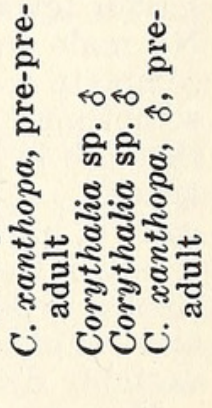 \\
\hline
\end{tabular}


TABLE VI.

Spectral Reflectance of Paints Used in Salticid Experiments.

Conditions: Ultraviolet (UV) reflectance judged optically from comparative inspection of negative images of paint samples; lens, Leitz $50 \mathrm{~mm}$. Summar; film, Eastman Super XX; filter, Wratten No. 18A; exposure, 1 sec. @ F 3.5; illumination, light from north sky, partly cloudy, noon, June, latitude $10^{\circ} 21^{\prime}$ north. Spectral reflectance readings from curves furnished by Electrical Testing Laboratories, N. Y., made from same samples on Hardy spectrophotometer; reflectance factor in terms of magnesium oxide.

\begin{tabular}{|c|c|c|c|c|c|c|c|c|c|c|c|}
\hline \multirow[b]{2}{*}{$\begin{array}{l}\text { Wave- } \\
\text { length } \\
(\mathbf{m} \mu)\end{array}$} & \multicolumn{11}{|c|}{ Reflectance Factor } \\
\hline & $\begin{array}{l}\text { White } \\
\text { (Devoe) }\end{array}$ & $\left\{\begin{array}{c}\text { Blue } \\
\text { (Devoe) }\end{array}\right.$ & $\begin{array}{c}\text { Green } \\
\text { (Devoe) }\end{array}$ & $\begin{array}{l}\text { Yellow- } \\
\text { green } \\
\text { (Devoe) }\end{array}$ & $\begin{array}{l}\text { Yellow } \\
\text { (Devoe) }\end{array}$ & $\begin{array}{l}\text { Yellow } \\
\text { (Flo- } \\
\text { quil) }\end{array}$ & $\begin{array}{l}\text { Orange } \\
\text { (Devoe) }\end{array}$ & $\left|\begin{array}{c}\text { Red } \\
\text { Devoe) }\end{array}\right|$ & $\begin{array}{l}\text { Red } \\
\text { (Flo- } \\
\text { quil) }\end{array}$ & $\begin{array}{l}\text { Red-\&- } \\
\text { white } \\
\text { (Devoe) } \\
\text { (Pink) }\end{array}$ & $\begin{array}{l}\text { Black } \\
\text { (Devoe) }\end{array}$ \\
\hline UV & $\begin{array}{c}\text { very } \\
\text { strong }\end{array}$ & strong & weak & $\begin{array}{l}\text { very } \\
\text { weak }\end{array}$ & $\begin{array}{l}\text { very } \\
\text { weak }\end{array}$ & $\begin{array}{l}\text { very } \\
\text { weak }\end{array}$ & $\begin{array}{l}\text { very } \\
\text { weak }\end{array}$ & weak & $\begin{array}{l}\text { very } \\
\text { weak }\end{array}$ & strong & $\begin{array}{l}\text { very } \\
\text { weak }\end{array}$ \\
\hline 400 & .715 & .432 & .080 & .067 & .115 & .067 & .050 & .080 & .030 & .450 & .025 \\
\hline 410 & .725 & .450 & .082 & .070 & .120 & .067 & .055 & .087 & .032 & .462 & .032 \\
\hline 420 & .735 & .480 & .090 & .075 & .130 & .067 & .057 & .092 & .033 & .477 & .035 \\
\hline 430 & .750 & .515 & .095 & .082 & .145 & .067 & .058 & .095 & .035 & .492 & .035 \\
\hline 440 & .755 & .535 & .110 & .090 & .165 & .068 & .060 & .098 & .035 & .512 & .035 \\
\hline 450 & .765 & .550 & .135 & .107 & .197 & .070 & .063 & .013 & .035 & .522 & .035 \\
\hline 460 & .770 & .545 & .180 & .145 & .250 & .070 & .065 & .012 & .037 & .520 & .035 \\
\hline 470 & .775 & .505 & .255 & .215 & .330 & .075 & .067 & .095 & .038 & .518 & .035 \\
\hline 480 & .780 & .440 & .365 & .345 & .425 & .078 & .068 & .087 & .040 & .513 & .035 \\
\hline 490 & .782 & .365 & .475 & .475 & .520 & .087 & .072 & .085 & .043 & .507 & .036 \\
\hline 500 & .785 & .280 & .545 & .565 & .597 & .105 & .075 & .077 & .045 & .498 & .037 \\
\hline 510 & .785 & .215 & .552 & .617 & .640 & .157 & .077 & .072 & .052 & .492 & .037 \\
\hline 520 & .787 & .160 & .520 & .637 & .667 & .265 & .080 & .068 & .057 & .488 & .037 \\
\hline 530 & .787 & .125 & .470 & .637 & .680 & .402 & .083 & .070 & .060 & .493 & .037 \\
\hline 540 & .790 & .097 & .405 & .620 & .685 & .515 & .105 & .070 & .062 & .502 & .037 \\
\hline 550 & .790 & .080 & .335 & .592 & .692 & .575 & .160 & .067 & .067 & .507 & .038 \\
\hline 560 & .792 & .067 & .275 & .560 & .697 & .615 & .270 & .068 & .075 & .510 & .038 \\
\hline 570 & .795 & .060 & .220 & .535 & .700 & .640 & .420 & .075 & .080 & .530 & .038 \\
\hline 580 & .800 & .057 & 185 & .525 & .705 & .657 & .550 & .100 & .085 & .580 & .039 \\
\hline 590 & .805 & .055 & .167 & .523 & .713 & .670 & .625 & .180 & .115 & .650 & .040 \\
\hline 600 & .810 & .057 & .155 & .525 & .715 & .677 & .665 & .335 & .195 & .715 & .040 \\
\hline 610 & .812 & .060 & .147 & .532 & .725 & .678 & .688 & .550 & .310 & .747 & .040 \\
\hline 620 & .817 & .062 & .137. & .550 & .737 & .678 & .705 & .575 & .395 & .755 & .040 \\
\hline 630 & .820 & .067 & .132 & .577 & .747 & .678 & .718 & .625 & .450 & .777 & .040 \\
\hline 640 & .825 & .080 & .135 & .615 & .752 & .677 & .735 & .657 & .478 & .787 & .040 \\
\hline 650 & .830 & .092 & .145 & .640 & .763 & .677 & .750 & .680 & .493 & .798 & .040 \\
\hline 660 & .835 & .115 & .167 & .657 & .777 & .678 & .765 & .700 & .502 & .807 & .041 \\
\hline 670 & .845 & .145 & .195 & .665 & .790 & .680 & .780 & .722 & .510 & .818 & .041 \\
\hline 680 & .850 & .190 & .225 & .657 & .795 & .683 & .792 & .740 & .513 & .827 & .042 \\
\hline 690 & .855 & .242 & .280 & .653 & .805 & .685 & .802 & .755 & .522 & .838 & .042 \\
\hline 700 & .860 & .315 & .342 & .663 & .815 & .688 & .813 & .767 & .527 & .843 & .043 \\
\hline 710 & .863 & .392 & .407 & .692 & .820 & .690 & .820 & .773 & .532 & .850 & .043 \\
\hline 720 & .865 & .465 & .463 & .720 & .823 & .693 & .827 & .787 & .535 & .853 & .042 \\
\hline 730 & .867 & .530 & .515 & .745 & .827 & .697 & .832 & .795 & .538 & .858 & .042 \\
\hline 740 & .870 & .577 & .558 & .770 & .830 & .698 & .835 & .780 & .540 & .860 & .042 \\
\hline 750 & .872 & .610 & .595 & .790 & .834 & .702 & .840 & .887 & .542 & .862 & .042 \\
\hline
\end{tabular}

they have slightly greater attention and display limits, thus illustrating a general principle of the spatial limits of salticid responses.

In comparison with Corythalia, species which still place a relatively high dependence on chemotaxis and/or distance chemoperception, appear relatively short-sighted. Thus, Ashtabula and Semorina, although similar in length to $C$. xanthopa, rarely give evidence of first attention at more than four inches, and usually much less. Display begins even closer, and, as always, Stage II starts closer than Stage I.
It must be kept in mind that two spiders are seldom in the same plane in the field; therefore, one customarily enjoys the advantage of an obliquely downward view on the expansive dorsal surface of the other.

Once more the importance of the physiological state should be emphasized: A-tone males tend to start attention and display responses at greater distances than others.

iv. Size. The display responses of salticid males to stimuli of unusually large and small size do not appear to have been previously investigated. In this study $C$. xanthopa was subjected to a series of experiments, the 
distinctness of its threat and courtship responses making it an especially interesting species. Because of the importance of distance chemoperception in its courtship releasing mechanism, males rather than females were usually selected as stimuli. The results of the tests appear in Table V. In casual observations on other species, primarily concerned with inter-specific display, it was always true that where two species had display relations, there was never much discrepancy in size.

Conclusions: First, Appropriate size is an important secondary sign stimulus to display. No male xanthopa will give any kind of a positive display reaction to a spider with a frontal area of more than five times, or less than one-third, of his own. In other words, in linear measurements, positive responses may be given to stimuli measuring up to about twice natural size and down to about onehalf.

Second. The responses within this range are highly variable and signs of confusion are frequent. The courtship response is often given in these unusual size ranges to stimuli to which a threat response would seem more appropriate.

Third. Addition of a clypeal band of yellow paint to an otherwise black frontal view, sometimes changed negative to positive responses. This yellow resembled, to human vision, that of xanthopa males. Both brands used had slight reflectance below about 520 $\mathrm{m} \mu$ (Table VI).

Fourth. As usual with unnatural stimuli, responses were usually obtained only by deliberately reinforcing the stimuli. This was accomplished by repeated presentations in quick succession, and constant chivvying to keep them moving in the direct front visual field of the spider. Spiders below A-tone gave consistently negative results.

Fifth. There was a tendency to respond to large stimuli at longer range than the normal.

v. Form. The general shape of the spider is another secondary sign stimulus for releasing display. Heil (1936), working with life-size pictures of Evarcha, performed some experiments on this subject. He found that the number of positive display responses decreased rapidly with the simplification of the drawing, particularly in the reduction of lines representing the legs. The following results, which support and extend those of Heil, were obtained at Rancho Grande.

As in other factors, the importance of form varies inversely with the normality of the test situation, and with the drive of the individual; an A-tone C. xanthopa of especially strong drive will respond (with threat) to a jerked, life-size paper model of great simplicity, to the jerked carapace of a dried male, or to a jerked or naturally moving normal male with a high black paper "hat." None of these extremes is successful under other conditions, or in combination with one an- other. For example, none of them draws display from a male of mediocre drive, while a legless paper model or a motionless carapace is unsuccessful even with males of the highest tone.

Because of the variety of contributing factors, a tabular representation of the experiments in this series would not give as true a synopsis of the results as the following running account with selected and annotated field notes. All of the experiments were performed under the conditions described under Table VI. In this series the tested species were Corythalia xanthopa, C. chalcea and Phiale flammea, all visually advanced species in which chemotaxis and distance chemoperception are of reduced importance.

Models. Cardboard models were tested on male $C$. xanthopa. Drawings of successful and unsuccessful models, made through a binocular microscope, are shown in Text-fig. 7. "A" represents a careful drawing of a male in threat position, for comparison, and was not used as a model; such detail, would, of course, have been impossible to include on a

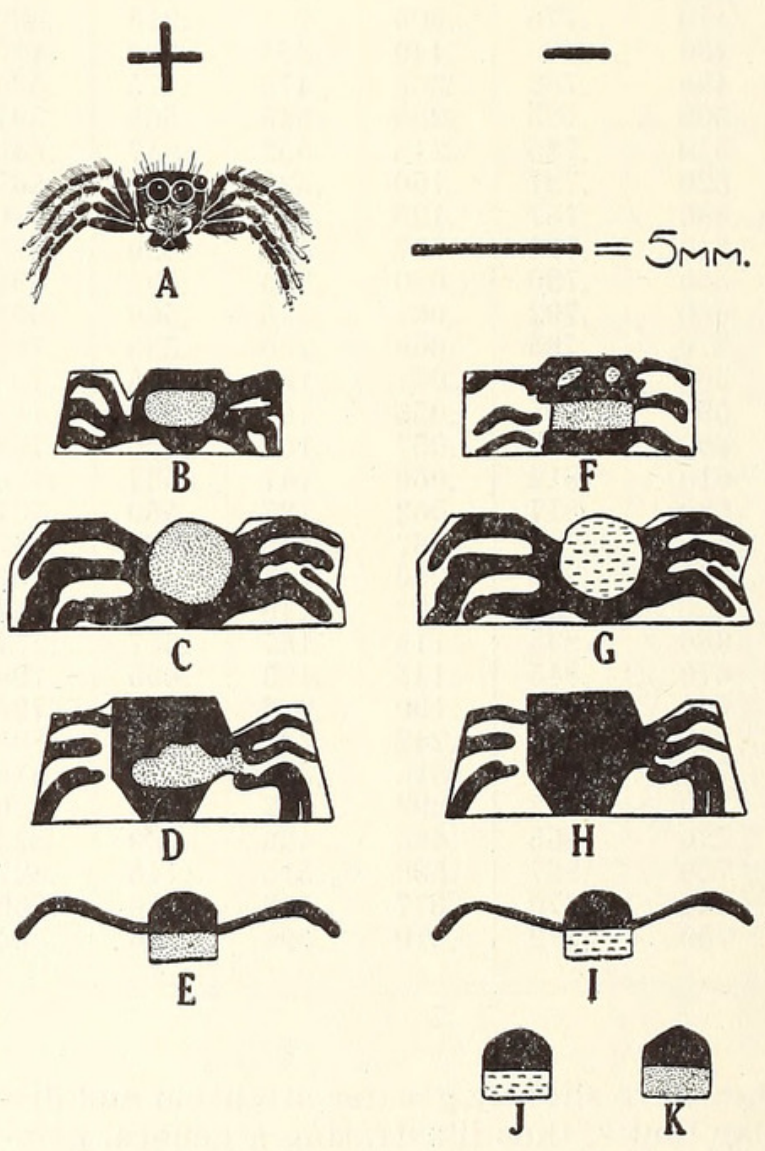

TExT-FIG. 7. Examples of models used in experiments on form-pattern-color perception in Corythalia xanthopa. The stippled areas were painted yellow, the dashed areas white, the backgrounds light green; spectrophotometric data in Table VI. A, detailed drawing of C. xanthopa in threat position; B-E, drawings of pasteboard models which drew threat responses, in order of their success, from the most (B) to the least (E); F-J, unsuccessful models. Note that the only difference between successful and unsuccessful in some cases was the presence or absence of a yellow median area. See text. 
surface $5 \mathrm{~mm}$. across. Similar models, but relatively larger or smaller than those shown were never successful. Even the unsuccessful models (right column) drew some attention from A-tone males. All were drawn in Higgins India Ink on bits of pasteboard; interstices between "legs" were painted pale green (see wave length analysis, p. 189 for this and other colors mentioned hereafter), from the same jar as the mounts and similar in reflectance curve to the paper substratum. This tint, used frequently as background in series of experiments involving living stimuli, appeared, from the tested spiders' behavior, to provide for them excellent contrast.

The most successful model was B, the least successful in the positive series, E. The best of them, however, drew only delayed display. It will be noted that all successful models had the following characteristics: a roughly squared or rounded central portion, painted matte black and yellow, with a greater or lesser series of lateral extensions. The "eyed" model (F) was never successful, nor were models similar to or identical with the successful one except for black or white in place of yellow in the central region. Plain black quadrilaterals-i.e., without "legs," but covering the same area as B and D-were always unsuccessful, even when furnished with a median yellow spot or bar. Also unsuccessful were all more extreme models, including equilateral and isosceles triangles; the latter were tried both vertically and horizontally, and all were furnished with a median yellow area. Finally, no small, median portion, representing the carapace only, ever drew a response.

\section{Form Experiments with Specimens.}

General Shape. The following experiments also show the necessity for a general shape approaching the normal. A young adult female $C$. chalcea was lightly chloroformed, placed on an L-mount and covered with a bit of flimsy black silk (chiffon), which scarcely enlarged her, but effectively concealed her shape. When she was jerked before a high tone male, no display was drawn. However, when the whole was surmounted by a large, dried Eustiromastix sp. (a male, plain dark brown with a painted yellow clypeus), the chalcea promptly courted, following through to attempted mating - not with the hidden chalcea, but with the Eustiromastix. Single, fresh abdomens, of both males and young females, were presented to males of $x a n$ thopa, chalcea and P. flammea; none ever drew display, or even attention, from a total of about 25 tests. Detached fresh legs, singly or in groups, were equally ineffective.

Importance of Legs. A legless, dried male xanthopa cephalothorax was very rarely successful in drawing threat display. Similarly, a legless and palpless young female chalcea (but with abdomen intact) drew delayed display in only three of nine tested males. However, none of these positive responses was complete: one male broke off display and jumped, several times in succession, at the female; another, after a delayed Stage I, merely climbed onto the cardboard mount beside her, palpating its surface; a third reached Stage II, but did not follow through to twisting the abdomen, his display dying out in palpation of her body and the surrounding mount.

A single real leg was then laid flat at each side of the female, without drawing a response; but when two pairs were used, delayed but complete courtship followed.

When a sling of stiff black cotton, shaped like a broad, inverted W, was substituted for real legs, brief and abortive display followed. When a second sling was added, so that the front view showed lateral stripes of alternating light and dark, prompt, complete courtship ensued. When the second sling was removed, there was once more no response, which however followed promptly upon the second sling's replacement.

Throughout all the experiments with xanthopa, it proved axiomatic that mounted dried or chloroformed males with the legs stretched out at the sides drew threat display from males of mediocre drive faster than those in a huddled position.

Upsidedown females of xanthopa, chalcea and $P$. flammea were tested. These almost never drew display, the rare exceptions being from males of the very highest tone. The display never started until abnormally close to the stimulus and Stage I was exceptionally brief; occasionally a male would approach a female without display, palpating her for a time before wandering off. No actual mating attempts, which were always preceded by some display, were ever successful, the males groping about in evident confusion. Upsidedown males, on the other hand, never drew threat display or, in fact, more than passing attention.

Importance of Carapace Height. Compared with the legs, the height of the carapace is of very minor importance. Its elevation off the ground has no perceptible significance, judging from the prompt response of male xanthopa to the various mounts and of other forms, including Menemerus, Sassacus, C. chalcee and Phiale, to various dried or chloroformed mounted examples of their own species, none of which was ever presented balanced in life-like fashion on the legs. It must be remembered, however, that in normal display one of the most usual factors is the elevation of the carapace high on the legs.

Black and white paper "hats" of various sizes and shapes were fastened above the eyes to males and females of C. chalcea and $P$. flammea with rubber cement. So long as other conditions approached the normal, appropriate display was delayed little or not at all, and a female chalcea readily accepted a black-hatted male. However, in the case of hatted females, the males did not carry display through to actual mating attempts, in 
this small set of "hat" tests which totalled about a dozen. The highest addition tried measured twice the height of the clypeusplus-AME-diameter.

Conclusions. First, shape is of secondary significance in the release and direction of display.

Second, deviations in shape which do not hinder display release nevertheless often prevent mating.

Third, the primary shape requisite for releasing and directing either courtship or threat in Corythalia and Phiale are a roughly quadrilateral figure, broader than high, the lateral portions of which show some suggestion of dark and light horizontal stripes.

Fourth, the vertical dimension is less important than the horizontal as a factor in display.

Fifth, when the shape of a stimulus deviates from the normal range of variation, the tested spider must be of high tone and the other factors in the display situation must in general be normal, in order to draw a display response.

vi. Pattern, Intensity and Color. The parts played by pattern, intensity and color in courtship and threat displays are, as in other groups, exceedingly difficult to determine and to distinguish; in the present study only the surface of the question has been scratched. It should be pointed out that the distinction made here between "shape" and "pattern" is obviously artificial, although, in the preceding section on shape the emphasis was on the general form of the figure, rather than on the details; however, the stimulus value of the legs certainly belongs as much under "pattern" as under "shape."

The Peckhams (1887, p. 403) were the pioneers, as usual, in investigating color perception in spiders. Working altogether with lycosids, they approached the problem through a choice method, the lid of the cage being covered with glass squares differing in color. Since neither intensity nor wavelength was controlled, their results can have no final significance for modern workers. Nevertheless, it is very suggestive that the vast majority of Lycosa chose "red," since these spiders are largely negatively phototropic; very likely the hunting spiders in general, like the majority of insects, will prove to be relatively insensitive to the red end of the spectrum.

The Peckhams performed another series of experiments, painting female salticids partially or completely "blue." Following painting, the previously displaying males paid them much less attention, either not displaying or delaying the response, although it was resumed promptly when normal females were introduced. A number of uncontrolled factors were of course involved in this series (1894, p. 249).

Kaestner (1949) has just published a preliminary report indicating that color percep- tion does occur in the European genus Evarcha.

Apart from the question of actual color perception in salticids, the minor role played by color, or at least by lightness and darkness, in courtship is shown by Maevia vittata, the North American salticid with dimorphic males. Painter (1913) seems to have been the most recent worker on the subject. The dimorphism is controlled by the presence or absence of a small sex chromosome, and in the population studied the two forms were about equally abundant. The principal distinctions consist of general color-black in one, gray with orange palps in the otherand the presence of a pair of tufts on the carapace in one, absent in the other. In spite of considerable individual variation, the two forms are quite distinct visually; in addition, the display patterns show differences. Nevertheless, both were readily accepted by females, as were dark males with their tufts missing. According to the Peckhams (1889, p. 54), who worked in a different part of the United States, the darker, tufted form was more aggressive, and was preferred by the females; also, differences in display of the gray form from that described by the Peckhams were reported by Painter. In spite of the fact that in neither study were controlled experiments performed, which guarded against summation, etc., it still seems likely that a most interesting series of behavior differences has evolved in this widespread species. Here is certainly splendid material for worthwhile work.

The disagreements between the Peckhams and Painter do not affect the conclusion that degree of lightness or darkness in males is not, in that species, of primary importance in gaining acceptance by the female.

In the present experiments, two groups of colors were used, the Floquil "Flo-paque" series and Devoe opaque water colors. Since spectrographic analysis could not be conducted in the field, library cards were painted with each hue and combination used; later these were analysed spectrophotometrically (Table VI), along with fresh samples from new jars. The latter check was employed to determine the degree of changes in the samples since their field use; these differences proved insignificant. Although the paints are far from a theoretical monochromatism, most of the hues do show steeply ascending curves near the regions of highest reflectance.

During the field experiments, the paints and the yellow of $C$. xanthopa (cut in two, without exposure to chemicals, just before the photograph was made) were photographed through Wratten Filter No. 18A, which screens out virtually all light except the ultraviolet; the spider's yellow areas did not perceptibly affect the negative according to observations through a binocular microscope. (Spider photographic data: lens, Leitz 90 mm. Ektar; exposure, 13 sec. @ F12.7; other data as in Table VI). In view of these 
negative results, it is apparent that ultraviolet is not a factor in the effect of xanthopa yellow as a sign stimulus; they do not of course, preclude the possibility of the spider's visual sensitivity to ultraviolet wave-lengths. So far the yellow of the spiders has not been further analyzed: dried specimens appear to be too changed to give trustworthy results.

It will now be shown that the various characteristic "display ornaments" are in themselves of minor importance in the samples studied as display sign stimuli, except in certain inter-male relationships. C. xanthopa was the subject of most of the experiments; C. chalcea, C. fulgipedia, Menemerus bivittatus, Phiale flammea and P.dybowskii were used to a lesser extent; a few illustrations were taken from Semorina, Ashtabula and Sassacus.

The Role of Female Pattern, Intensity and Color in Stimulating Male Display. The female's pattern and color equipment may be divided between that of the frontal and the dorsal (particularly abdominal) regions. It must be kept always in mind, however, that in practice the male's first view of the female is often obliquely downward, so that both regions are simultaneously visible. In the experiments below, the two regions were kept separate, the stimuli being presented on a plane surface in direct frontal or rear views.

Frontal pattern. (Text-fig. 8). In females, this may be divided functionally into two well-marked classes ; first, differentiation of frontal markings, including those of clypeus and palps as a unit, and, second, distinctions concerning the palps alone. The sexual difference of frontal markings is noticeable in many salticids, but ranges through all degrees and is often absent. The following examples are from the present series: In $C$. xanthopa and Phiale spp., the females are black-faced while the males have strong yellow or white clypeal bands which continue, when the palps are bent, onto certain palpal segments. In contrast, in $C$. chalcea, $C$. fulg $i$ pedia and Eustiromastix sp., the females are frontally moderately or very hairy, chiefly gray and white, while the males are almost completely black and naked. In Menemerus bivittatus, both sexes have the hairs pale, but the female more so than the male, where they are confined to a white clypeal band. Finally, in Mago acutidens, the frontal region is black and naked in both sexes. It should be remembered that the legs, particularly the first, are often much darker in males than in females.

Experiments were made with $C$. xanthopa and $P$. flammea, both having sexual dimorphism in this respect, to determine the effect on the male of alteration of the clypeus.

When normally black-faced young female xanthopa were given yellow clypei and palpi, resembling those of the male, the courtship display was always drawn as promptly as ever with no hint of threat or confusion. Chemotaxis, but not motion or distance chem-

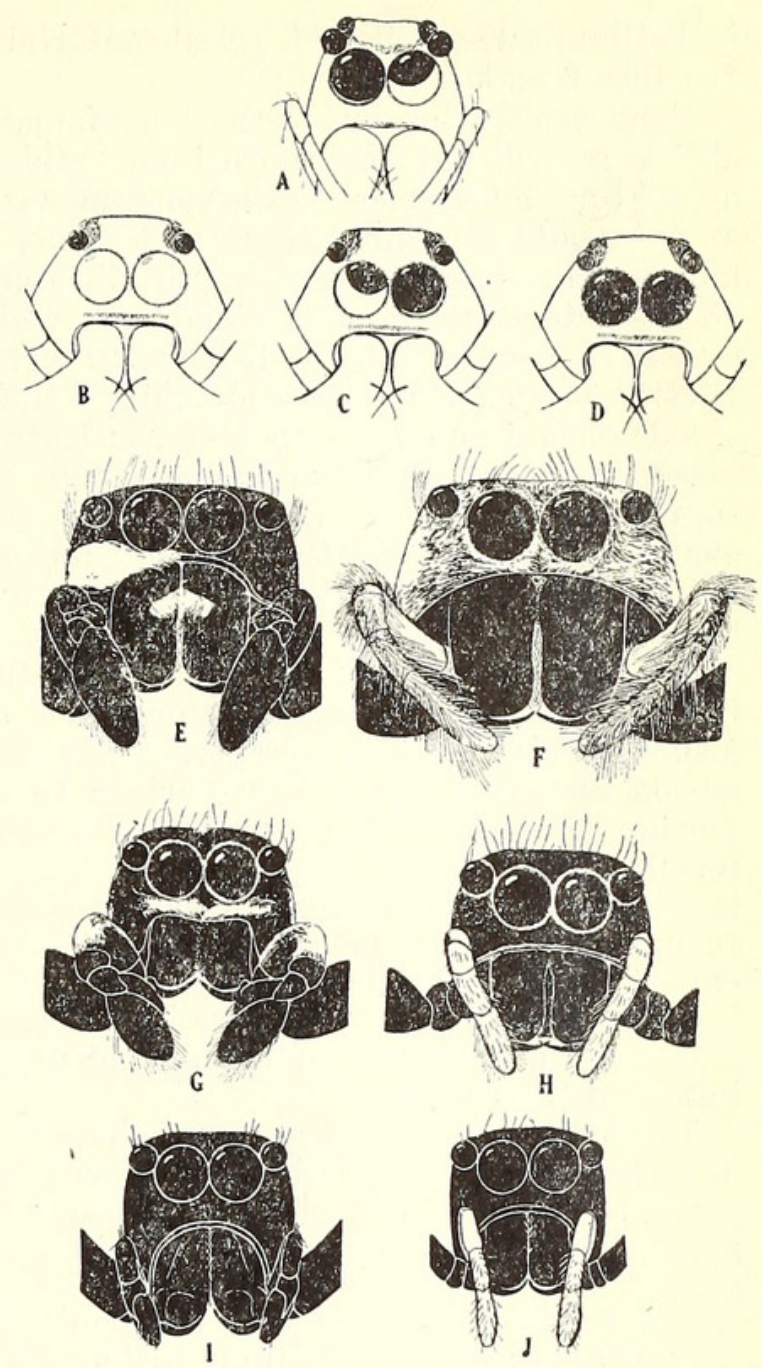

TEXT-FIG. 8. Examples of frontal sexual dimorphism and types of "ornamentation" in representative salticid genera. A, Lyssomanes bradyspilus, female; B, C, D, same, male, showing three positions of ocular color "change"; E, Menemerus bivittatus, male; F, same, female; in the male, one-half of the white clypeal band has been shaved off to show narrowness of true clypeus; G, Phiale flammea, male; $\mathbf{H}$, same female; I, Mago dentichelis, male; J, same, female. All figures drawn to same scale; note how in Mago the individual female depicted happens to be smaller than the male; this often occurs in salticids, although the carapace size of the average female in a given species is always somewhat larger than that of the average male.

The adaptive value of the "ornamentation" is by no means equal throughout the family. In Phiale, the clypeal band of the male is a releaser for threat display; in Menemerus there seems normally to be no inter-male display at all, although a similar clypeal band is well developed, nor is it of apparent importance in courtship; Mago, lacking all clypeal "ornamentation", but having a plain, high, black carapace and clypeus, has both courtship and threat well developed and moderately well differentiated. Note the prevalence of pale palps in the female; these are usually vibrated during display, but do not, in the several tested genera, function as either primary or secondary releasers of male courtship. Sexual dimorphism varies from negligible (e.g., Mago) to extreme (e.g., Menemerus); see also Part I, 1948.1, text-figs. 12-15 incl., for examples of the latitude of dimorphism within a single genus, Corythalia. 
ical stimuli, was excluded. (Test-material: 2 females, 6 males, 9 tests).

Four weeks later, one of the same females, still unmated, but now more than "middleaged" for that species, was given a new coat of paint and presented to a fresh series of males. The results were quite different: (Test-material: 1 female, 7 males, of which 6 were of A-tone and 1 of B-tone; 10 tests.) First round: 2 threat, 3 courtship, 2 undecided; second round ( 3 only tested) : 1 threat (last time this individual was uncertain), 1 courtship (last time this individual also courted), 1 courtship (last time this individual was uncertain). Total of responses: 3 threats, 5 delayed courtships, 2 confused responses (including that given by the low-tone individual). The threat reactions were all promptly given, while courtship followed a period of uncertainty characterized by attention, "following" with the eyes, and intermittently dropping the abdomen (i.e., alternating in courting and threat position). It seems apparent, in conjunction with other experiments, that the waning airborne chemical stimuli of the female were here responsible for the inclusion of threat and uncertainty in the results.

Two male xanthopa were now altered; in one the yellow scale-hairs of clypeus and palps were painted black; in the other the palps were detached and the clypeal scales scraped off with a razor. The results ( 5 males tested, 5 tests) consisted of 2 very rudimentary brief courtships (1 single rock each), 1 abortive, brief, courtship-plus-threat and 2 responses which were negative except for brief attention. When a mirror was presented to the palpless, shaved male, as he stood on the same spot where a young female had just been sitting, he gave prompt attention, courtship stance and a few rocks, then retreated briefly, and ended by leaping at the mirror, but above the image level. The same response was repeated on fresh paper, but since no rest time was given in this instance, summation may well have been involved; unfortunately because of an accident to the shaved male, and lack of time for repetition, the testing was not resumed.

When similar experiments were conducted on Phiale, the results were as follows:

When a normally black-faced young $P$. $d y$ bowskii female was given white spots on the palps and, later, a white clypeal band similar to those of the males, repeated tests always drew complete courtship, not threat.

When an old P. flammea female was similarly treated, two males courted relatively promptly so long as she was motionless, but approached her, for mating, from the side, out of sight of the abnormal, white palps and never got properly oriented toward the abdomen.

When the female mount was moved during the presentation, the male first gave threat, changing to a prolonged, side-approach courtship only when he was unusually close to her.
When her paint was washed off, both males gave prompt, normal, complete courtships.

The entire frontal aspect of a young chloroformed $C$. chalcea female, excepting the eyes, was painted white. As she sat motionless on a mount, an A-tone male was introduced with the following results: "He soon vibrated palps in the air, making semi-circles until he came close to the mount. Then he palpated and further vibrated the palps, circling off on the surrounding paper and returning to mount time and again. However, there was no trace of display, and no attempt to mate. It was exactly like the behavior of a male introduced to the spot where a female had recently been sitting or moving about. Finally, after more than five minutes, he went away. When he was brought back, to a distance of about two inches, the female was jiggled infinitesimally. He displayed at once, with good courtship. The first mating attempts in Stage II were from her unpainted rear. Then he displayed Stage I again and approached with a typical Stage II from the front." (Field lab. note).

One typical feature of the female frontal appearance in many species is the rapid vibration of contrastingly pale palps at a certain stage of courtship; it occurs usually in the earlier phases, during her first apparent awareness of the male's Stage I. Sometimes, as in Semorina, Ashtabula, Phiale and Mago, contrast to the otherwise dark front (including or excluding legs), is attained principally through pale integument; sometimes, as in Menemerus, the effect is accentuated by long white fringes. In species such as $\boldsymbol{C}$. chalcea, where vibration of the palps by the female is of casual and infrequent occurrence, they are not notably lightened or "ornamented." When present, the paleness and "ornamentation" usually extends to most segments, unlike special spotting with scalehairs of certain segments which is so typical of some males, as in C.xanthopa and Phiale.

In order to determine their importance as display sign stimuli, the female's palps were removed from examples of Menemerus and Phiale. In every case the males courted the mutilated females as readily as normal forms. (Menemerus: 1 female, 8 males, 10 tests; P. dybowskii: 1 female, 1 male, 2 tests.) Palps were not removed from any of the other species, but males of all genera mentioned in the preceding paragraph always displayed as readily to a chloroformed female when her mount was slightly twitched as to a normally moving individual; the separate motion of contrasting palps is certainly not even a secondary sign stimulus.

In most females, as in males, the eyes are rimmed more or less conspicuously with reddish, yellowish or white scales. Since males display as readily to clumsily blinded females, in which all trace of the scales is covered, as to normal ones, these scales seem to have no primary or secondary display value in modern times. 
Dorsal pattern: Dorsal carapace markings are almost always absent in the species studied, except in C. fulgipedia and Phiale, where they are highly variable and practically identical with those of the male; the white submarginal carapace bands characteristic of many species do not appear to be displayed in any of the ones I have observed and, indeed, short of a theoretical lateral display, involving flattening of the legs, it is difficult to see how they would ever be plainly visible.

The females of $C$. xanthopa have a naked black carapace, but a prominent abdominal pattern, consisting of a pair of broad, longitudinal, yellow stripes on a black ground. Males frequently display to the rear view of normal females before they have seen her dark front view at all. Blackening of the female abdomen produced no change in reaction time ( 1 female, 2 males, 6 tests). Then two young females were selected, of similar age and condition; the abdomen of one was blackened; they were then placed, facing. away from the center, about eight inches apart on the ten-inch line of the concentric test circles (Part II, 1948.2, p. 145), this being about the limit of perception-response in this species. Six males in A-state were then placed in succession in the circle's center, facing exactly between the two females. In every case the male became first aware (as judged by his shifting position to look toward her, and the adoption of preliminary courtship stance) of the female whose mount was twitched first, no matter how slightly. His progress toward her was invariably interrupted by a movement from the other female, regardless of her color. By the time the male arrived within actual courting distance (several inches away), he would either court first one, then the other, impartially, or simply sit, restlessly, between them in apparent confusion. In all, four of the six males courted somewhat, and two sat quiet at courting distance and eventually retreated. Of the courters, two eventually stopped and ran between the females out of range, one retreated, and the fourth's test was broken up when the normal female came out of the chloroform and moved off. At that point the male made no attempt to follow, but concentrated at once on the black female nearby, now not being twitched, and followed through into advanced Stage II before they were forcibly separated. A second round of tests, using the same males, brought similar results, although a given male did not always behave in the second test as in the first. The overwhelming effect in all tests was uncertainty and conflict. The only possible difference noted in the response to the two females was a very slight tendency to notice the normal female first at the greatest distance (10 inches), when both were twitched simultaneously.

Thus, although the female's pattern certainly has no value as a releasing stimulus, it seems likely that in the long run the two light stripes may have some slight directive value in the field. Under those natural conditions, three-dimensional vision is of course the rule. Therefore, the striking contrasts may make the attraction of the male's attention from farther than 10 inches, beyond the range of distance chemoperception, easier, among the dead leaves and shadows. To human vision, both males and females of this species are conspicuous in their normal habitat. However, I have never been able to gather the least evidence of this possible function, although it has been kept constantly in mind in field observations. In regard to $C$. fulgipedia females, which exhibit an abdominal pattern and color striking enough with their strong black and white, there are no distinctions from either immature specimens of almost equal size or from those of adult males; therefore the adaptive nature of abdominal pattern in any fashion, except that perhaps of disruptive coloration, is even more unlikely.

In female chalcea, any adaptation to display use is the most questionable of all; its dull bronzes, pale gold and black bandings are not only indistinguishable without a microscope from those of the preadult female, but they merge exceedingly well into deadleaf or tree-trunk backgrounds, and when the spider moves it is even less conspicuous than an all-black form. If the color and pattern have any adaptive significance, it would appear to be as disruptive coloration of a protective nature; certainly it cannot help in attracting the attention of the male. A further point is that chalcea and fulgipedia females, although of strikingly different appearance, each draws display from males of the alternate species even when the males have only a posterior view.

When the abdomens of xanthopa females were painted solidly yellow to resemble those of males, there was no confusion: as when the clypeus and palps were painted, the male courted from the rear if the female was a young adult; as in the case of the altered front view, he became confused with old painted females.

In Phiale, the quite constant flaming rusty red of many species in the male is variable in females, ranging from almost male vividness to nearly black. The white spots and bars, though also variable, are nevertheless always present and, to human eyes, conspicuous, especially posteriorly. However, when the female abdomen was painted uniformly black in P. flammea, three males courted her promptly from the rear at close range. Nevertheless, in this genus pursuit is a fundamental, normal part of the courtship, and as often as not the male is displaying for a time to the female's posterior view. It seems therefore that while female white posterior markings have no releasing value, they, like the xanthopa stripes, are probably directive in the sense that they facilitate following. 
In perhaps a majority of genera, the abdominal pattern appears completely undistinguished, except as probable examples of protective coloration. In Sassacus ocellatus, one of the species in which the female abdomen is both striking and closely similar to that of the male-i.e. iridescent green with posterior black-and-white spots-it is noteworthy that abortive female display was once observed (Part III, 1949, p. 46).

There is, however, one female abdominal marking which appears of importance in courtship. This is the sub-basal pale band, usually white, which is of such frequent occurrence in both sexes throughout the family. It is found even more often in females than in males. It is present in all of the adult females discussed in the present paper except Lyssomanes, Semorina, Ashtabula and Corythalia xanthopa. It always crosses the highest point of the abdomen and is preceded only by the naked black region immediately behind the pedicel.

In order to test its display value, abdomens were variously covered with white, yellow, black or red paint in females of $C$. xanthopa, $C$. chalcea and $P$. flammea. In painted xanthopa, in which the abdomen is normally striped, display proceeded though normal mating, as described earlier. In the other two species, which normally have sub-basal bands, the males appeared to become confused in the middle of Stage II, when the time came for twisting the abdomen. The following instance is typical: A chalcea female was painted completely white above, except for the thoracic slope of the carapace, which was inadvertently left black. Three males in seven tests courted normally until advanced Stage II, whereupon all of them tried to twist the carapace, not the abdomen, and made fumbling efforts to insert the palp too far forward. All of them gave up and moved off. When black paint was applied to this area also, lest the behavior difference involve negative chemical or other stimuli from paint, the same reaction followed. Finally, the base of the abdomen was blackened, the crest and all posterior to it remaining white. The two males still in display condition now promptly started mating after normal courtship, in the typical position. Cases of similar confusion occurred in Phiale: When the female abdomen was completely blackened, the males did not locate the epigynum; when a subbasal white band was added in the usual position, courtship was completed without delay. ( 1 female; 3 males; 3 tests). The confusion following lateral approach in response to legless females has already been discussed (p. 191).

The following interim summary may now be made in regard to the role of female pattern and color in stimulating male display:

First. They are of the most minor importance, in comparison with other stimulus situation components, having no releasing functions and only rarely a directive value.
Second. Young adult females in the tested species, when painted to resemble males, or when the typical pattern is severely altered, are nevertheless courted as females, so long as the remainder of the stimulus configuration remains normal; otherwise there is no response.

Third. Old females so painted, or males painted to resemble females, draw delayed or confused responses, or, sometimes, complete threat display.

Fourth. The correlation of palp ornamentation and vibration in females, although it may well increase visibility to and/or excitement in the male, is certainly not even of secondary releasing value; males court palpless females of Menemerus and Phiale, as well as chloroformed-and hence quietpalped-females of these and other genera, promptly and completely.

Fifth. While the white posterior markings or other patterns of some females may increase visibility to pursuing males, this is pure speculation; the markings are not necessary to release display, nor are any of the other tested female abdominal patterns.

Sixth. The white sub-basal abdominal band, which occurs so frequently in the family, proves to be a directing mechanism for copulation in Corythalia chalcea and Phiale flammea, the only two species tested. There is contributory evidence that this is also true in other species.

The Role of Male Pattern and Color in Gaining Acceptance by the Female: The following paragraphs summarize the experiments in this series. The difficulty in assembling data was in bringing treated males back to full A-tone display condition after the operation, and in having receptive females on hand at the right time.

Menemerus bivittatus. Five females all paid prompt attention to the display of two males, each with the white clypeal bands and palpal spots scraped off, showing black integument beneath. Though all the females allowed a male to reach the part of Stage II in which he was entirely out of range of her AME, on top of her, mating was not completed in any case. However, these females on the test days rejected even normal males, and two of them proved to be already fertilized.

Phiale flammea. Four females paid prompt attention to two displaying males, each with

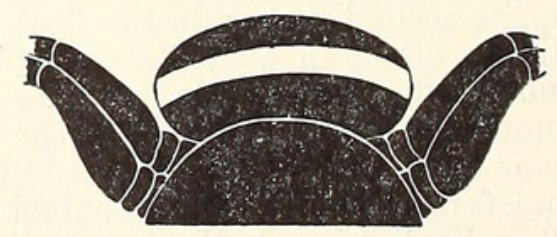

TexT-FIG. 9. Antero-dorsal view of a female abdomen (Phiale flammea). The pale band acts as a director for turning the abdomen in the final part of Stage II courtship display. 
the white clypeal bands and palpal spots scraped off (as in Menemerus); in two cases the males, during prolonged ( 20 minute) sessions, were allowed to reach Stage II; there were no acceptances; the females appeared very sluggish, but normal, control males were not then available for determining the females' true tone.

Corythalia chalcea. A female accepted promptly a male painted to resemble $C$. fulgipedia, having white pigment on the femur and patella of the normally black palps. These two species display to one other freely, but never, in numerous observations, did display proceed beyond early Stage II.

C. fulgipedia. A female accepted promptly a male with the white-spotted palps blackened to resemble those of $C$. chalcea (see above). Another female accepted a male with the frontal aspect, including the legs, completely covered with white. It will be recalled that in fulgipedia the iridescence and fringes of the legs are displayed in courtship as well as in threat. Complete blackening of the legs did not affect the female's reaction in the least, nor did removal of the fringes. In three other pairs the male was variously painted with red, from a median red spot above the AME through covering of the clypeus and palps to a complete coating of the frontal aspects (excepting the eyes) including again the legs. Once more acceptance was complete in each case, and within the normal acceptance time of the species ( 3 to 6 minutes).

C. xanthopa. Two females each accepted a male with the yellow of palps and clypeus changed to white, and another in which the clypeus had been painted black and the palps removed. When the latter male reached advanced Stage II, he could not of course proceed and eventually backed off the carapace; the female, however, had showed no signs of restlessness. Another female accepted a male with the yellow areas replaced with orange.

From these examples it appears that deviations in the color and pattern of the male play a very minor part in acceptance by the female. To summarize: In three species of Corythalia, altered males were readily accepted by six individuals. In Menemerus and Phiale, although mating was not completed by frontally altered males, they were allowed to reach advanced Stage II; in these two genera the available females during the tests appeared to be in non-receptive condition.

The Role of Pattern and Color in Intermale displays. This aspect was investigated rather fully in $C$. xanthopa and less so in $C$. chalcea and $P$. flammea. The following results were obtained:

C. xanthopa. Males of A-tone responded invariably with more or less prompt threat display to the following moving stimuli in which the yellow clypeal band and spotted palps appear to be involved: conscious, chloroformed or mounted-and-dried males with yellow, orange or yellow-plus-white paint covering the front yellow areas; legs painted dark brown or black (covering iridescence) ; two-dimensional models of appropriate size and general shape so long as a yellow or orange bar or spot appeared across the middle; dried females painted like males; unrelated species of large size with a yellow clypeal band added; preadult male xanthopa, or other Corythalia species of similar subxanthopa size, in which males were painted like adult xanthopa males.

On the other hand, males responded with incomplete courtship or did not respond at all to the following stimuli: conscious, chloroformed or mounted-and-dried males with the yellow of palps, clypeus and abdomen altered to any of the following colors : red, blue, blueplus-white, red-plus-blue; six intensities of black-plus-white which included values comparable, by Weston meter, to those of the yellow, yellow-plus-white and orange which elicit threat display ; to receptive young adult females of other species of Corythalia painted like male xanthopa.

To the stimuli listed below, the reaction was variable and included incomplete courtship, threat, no reaction and a confused mixture of threat and courtship. The variability was not only between individuals, but in the same individual on different days or even at different parts of the same test period. These borderline stimuli are the following: males, or the testee's mirror image, with the yellow parts painted black as in females, white, red-plus-white or green; males with the black legs altered to white, yellow or red; females, middle-aged or old, painted to resemble males; a normal male Phiale flammea, characterized frontally by strong white markings on a black ground. When a male xanthopa face was blackened and the legs painted yellow, there was no reaction. When, as occasionally happened, a blackened, chloroformed male suddenly became conscious and threatened a normal subject, the latter either appeared startled, leaping in the air, and retreated, or, if he were courting, stopped courting and, in several instances, changed the courtship to threat display.

Male xanthopa in B-state responded to very few unnatural stimuli, and the few reactions which did result were so erratic and variable that no general listings would be profitable. The only invariable reaction was that orange or buff-faced males were threatened as promptly as yellow-faced examples.

The solid abdominal yellow of xanthopa, as seen from the rear, drew as prompt threat display as a front view; males with the abdomen striped black and yellow like females, also drew threat display. Males with the abdomens blackened, however, drew confused responses.

Unfortunately, during the inter-male series of xanthopa tests, which took place early in the salticid experimental period, the full 
importance of the amount of mount-jerking in some species was not fully realized (infra). Nevertheless, in all the xanthopa tests, the responses did not appear in general to be dependent on the type of motion. It can be stated without reservation that the stimuli which drew the most variable, confused or inappropriate reactions (i.e., anything except threat) were almost always ineffective unless strongly reinforced by constant jerking and repeated presentations: in other words, the single twitch which in $C$. chalcea and Phiale sometimes made the difference between threat and courtship responses (see below) was inadequate for the less successful stimuli of the xanthopa series.

C. chalcea and C. fulgipedia. These two species, in one of which the palps are black and in the other spotted with white, display to each other freely, each maintaining rigidly its own threat pattern.

Under experimental conditions, the following tests were made: Two chalcea males each displayed promptly with threat to another male with his normally black face painted yellow (as in the smaller xanthopa, to which species it will not display). They also displayed to a larger male Eustiromastix sp., dried and mounted, his normal dark brown having a painted yellow clypeus. Again, a chloroformed, mounted male chalcea with the legs whitened, drew various responses from a single A-tone male; these ranged from incomplete courtship with a poorly oriented side approach, to prompt threat, depending on the motion of the mount: when the latter was not moved, attention only resulted; a single twitch was followed by courtship; continued jerking drew threat. When the same mount was presented to the same male on one of his B-tone days, the incomplete courtship responses occurred, with the previously successful single twitch, but no threat could be drawn with any type of motion. A male chalcea's legs were blackened, to eliminate iridescence, and the now completely black indivdual mounted on a black background, and jerked slightly before an A-tone individual. Incomplete courtship was eventually drawn, with no trace of threat.

From the above it appears that at least in chalcea, change of the normal black color on the mid-frontal region to white or yellow does not affect threat response, while confusion may result when the legs are painted white; this complex would seem however to be more concerned with shape than with pattern and color in the sense used in this section; the importance of type of motion is once more emphasized; the response to the mount on black seems to be connected with visibility.

Phiale flammea. The white scales were scraped from the palps and clypeus of two males, so that they now had in frontal view the wholly black appearance of females. Neither male was chloroformed thereafter and each was of A-tone. When placed to- gether, both gave complete threat displays starting at three inches, followed by brief sparring, in six tests on two successive days. The displays were never mixed with courtship, except that on one day the larger, less aggressive male tended to start with a generalized display (high stance, first legs high). However, when another male was chloroformed, palps and clypeus blacked and the whole mounted, the following occurred: "A normal male took no notice when the mount was not moved. When the mount was given a single twitch, the testee hesitated, adopted a high, generalized stance, then, at one inch (unusually close) he changed into a typical crawling courtship; he continued to persistent attempts to mate, even including complete twisting of the mount's abdomen." (Field lab. note). On the second round, when the mount was persistently jerked, prompt threat response was drawn; courtship resulted once more when the movement was restricted to a twitch. Here again, as in chalcea, the significant difference was in the amount and type of motion; and as in the yellow of xanthopa, the median white frontal markings were, under appropriate conditions, badges of masculinity. (cf. also p. 194 for threat display toward females with whitened palps, and the role played by distance chemoperception, p. 183).

When the first legs of a normal male were painted white, incomplete threat was drawn from three individuals.

When the flame-red abdomen of a dried male was painted completely black, including the white terminal spots, prompt threat display was drawn from three individuals; the same results followed when the white carapace stripe and submarginal band were also removed. However, when the abdomen was whitened, there was no display from any of the three in a total of ten tests; one of them stalked and leapt upon it once, apparently treating it as prey, but dropped it promptly (perhaps because it was stiff). When it was re-blackened, all three males once more threatened promptly. Intensity, rather than hue, seems to be the important factor here.

The abdominal red of Phiale shows no evidence of being an aposematic hue. Small Irogs and lizards of several species stalked and ate Phiale without hesitation or apparent distaste. Furthermore, a Phiale, in all three tests made, showed a decided fear-flight response when dropped near a young Anolis; this occurred several seconds before the lizard appeared aware of the spider.

The results of inter-male display experiments may be summarized as follows:

First. The light-colored contrasting clypeal and palp markings of male Phiale and $C$. xanthopa have definite releasing value for threat display, subject to superior control by airborne chemical stimuli and motion. White clypeal and palp markings in the naturally black-fronted C. chalcea have no such value.

Second. Reflected light appearing in the (to human eyes) yellow region of the spec- 
trum has threat releasing value in xanthopa, irrespective of intensity, when occurring in the palp-clypeal region. Other spectral regions in general release incomplete or inappropriate responses.

Third. Reflected light in the red region, added to the black frontal view, does not affect threat display in $C$. chalcea.

Fourth. When the scarlet abdomen of Phiale is covered with black, threat responses are not affected.

Fifth. White paint applied to legs or abdomen of male chalcea or Phiale usually draws an incomplete response, or none.

Sixth. The obliteration of iridescence in Corythalia legs by black or brown paint does not affect display responses.

General Summary of Value of Color-Pattern-Intensity in Epigamic Display.

First. Pattern, color and intensity are of minimum importance in the stimulus configuration of courtship, at least in Menemerus, Phiale and Corythalia: Male or female "ornamentation" is not a primary or secondary releaser for either female acceptance or male courtship display, respectively.

Second. It is probable, however, that in both sexes, certain spots and patterns, particularly when correlated with motion (as in spotted palps) have definite directive and/or excitatory value, or at least function as visual aids. An example of an unquestionable directive stimulus is the pale sub-basal abdominal band which, at least in Phiale and Corythalia functions during advanced Stage II as a copulation guide for twisting the abdomen.

Third. Clypeal and palp markings contrasting strongly in brightness with the black integument and present only in the male have definite releasing value in intermale display at least in two species, Phiale flammea and Corythalia xanthopa. In two other Corythalia, however, one with minor markings and one with none, facial ornamentation is not a threat releaser.

Fourth. There is some evidence that at least Corythalia and Phiale have poor sensitivity in the red region.

Fifth. The application of white paint to extremities in Corythalia and Phiale sometimes affects display reactions, perhaps because of apparent form alteration.

Sixth. The obliteration of leg iridescence in Corythalia has no perceptible affect.

The significance of deviate responses will be discussed under displacement behavior (p. 202).

\section{INNATE RELEASING AND DIRECTIVE MECHANISMIS.}

From data given in the preceding sections, the innate mechanisms in courtship and threat may now be viewed as integrated patterns. In all display, adequate physical conditions, including light, humidity and tem- perature, are prerequisites, as described earlier; they, as well as the general good health and nourishment of the spiders are essential and will not be referred to again in the following discussion. Courtship and threat displays as a whole will be taken up in turn, from the points of view of both sexes, followed by a more general discussion.

\section{A. Courtship.}

1. Mechanisms of courtship display in males.

a. Releasers in A-tone males of hopper groups.

i. The stimulus must be within range of the AME.

ii. It must fulfil certain rough size-shape-distance require. ments.

iii. One of the following factors tors must be present.

(a). Airborne chemical stimuli.

(b). Generalized motion (for Stage I) ; lack of motion is customary for advanced Stage II.

iv. The following often contribute to the configuration, but are not essential as releasers :

(a). Special frontal and/or abdominal patterns, often displayed with spespecial motions, such as the vibration of pale palp.

(b). Chemotaxis.

(c). Cessation of motion, including that of palps, often accompanied by crouching; this behavior has releasing value for Stage II, although it is not essential; close proximity is of first importance, with or without crouching.

b. Directors of A-tone males of hopper groups.

Groups iii and iv above are probably partly and primarily, respectively, directive in function. A light, sub-basal abdominal band is sometimes a specific director for copulation.

c. Releasers and directors of $A$ tone males in runner groups. These differ from the hopper group requirements in the greater importance of both airborne and contact chemical stimuli, as well as of proximity. The visual stimuli of $i$ and ii remain essential, however, as releasers; 
the visual stimuli of iv are probably of less importance as directors.

d. Releasers and directors of males of lower tones.

Stimuli from all groups, acting in conjunction when necessary. Alternatively, a few stimuli may release and direct courtship display when strongly reinforced.

2. Mechanisms for courtship response in females.

a. The stimulus must be within range of the AME.

b. It must fulfil certain motion requirements.

c. Airborne chemical stimuli are probably involved at close range in Stage I, at least in the runner groups.

d. Tactile (and probably chemotactic) stimuli are essential in Stage II.

e. No obvious secondary sexual character, including special structures, "decorations" and colors, is essential to succesful mating in the genera studied.

3. Course of mutual display in courtship.

In general, a system of progressive, mutual stimulation exists between the sexes, on the order of that demonstrated in sticklebacks (Tinbergen, 1948 et ante). However, in the salticids, especially in the more specialized forms, the situation is far less clear-cut. Omitting, for the sake of clarity, special exceptions and qualifications, the usual course of normal field or laboratory display in salticids is presented in Table VII.

4. Comments on various aspects of courtship.

Stage II is never entered upon without at least a rudimentary Stage I, even when it is only a resumption of a display briefly broken by the female's temporary retreat during Stage II, or even in the middle of copulation.

The role played from the female viewpoint by the size and shape of the male, as well as by his motion-configuration, has so far unfortunately proved impossible to test. The most pertinent data bearing on this are supplied by observations on the behavior of females watching males other than those of their own species in display; in each case the size and shape were similar to those of their own males, and they always retreated before allowing Stage II to commence; this subject will be further discussed under species barriers.
The female's own occasional reciprocal display during Stage I and early Stage II is not a vital factor in self-stimulation, at least in Phiale and Corythalia, since it is not of regular occurrence; it is practically absent in xanthopa, and only fairly common in the other two Corythalia species; much of the apparent display in Phiale females probably should be interpreted rather as distance chemoperception ("sniffing") motions with the front legs and palps.

B. Threat Display. The mechanism of threat display differs from that of courtship in the absence of positive releasing or directive value of any chemical stimuli and of the greater importance of special colors or "decorations." These badges combine with non-female behavior-i.e., height and width accentuation, plus increasing instead of decreasing activity-to release threat. The various signals, in order of importance, are general motion, motion configuration, a form-size element and, finally, any special male pattern-and-color badge. In nature, all normally act together as a configuration.

In runner genera, inter-male displays practically never occur; when they do, they are indistinguishable from courtship and break off before actual contact, probably because of the absence of female chemical releasers and/or directors. In intermediate genera, courtship and threat are usually identical until the spiders are practically touching. As in the runners, inter-male displays in these groups probably are the result of a male treating another male as a female. When the requisite close-range signals-visual, chemical or both-are not forthcoming, displacement behavior then occurs as special fighting or sparring. In hopper genera, cases of mistaken identity appear to occur only rarely, since threat and courtship are usually distinct throughout display.

C. COMPARISON AND COMMENT ON INNATE RELEASING MECHANISMS IN COURTSHIP AND THREAT. Before proceeding to a discussion of the functions and evolution of display, it may be helpful briefly to compare the principal aspects of the innate releasing mechanisms of display.

The perceptual sign stimuli for releasing display are overwhelmingly visual in both courtship and threat, involving motion, form and size. Neither contact nor airborne chemical stimuli alone will release display of any form in the genera studied, no matter how great the reinforcement, nor how strong the internal drive. However, both forms of chemical stimuli play an important differential role in display, their importance varying phylogenetically: in general, the presence of an airborne and/or contact chemical signal is a positive differentiator for courtship, while a pattern-and-color signal in some species plays a corresponding positive role in threat. Absence of either one usually acts as a positive signal for the alternative 
type of display, other factors being equal. Airborne chemoperception takes precedence over a color-pattern badge in test situations where both are present, since males court, not threaten, young adult females painted like males. Motion-configuration also supersedes color-and-pattern, since males change courtship to threat when a previously quiescent, female-painted male starts threat display. Motion-configuration itself is a strong differentiator of the two types of display, particularly in the earliest and late stages; in the middle portions of courtship (i.e., late Stage I), the tendency of some females to reciprocal display never confuses the male.

As in other groups of animals, deficiency of one signal can often be compensated for by increase in another in the same stimulus situation. An example may be given of an unnaturally painted spider, which stimulates no response when running freely in the field. When it is chloroformed or killed, and mounted, so that it can be persistently manipulated with appropriate jerks close to the tested spider, it will frequently arouse a response through reinforcement. The same situation occurs when an old female is placed with a male in a small, closed container; with either contact or airborne chemical stimuli reinforced, the male frequently displays, although he would not be sufficiently stimulated to do so in the field.

Also as in other groups, maximal stimulus is needed to arouse minimal response in spiders of weak internal drive, while spiders of strong internal drive give a normal response to a minimal stimulus, often responding to fraction of the usual configuration. As previously noted, summation readily occurs in this family.

Highly stimulated spiders in unnatural test situations, and spiders in states of moderate and low internal drive, frequently confuse threat and courtship reactions and behave inappropriately in other respects. These actions, which may often be classed as typical displacement behavior, give provocative clues to evolution; they will be considered later.

Wholly aside from test situations, however, the reaction of spiders in the field is to complex, closely integrated, mutually dependent configurational stimuli. Although there are no simple, lock-and-key arrangements, the more the stimulus situation departs from the normal, the less likely is it to release display.

In an over-all view, salticid display presents a complex combination of rigid and fluid aspects. It is true that display patterns are wholly fixed and instinctive. Learning plays no discernible part in this field of activity, since males reared in solitude perform either courtship or threat to perfection on their first attempt. Again, there is no evidence that imprinting ever takes place. Finally, when two males of different species display, each maintains rigidly his own dis-

\section{TABLE VII.}

Generalized Course of Display in Salticids.

\section{Male.}

Becomes aware of $\%$; starts display, Stage I. (Minimal releaser: several sight factors; airborne chemical stimuli also usually involved).

Approaches, in zigzags, or follows (if female retreats), continuing or resuming display. (Minimal releaser and director: above sight factors, plus type of female motion or lack of it). Special o signs, such as vibrating palps and light abdominal spots probably have directive value.

Speeds up display tempo. (Releasers and directors: reduced motion of female, plus chemical stimuli. Self-stimulation is doubtless also a factor).

\section{Enters Stage II.}

(Releasers: primarily, proximity of female; also involved, usually, her lack of motion, low position, and, doubtless, reinforced chemical stimuli). Copulation follows unless female withdraws. (Director: sometimes a pale abdominal cross-bar).

\section{Female.}

Retreats, or watches ô, usually in braced, high position, often vibrating palps. Rarely attacks. (Minimal releaser and director: several sight factors).

Becomes completely attentive; sometimes gives weak reciprocal display. (Minimal releaser: summative effect of display motions).

Ceases motion and, usually, crouches low, legs drawn in. 
play pattern; no temporary modifications were ever seen to occur; by contrast, imitative behavior is frequent in vertebrates, as in the cormorants which altered their flight pattern to match that of their pelican companions (Beebe, 1938, p. 106).

Nevertheless, in working with living salticids, both their own individuality and the dynamic, unfinished, untidiness of display mechanisms are constantly apparent. A given spider's behavior is scarcely more predictable than that of a single electron. It depends, at any given instant, on great numbers of factors, external and internal, all in various stages of evolution, all related, and all themselves in a state of constant change. Wasted energy, abortive displays and lost opportunities are the rule. Altogether, the lumbering, complex, display mechanisms do not appear efficient. The most that can be said of them is that they work adequately enough, often enough, to ensure the perpetuation of the species. In the end, however, all the billions of salticids, hopping at this moment about the globe, are lively proof of their success.

\section{BEHAVIOR RELATED TO DISPLAY.}

The basic similarity of behavior trends in all higher organisms - whether invertebrate or vertebrate-becomes increasingly clear. Not only do animals agree in the obvious, basic activities essential to all life, but they prove also to be surprisingly similar, among the end forms, in the more complex aspects of behavior. It has long been recognized that when vision becomes the dominant sense, elaborate, visually dominated courtships often evolve; the principle applies in certain cephalopods, crabs, spiders and insects as well as among fish, lizards and birds. The importance and frequent distinctness of threat display in salticids has been emphasized throughout this paper, and is in accord with results of recent behavior studies of birds and other vertebrates. Similarly, it is increasingly evident that dominance hierarchies, social and territorial behavior and displacement activities very often occur in higher invertebrates, though usually in primitive form. Although these latter aspects were studied only incidentally in the Rancho Grande salticids, the following observations appear to be worth recording.

A. Displacement or Substitute BehavIOR. Experimental work sometimes drew inappropriate responses which correspond closely with typical displacement behavior in birds and other groups. When a stimulus configuration, while partly effective, was yet too exaggerated or incomplete to draw an appropriate display, the spider either retreated, attacked or by-passed the stimulus, exchanged threat for courtship and courtship for threat or regressed to a more primitive level of display behavior. It is interesting, however, that at no time were the substitute activities wholly outside the sexual field. That is, never did the spider stalk an insect, pick up a discarded fiy, spin a retreat, or even resort to grooming - that substitute action so common throughout much of the vertebrate world.

This restriction of displacement behavior appears to be an example of the rigidity typical of higher invertebrates. The compartments of life are kept distinct even in the midst of "mental" confusion, shock or frustration. With such restrictions, a girl would not reach for her lipstick when frightened by a bomb, nor a startled bird fidget with the makings of an off-season nest. To lapse into anthropomorphism, a salticid, when his prey escapes, never picks a fight with another male, nor does a rejected suitor gorge on extra flies.

B. Dominance. In salticids, little hint has yet been found of long-term dominance relationships. Day to day variation, as shown in energetic courtship and threat or apathy and retreat, is on a rhythmic, physiological basis. It is true that some males never develop as high tone levels as others, the peaks of their rhythm curves being lower; in this sense dominance may be said to occur. I have never found, however, that rank is altered by a series of successes or failures in threat display or in actual combat. In primitive groups, where inter-male combat does not ordinarily exist, nothing approaching dominance relations was seen (apart from the usual physiological fluctuations, which determined the degree of courtship activity at a given time). In groups of young and old spiders placed together in a cage, the small ones invariably showed a healthy wariness of the large individuals; in view of the carnivorous character of the spiders, however, this behavior certainly needs no more explanation than the obvious one of self-defense. (See also p. 203).

C. Sociality. C. xanthopa was one species in which traces of social behavior occurred. Along the leaf-strewn Water Trail, the richest habitat for this species, three to ten individuals were often found fairly close together. These groups included individuals of various ages and both sexes. They occurred in an area of about a square yard or two, divided by 10 to 20 feet from the next group. There was absolutely no discernible difference in the ecological characteristics of the populous and barren stretches, and indeed they shifted back and forth in quite irregular fashion over a period of weeks. Intra-specific relations within a group appeared purely casual. Abortive courtships and threat displays were brief and frequent. There was a high degree of mutual toleration, but, except for sexual situations, no inter-individual associations. It is noteworthy that quite small individuals, measuring less than half the size of the adults, were included in these groups, and apparently not stalked as food. Often their attention was attracted by the 
displays of nearby adults, and at times they appeared to watch attentively these encounters of their elders, although they took no part whatever. The same behavior was noted in non-displaying adult males, and in fat females, obviously soon to lay eggs. On other occasions, these non-displaying members of the group simply continued their previous occupations, paying no attention to the others; they either maintained hour-long lookouts from the top of a projecting twig, stalked prey with indifferent success, hopped slowly along a meandering course, or simply moved occasionally out of the shifting sunlight.

An example of more advanced sociality was found in Semorina megachelyne. A large silk shelter was taken containing a group of 14 individuals of various instars, including several adult males and females. The young ranged from the first through the preadult stadia, the youngest being sheltered in a subcocoon. The morphologically primitive position of Semorina, compared with the advanced niche of Corythalia, indicates that sociality is not dependent in this group on phylogenetic specialization. Comparable dissociation of these two factors is found in other groups, including non-salticid spiders, lepidopteran caterpillars and birds.

It is probably significant that in neither of these examples of incipient sociality, Semorina and Corythalia, is inter-male fighting developed; in the one case the males follow the primitive pattern of mutual disregard; in the other, combat has been sublimated into threat. Never have I seen any signs of group formation in the more pugnacious genera.

D. TERRITORY. A territorial concept almost certainly exists in salticids, but work has scarcely been started on this angle. In captivity, all salticids generally returned to the same shelter, if they made one, night after night, even occupying it through several successive molts, so long as it was undisturbed. It seems probable that such a practice occurs also in the field. It is certainly a likely beginning for a concept of territory, or at least of home range. When siblings of Phiale, Corythalia and Eustiromastix young were reared in groups of three or four through the early molts, they not only got on peacefully at all times, but each always-on the many occasions when they were observed with this point in mind-returned to his own shelter at night and during ecdysis. One group of three Phiale dybowskii was reared to adulthood in this fashion. Individual variations in size and pattern made the identification of individuals easy after the second instar.

Cannibalism is exceedingly rare in this family, and when it occurs it is only under extreme provocation of hunger or gross size disparity. In the few cases where females killed the males, they were eaten only twice, both in Eustiromastix. After inter-male battles, the losers were never eaten, even when they had been disabled or killed.

On the other hand, there is no evidence yet that salticids actually defend a territory, even in the case of adult males. I am quite sure that the young at least do not have one, although the concept of home range seems applicable, at least in C. xanthopa. This term, as defined by Burt (1943), signifies that wandering of individuals is limited, although the area is shared at least tolerantly with others of the same species.

It is notable that although in the orbweavers the adult males wander, in Corythalia xanthopa - the only species where field marking has been initiated-the females did the roaming. One female, recaptured after 34 days, was taken 186 feet from her original location, while several marked males were seen repeatedly during a single month within two feet of their original positions. A similar situation exists in fiddler crabs (Crane, 1941, p. 160) and, of course in vertebrates (e.g., Evans, 1938; Lack, 1943).

When a strong adult male xanthopa in Atone was dropped close to a wild male who had hitherto been undisturbed, the usual threat display took place, but I saw no sign whatever that the strange male was usually driven off by the previous "tenant," or showed much perturbation. The response was tested more than ten times. This result is in strong contrast to the behavior of an orb-weaver dropped into a strange web. The retreat of a protagonist seemed to depend only on his physiological condition, rather than on any general reduced pugnacity or sense of security when out of his own range.

The other intermediate and hopper groun calticids were in general strongly individualistic: two or more adult males were rarelv shaken from the same herh or bush, and it may be that in these cases definite territoriies are maintained and defended. On the other hand. nossession or invasion of a territorv is certainly not a prerequisite to display. iudoine by the nromnt reactions of A-tone males dropper simultaneously on a strange table-ton. Altoogether. develonment of territoriality annears to be a very primitive level.

\section{VIIT, FUNCTIONS OF DISPLAY}

\section{A. Courtship.}

The theories concernin $\alpha$ the functions of courtshin disnlay in spiders have already been reviewed (p. 170). The conclusions resulting from the Rancho Frande studies are as follows: First. courtshin disnlay is unquestionably a necessary nreliminarv to mating. and not merelv an outlet of excess energv for males in breedino condition, as suggested by Wallace and Berland. Second. sexulal selection in the original sense used bv Darwin and the Peckhams is not onerative. Third. as Savorv noints out. the roncent of recognition as distinct from. and precedino stimulation, does not appear to be necessary. 
Indeed, any concept of preliminary recognition seems to be highly questionable, even when recognition is regarded merely as a kind of realization by the female that a potential meal is not at hand. Rather, it seems probable that it is through her sexual stimulation that her feeding impulses are inhibited. In this view, the two processes are merely different results of the same psycho-physical sequence, developing simultaneously and governed by the same stimulus configuration. To distinguish between recognition and stimulation in salticids seems as difficult as to differentiate temporally between human fear and loss of appetite when a charging bull interrupts a picnic: in each case two emotions, or at least sensations, are involved, one positive, one negative, and bearing an inverse ratio to each other.

As modern observers agree (e.g., Savory, 1928 ), the stimulation of the female is probably physically as well as psychologically necessary, since alterations appear to be made in the epigynum itself in order to permit the insertion of the palps.

The following summary may now be given of the functions of salticid courtship, as they appear from the Rancho Grande studies. It is, in essence, a selection and elaboration of certain earlier views, especially those of Savory and Bristowe. Most of it applies to animal courtship in general. The term "courtship," as used throughout this paper, includes the responses of the female as well as those of the male, and the production as well as the reception of sign stimuli.

The primary functions of courtship in salticids, then, may be expressed as follows: Courtship serves to bring to mutual attention and proximity two individuals of the same species, opposite sex and requisite physiological condition; simultaneously it inhibits their usual predator and self-protective behavior while stimulating each sex so that copulation may take place. These are the primary functions, of obvious and immediate biological use in the life of the individual.

Secondary functions, which may be considered by-products of the above, are of importance in the life of the species. First, sexual selection operates in the sense that males of chronically mediocre drive-among which are doubtless individuals of genetic weakness-do not use sufficient energy and persistence to win acceptance by females. Second, courtship display acts as an effective isolating mechanism between similar but wellevolved species: Since crosses would, judging by analogy in other animals, often prove sterile or unfit, the progressively exclusive action of individual courtships must prevent considerable germ cell wastage. The effectiveness of display as an isolating mechanism will be discussed in the section on evolutionary aspects.

\section{B. Threat.}

Earlier views on the cause and function of fighting and/or threat display among salticid males were summarized on p. 170 . To recapitulate briefly the two extreme hypotheses, the Peckhams accepted the unmodified Darwinian premise that inter-male fighting was brought on by rivalry; as a result, the females mated with the strongest or bravest or boldest, either through male conquest or female choice. Bristowe, on the other hand, holds that inter-male display occurs when males temporarily mistake each other for females; actual fighting sometimes results through frustration.

Neither of these views explains satisfactorily the condition in many salticids, including Corythalia. Against the Darwinian hypothesis stand the facts that the winner of a combat does not necessarily get the adjacent female, females certainly do not necessarily "choose" the winners, the fights are usually no more than slight psychological sparring matches, at which females may or may not be present, and the winners - that is, the more aggressive-are certainly not necessarily the largest or brightest of the males. I have seen a six or seven-legged male, of small size, prevail over larger individuals on successive days; almost certainly the epigamic physiological rhythm was involved; but some individuals appear regularly to be more dominant (in their A-tone periods) than others of the same threshold. (See also p. 202). In the species Bristowe observed in England, courtship and threat display were identical. For such as these, his hypotheses of mistaken identity is completely satisfactory. According to the hypothesis of phylogeny presented in the present paper, these represent an intermediate phase of development of dependence on sight practically superseding dependence on chemical stimuli. In genera taken to represent more primitive forms, such as Menemerus, Ashtabula and Semorina, all far more dependent on chemical stimuli, threat display is apparently nonexistent and mirror display never occurs (except in self-stimulation in Menemerus, $p$. 182 ). Finally, in the most visually dependent genera, the hopper groups, of which the best ultimate examples are in Corythalia, threat and courtship are completely divorced. In $C$. xanthopa such an extreme is reached that different appendages are used in the two kinds of display, and true fighting has never been known to occur except under extremes of crowded, hot laboratory conditions. It seems that here there is a sublimation of aggressive impulses, as in many birds, and that a type of mutual stimulation takes place which is useful in maintaining or increasing sexual tone.

Just as in courtship display, it must be kept always in mind that male spiders are potentially dangerous to one another, both because of their carnivorous habits and their poison glands; this is rarely the case in other 
groups of animals. Where mistaken identity in salticids results in actual fighting, with consequent frequent casualties, the following conclusions concerning its functions appear to be valid. All of them are of the secondary type, of importance to the species, rather than to the individual.

1. The elimination through disability or death of weaker males, thus strengthening the strain through natural selection.

2 . The prevention of weaker males mating as often as do stronger individuals.

3 . The encouragement of excess males to go elsewhere in search of mateless females, and so ensuring the more even distribution of the sexes.

These three points conform to Darwin's general hypothesis, excepting only that females do not deliberately choose superior males. Although it is true, as Bristowe and others maintain, that actual fighting, to the point of inflicting injury or death, is rare among spiders, it most certainly does occur, under natural conditions at that, among some salticids at Rancho Grande. For example, an apparently new genus near Capidava (not yet described) time and again fought to the death in large display boxes and on open table tops; twice they were seen fighting beside trails in the forest; in one of the latter cases a male was killed; in the other both were injured.

In the majority of salticids, and especially in Corythalia, where threat display is highly ritualized and actual fighting occurs only rarely and atypically, the physical elimination of males does not take place. In these cases, the threat display undoubtedly represents an advance over the more wasteful practice of actual fighting.

In these ritualized displays, the additional function of maintaining emotional tension is probably of importance to the species as a whole. although it is not necessary to individuals. Perhaps males having frequent opportunity for epigamic display maintain A-tone for longer periods. Armstrong. 1947. discusses tone maintenance in birds and gives excellent examples. No experiments whatever appear to have been done on this auestion in spiders. but its importance is becoming increasingly recognized in other groups. Experiments at Rancho Grande proved only that threat disnlav is not a prerequisite to successful mating. either from the male or female noint of view. Phiale and two snecies of Corvthalia all showed conclusively that virgin males displaved nromntlv and completelv to viroin females and were accepted by them. without any of the males ever having seen another male, much less practised or observed threat disnlav. Each of the individuals tested was reared through at least three nrevious instars. and permitted to molt to the adult, in complete solitude. Precautions were taken, as in all displav experiments. to eliminate the danger of chemical stimuli remaining from previous spiders.
Conversely, virgin male Phiale, $C$. chalcea and $C$. xanthopa performed threat display perfectly to virgin males of their own species without ever having laid eyes on or received chemical stimuli from a female or another male.

Nothing is known of territoriality in any of the species except in xanthopa: here it appers to exist, but in rudimentary form ( $p$. 203). This amount, however, might account for the development and maintenance in this species of a completely separate threat display. But it seems certain, as said above, that at least equally important to the species is its function of mutual stimulus and of keeping males to some pitch of excitement, perhaps in a state of long-sustained A-tone for dealing with wandering and scattered females. There is no question but that males tend to display to each other more promptly in the presence of a female: in photographing threat displays, one female was always placed with the two male subjects, since females were repeatedly found to have this decided catalytic effect. Often the males spent more time displaying to each other than to the female.

Another function of threat display doubtless is its usefulness as a "safety valve," its displacement behavior aspect, for spiders already keyed to display pitch (p. 202).

No true group displays, comparable to those reported by the Peckhams (1889, p. 40) for several dendryphantinids, were seen at Rancho Grande. They undoubtedly should be regarded as rudimentary social affairs, again with the double function of inhibiting hunger and stimulating sex.

\section{EVOLUTIONARY ASPECTS OF DISPLAY.}

The purpose of this section is to interpret salticid display from an evolutionary point of view. Although the dangers of top-heavy generalizations are fully realized, it seems advisable to organize the limited data availbale. As Menninger puts it, "Classifications must never be taken too seriously - but the fear to use them has prevented much more thinking." (1945, p. 34).

\section{A. Hypothetical Philogeny.}

While many display similarities obviously coincide with natural affinities, others refiect only an extensive parallelism among the subfamilies. The salticids show a "bush type" of evolution, with similar basic trends in each branch.

The parallelism is well shown in the locomotive, sensory and display differences that have been discussed from time to time in this and preceding papers (Parts II and III). At Rancho Grande, Menemerus, Semorina and Ashtabula are examples of the apparently primitive "runner" group; Sassacus and Phiale are intermediate forms; and Corythalia and Mago are advanced "hoppers." Each of these groups contains representatives of two or more subfamilies, and each 
subfamily usually includes genera in two or more groups. Their various characteristics will now be assembled.

The "runners" never jump or hop during horizontal progress except to cross a gap or leap on prey. According to experiments, they depend more on chemotaxis than do the other groups, court less readily in its absence, rarely or never respond to a mirror image and are rather strongly affected by the loss of their palps and first legs. The first legs are often held in front of them, not helping in locomotion, but barely clearing the ground, while the palps may pat the ground lightly. When in a strange place, they run to and fro, palpating ceaselessly and appearing endlessly "restless" and "nervous." Although they stalk and leap on prey like the hoppers, they nevertheless tackle large prey in preference to small. Menemerus chooses moths and the larger Diptera instead of Drosophila; in captivity, when no choice is given, they miss fruit flies repeatedly and eventually become thin. Large, hopper-group Corythalia of similar size, in contrast, can live out their lives on a fruit fly diet, catching them with ease. Morphologically, the most obvious characteristics of the runners are low carapaces and few, weak leg spines.

The intermediate group seems to be in the middle of changing from moderate chemotactic to nearly complete visual dependence by way of distance chemoperception. They are long-sighted, hop when hard-pressed, pursue their mates via efficient short-cuts and are relatively little affected in display when deprived of palps and first legs. Yet they appear to gain chemical sense impressions from a distance largely through these members which, from the second instar, often wave in the air during normal exploration. Phiale, when near mates or food, before display or stalking begins, is especially prone to wave the first legs up and down. It seems probable that they are "sniffing" the air. Berland's accounts of Philaeus chrysops and others $(1914,1923,1927)$, waving their legs when completely alone in clean boxes, sound as though these were intermediategroup spiders. Philaeus, incidentally, is a close relative of Phiale. Bonnet's (1933) Philaeus, studied in another part of France, never waved the legs except in true display; why these observations should differ so radically remains, for the present. a mystery. Berland's Saitis barbipes waved the third legs at random, as well as in display.

Among salticids generally, it may be that the female is "sniffing" the male when during display she often vibrates the palps and first legs: if so, the sense of distance chemonerception may evolve through the female. Certainly in the runners, the female's palps are usually particularly active. whether or not thev quite touch the ground in true chemotaxis. It does not seem advisable to consider this activity solely as a symptom of nervous tension.
The "hoppers" are the visually dominated salticids; chemotaxis means little or nothing to them under natural conditions; distance chemoperception operates as a secondary releaser for courtship display. Their sight is magnificently developed, and their courtship sign stimuli overwhelmingly visual. These are the "poised" spiders; they sit quietly when dropped on the table, look about them, then hop away, at leisure and with frequent pauses, interspersed with a measured walk. All eight legs remain firmly on the ground except during a hop or display ; there is otherwise no raising at all of the first legs, or carrying of them clear of the ground. Carapaces are high and leg spines strong and numerous.

An inspection of Table II and Text-figs. 2 and 6 will show that among runners courtship is simple and threat practically nonexistent. In intermediate groups, actual fighting is frequent, but its early stages are little or not at all differentiated from courtship. In the hoppers, true fighting is rare and special threat display the rule.

The divisions appear to be based primarly on the different degrees of visual dominance. The eyes in each successive group seem to take over more and more from the chemical senses. And it is the dependence on the latter which appears, both functionally and morphologically, the closer to the pre-salticid stock. But, as in various studies of animal and human societies, the forms in midevolution seem most subject to combativeness. They appear to be in the middle of changing from one way of life to another, mistakes are made, frustration results and combat ensues.

One vitally interesting clue to the evolution of salticid display is given in the behavior of the highly specialized hopper, Corythalia xanthopa. Senile, over-stimulated or low-tone spiders often use primitive chemotaxis during courtship to the frequent and inappropriate exclusion of other sign stimuli (p. 178). These and other hoppers in a similar condition tend to leap at threat stimuli rather than perform their characteristic displays. This behavior seems unquestionably atavistic, regressive in a phylogenetic sense. Similar examples among displacement behavior (p. 202) consist in the replacement of threat with physical attack in experimental situations.

\section{B. ORIgins OF Display Motions.}

The biological principle of least effort, as presented by Zipf (1949), proves to be of considerable help in this attempt to understand the development of salticid display. The subprinciples of permutation (i.e., combination) and multiple function seem especially applicable. Armstrong in particular has implied their operation throughout his discussion of bird display (1947, e.g. p. 61).

From this point of view, display evolved through the use, with modification, of actions, senses and structures already serving 
less specialized purposes in the economy of the organism. Only rarely would a display action evolve especially to fill an epigamic need.

In direct agreement with this general concept is Bristowe's view of the origin of salticid display. It appears to him that the rituals grew from the groping and fendingoff motions of the primitive stock. Certainly, it seems far more likely that display grew from gestures like these, which had a different original function, than that an entire new series of motions arose for display alone.

The acceleration and exaggeration of simple motions, so typical of display, are clearly related to the excitement, to the nervous agitation, connected with breeding activity. The difference between this view and those of Wallace and Berland is that, to them, display appeared to have no function; it was simply an expression of high vitality or excitement.

The "groping" motions certainly included chemotaxic behavior, such as is used by many runners in casual exploration as well as in responding to the trails of females. The similar behavior of very young runners, just out of the cocoon, contributes largely to this conclusion. Again, high-in-air leg waving, found in numerous displays throughout the family, seems to have an undoubted origin in distance chemoperception of airborne stimuli.

Plausible origins of a number of other common display gestures may be proposed. Thus, the vibration of palps originated in the "sniffing" motions so characteristic of chemoperception, including both contact and distance types. The vibration is perhaps also useful in dissipating nervous tension during courting excitement.

Twitching or lowering the abdomen is another frequent display gesture which may be due to permutation. Probably it was concerned originally only in attaching silk to the substratum, in the usual salticid fashion of ensuring a quick escape. An almost universal part of display is the habit of approaching a female in zigzags, which obviously gives added time for necessary stimulation. When zigzagging was first combined with lowered spinnerets, it is easy to see how a side-swinging abdomen could have developed: in the more primitive, long-abdomened Dendryphantinae, it seems a natural result analogous to that of a train rounding a bend.

The elevation of the abdomen is characteristic of all the ant-mimicking or pseudoscorpion-like salticids in which display is known. It was also typical of normal progress in Semorina and related genera as early as the second instar. Its ultimate origin is not yet clear. Possibly the gesture started as the end of the dropping motion, as a spider hits the ground at the end of a silk cable. Possibly, actual scorpion or pseudo-scorpion mimicry was involved among larger for- bears; these hypothetical spiders may well have been large enough to win a mimic's protection from frogs and lizards (cf. Part III, p. 37).

Again, it is possible that abdominal lifting, quiverings, and even the swift rockings of some displays are concerned in the emission and wafting of a chemical display signal. I have as yet no corroborative experimental data; work with sealed genital grooves and epigyna-a promising approach -has not been adequate. The possibility is mentioned here as a potential X-factor, an "etc." that may prove important.

In Lyssomanes the retinal motion within the light-green, antero-median eyes seems to play a definite role in courtship. The resultant color shifts increase in tempo with excitement. They seem clearly to be a ritualization of incidental effects resulting from the mechanics of vision. Although the same motions occur throughout this and other large-eyed families, they are rarely as noticeable because of the dark pigment which usually surrounds the retina. The morphological basis has been discussed by Homann (1928, p. 235).

All of the display motions mentioned up to this point can have evolved through permutation of activities normally occurring in the simplest epigamic situations as well as in other fields - dropping from overhead, fixing a silk drag-line for quick escape, groping forward, and so on. In this way these postulated display origins parallel the epigamic character of displacement reactions (p. 202). Several possible exceptions will now be discussed.

The display crawling motion may have originated from the hunting rather than the sexual field of behavior. In this phase, the male lowers the carapace and creeps directly forward. Usually it occurs during late Stage I or early Stage II of courtship. It crops up sporadically, with variations, in almost every subfamily observed. It may have grown from a displaced stalking motion, definitely outside the sexual field. It appears more probable, however, that there is a sort of innate, anticipatory imitation: the crouch is extremely similar to that usually assumed by the female during the latter stages of courtship. As in many birds, this position often acts as an important releaser for the latter part of the male's display. Its previous assumption by salticid males, in combination with a typically masculine approach and leg stretching, perhaps has value in empathically inducing the female to assume a similar position. Whatever the origin, this motion is one of the most remarkable in all salticid display.

Two widespread groups of display gestures do not seem to be based on economical permutation, on made-over motions. They are the lateral leg displays and the stretchings up to maximum height. It seems, rather, that these salticids have evolved independently the widely successful animal custom of ap- 
pearing larger than life in a crisis. It is exceedingly interesting that they never use the technique in other departments of living; never do they display before prey or hungry enemies; in salticids, the "big bluff" is reserved solely for an epigamic crisis.

Posing is a frequent occurrence in displays of the size-increasing type, particularly in threat and especially among the plexippinids. The motionless state, amounting to a kind of catatonia, often persists for many seconds after the exciting object has been removed. Similar behavior occurs in many animals under various conditions; it has been discussed at length by Armstrong in connection with bird display (1947). Its origin in salticids remains obscure.

This effect of seeming larger-whether in connection with courtship or threat-is of special interest in comparing displays within the advanced genus Corythalia. Courtship and threat display are distinct in the three species studied. However, in xanthopa, courtship is simple and primitive, exhibiting only the first two legs, while the remaining pairs, all specialized, are reserved for the highly developed threat display. In chalcea and fulgipedia, on the other hand, the first legs are used only in Stage II of courtship, while more posterior legs take part in Stage I of both courtship and threat. It seems that xanthopa represents the more primitive form, with the size-increasing threat fan occurring first. Then, by permutation with modification, the original threat function was extended, in the other species, to form a more complicated courtship. In support of this hypothesis, xanthopa appears decidedly more generalized than the other two species in several structural and developmental characters; these include eye proportions, spinulation, course of color development and dentition of tarsal claws.

The displays of two advanced Dendryphantinae give similarly interesting clues to their relative evolutionary status. One species, Sassacus ocellatus, shows a vestige of the side-swing typical of the subfamily; in the other, S. flavicinctus, no swinging occurs. It is the latter form which is morphologically more advanced.

The subject of vestigial behavior characters is, of course, one of the most controversial. Which traits are to be considered vestigial and which rudimentary? One point, however, appears increasingly clear. Any successful animal species includes in its organization a hodgepodge of behavioral relics in addition to the usual morphological trash. When a dog revolves before lying down on a grassless rug, he is performing a well-worn example of a functional antique. Similarly, Sassacus, in a moment of face-toface courting, swings his stubby abdomen sideways, even though it and its ocellus are well hidden behind the sturdy legs; surely this example belongs equally in a behavioristic museum.

\section{Relation of Secondary Sexual Characters to Display.}

The question of vestigial characters leads directly to the problems of ornamentation, where morphological and behavioral relations are even more involved. Some "ornaments," including the fringes and iridescence on the displayed legs of Corythalia, are probably recently evolved structures: they are highly variable in individuals; their adaptive value is so slight that it has not been proved experimentally to exist at all; they develop (as do most epigamic characters) only in the final instar; and they are confined altogether to males. Yet their place in the perceptual sign situation seems unquestionable; on a mathematical basis these recent refinements would doubtless prove to have definite adaptive value, at least to the extent of making their possessor more conspicuous during display.

Next to these come such signs as the yellow or white clypeal bands of $C$. xanthopa and Phiale males, which have decided, contemporary releasing value for threat display.

Finally, in a confusing mixture, comes the mass of "decorations," including vestiges, characters linked genetically to selected structures, patterns aiding in camouflage, and mere byproducts of metabolism. Only rarely can their origins be satisfactorily discovered or inferred. They include the sexchromosome-controlled tufts of dark-phase male Maevia vittata (Painter, 1913), the scarlet-red of Phiale abdomens and the circles of colored scales around most salticid eyes. These circles occur as early as the second instar and are irrespective of sex. Possibly, among primitive salticids, they had adaptive value, making the large eyes or frontal regions more conspicuous in display; now they have no demonstrable function, and their early appearance, far back in ontogeny, indicates a vestigial, if not a purely metabolic, character.

A related instance is the occurrence of white scales on the legs of intermediate instars in Corythalia, followed by their obsolescence on the front of legs in adult males; they may well represent an old secondary or minor display character which has been superseded by iridescence; a similar explanation may apply to the reduction of clypeus white in adult male chalcea and fulgipedia.

The variable distal abdominal ocelli of Sassacus ocellatus, mentioned above, seem to belong rather definitely among the vestigial character group.

All of these relics, again in agreement with the principle of least effort, persist unless it takes less "effort" for the organisms to drop them than to carry them along

The old question as to the significance of elongate chelicerae recurs. Bristowe has pointed out that they are only rarely used in courtship or fighting, and also are unquestionably less efficient than those of the usual size (1929, p. 339). It seems to me that 
they are enlarged, not to aid fighting, but much as first legs are specialized, primarily for an increase in conspicuous area. It appears, too, that secondarily their very inefficiency may be adaptive in the way that a threat display is adaptive: the danger of mutual injury is reduced without reduction of the presumable toning value of aggressive behavior.

It is noteworthy that these enlarged chelicerae, in the genera with which I am familiar, occur in the middle groups: in the Dendryphantinae, and in Salticus (morphologically an advanced marpissinid), in which aggression reaching the contact stages is most developed. Elongate jaws occur also in the highly aberrant lyssomaninids, but I have never been able to induce any threat display in them whatsoever. Another point is that in some genera, for example Sassacus and Ashtabula, the length of the chelicerae is highly variable among individuals, exactly as in certain beetles (e.g., Beebe, 1947) without any reference to their general tone or health. No use as a specialized, female-holding tool, as is found in Pachygnatha, has ever been observed in a salticid.

In salticids, as seems increasingly clear in other groups, function appears basic, structure follows after. The male salticid raises his forelegs or middle legs, or jiggles his palps; elongation, thickening, blackening, whitening, polishing or fringing may or may not follow. A spider does not, as the older naturalists naively implied, show off his decorations; rather, his decorations evolved in a conspicuous position. Every experiment made in this study showed that motionfunction-was of more importance than morphological detail. This view does not, of course, rule out the obviously great reciprocal influence of behavior and morphology during selection. Nevertheless, in any general trend, it must be the function which usually changes first, while vestigial tufts and spots, seemingly placed to accent an obsolete display, persist indefinitely.

\section{Sexual Dimorphism and Display.}

The correspondence in forms of sexual dimorphism in both salticids and birds was discussed at length by the Peckhams (1889, $1890)$. Here their general points will only be summarized and remarks made concerning the relationship of dimorphism to female behavior. As in birds, dimorphism is of three principal types. First, and apparently most primitive, neither sex is strikingly marked, or greatly differentiated in secondary characteristics; display is primitive and the female remains completely passive (examples: Semorina, Mago); in the second type, sexual dimorphism is strong, the female remaining dull and adolescent in coloring and her behavior passive (examples: Sassacus flavicinctus, Plexippus paykullii, Corythalia chalcea); in the third, both sexes are strikingly marked and similar, with the female often acting aggressively or, in advanced groups, tending to reciprocal display with the male (examples: Sassacus ocellatus, Corythalia fulgipedia). However, there is by no means a fixed correspondence between female aggression and striking pattern: for example, the most aggressive females found at Rancho Grande were those of Eustiromastix sp.; structurally, this species is strongly dimorphic with the females dull and little differentiated from the young; they always killed the males shortly after mating if kept together, and, in courting, the males had to be excessively cautious. A similar situation occurs in some dendryphantinids (cf. Peckham, 1889). As in birds, all degrees of dimorphism, both of morphology and behavior, can sometimes be found at low taxonomic levels, including the genus. It seems certain that hormones and neurohumors are as deeply concerned in these characteristics as in vertebrates.

\section{E. Climate and Display.}

Another interesting aspect of phylogeny refers to a possible effect of climate on the development of display. It seems likely that there are fundamental differences in behavior in the tropics and in the north, which may well be responsible for some of the differences between the Rancho Grande observations and those in the temperate zone.

The differences in breeding season length is usually considerable. At Rancho Grande it is months long, while in the north the adult males are often active only a few days or several weeks. In the short-summered north the relatively few salticids which adapted themselves to the severe winters also had to adjust in less obvious ways. Basically this meant the more perfect coordination of the breeding mechanisms of the two sexes; in a short season there would be little time for the vagaries of physiological rhythms or of regressive behavior, both of which are so evident at Rancho Grande. Also, in a climate where many individuals of few species are the rule, instead of vice versa, there would be no economy in restricting a female to the single insemination which appears typical at Rancho Grande. Again, the same northern conditions might encourage the development of the almost communal displays described by Peckham $(1889$, p. 40), and which I have never had the fortune to see in the tropics. It must be remarked, however, that communal displays in birds reach a high tropical development, as in birds of paradise and cocks-of-the-rock.

Finally, in the brief northern summer persistent courtships and protracted fights apparently are usual, from accounts in the literature. By contrast, in Venezuela courtship and threat displays are almost always short; either they are unsuccessful, which is usually the case, and quickly broken off, or else they are consummated in a few minutes. This difference is probably also tied up 
with the leisure of physiological rhythm in the tropics, with the lack of a pressing hurry to coordinate the mechanisms.

\section{F. Displays as SPECIFIC BARRIERS.}

Almost every student of salticid behavior is familiar with the frequent occurrence of display between different species, both in courtship and in threat. At Rancho Grande, it was found that in general any A-tone male would initiate appropriate display before any moving male or female that showed a few sign stimuli roughly similar to those of its own species. The females, presumably because of the chemical factors, were invariably close relatives; the males, in inter-male display, had to conform in appearance only. The heterosexual pairs of species which displayed regularly to each other, under unconfined laboratory conditions, were the following: Corythalia chalcea and C. fulgipedia; Plexippus paykulli, female, and Eustiromastix sp., male; any two species of Phiale.

This weak selectivity would, on first sight, seem to indicate that differences in display have little value in erecting or maintaining specific barriers. Closer study, however, results in the following observations.

First, $r$ isplay is only initiated; it is rarely carrie' ${ }^{\prime}$ on beyond early Stage I. When it is continued longer (in courtship only), by a male of exceedingly high tone, the female always breaks away well before the end of Stage II. Even in experimental situations with chloroformed females, the male himself was never, in more than a dozen trials, seen actually to copulate; it seemed that in each case a mechanical barrier was reached in the epigynum. On the other hand, fertile eggs were secured after copulation with chloroformed females in one pair of Eustiromastix sp. and one of Corythalia chalcea, showing that the drugged condition of the female was not the final deterrent.

Second, when individuals of their own species are introduced to a pair of mismatched displaying spiders, attention is quite promptly turned to the appropriate newcomer.

The above does not of course show that inter-specific crosses may not occur in nature; it only indicates that, if they do so, they are probably unusual in the area studied, even though several pairs of closely related species occur, each having similar displays and occupying overlapping ecological niches. These include Phiale dybowskii with Phiale sp.; the latter with $P$. flammea; and Corythalia fulgipedia with $C$. chalcea.

The particulate nature of display explains its apparent inefficiency. It does not act as a single unit, but rather as a series of strainers of progressively finer mesh. An interspecific display is interrupted when the constantly changing stimulus configuration-releasing, directive or both-becomes too weak, from the viewpoint of one partner, to draw the requisite response. This positive response may, of course, appear active or passive, depending both on the stage of display and on the sex of the partner. The point at which the display breaks off depends largely on the physiological conditions of the two protagonists.

It was pointed out on p. 204 that display may aid in the economy of germ cells by preventing unproductive mésalliances. It seems clear, however, that as a practical barrier between established species it has relatively little importance; the primary walls are ecological and morphological. As in most other animal groups, there is usually slight overlapping of the microgeographical ranges, of the ultimate ecological niches, in closely related species; under natural conditions, interspecific display must occur but rarely. Also, even if such display runs its full course, the specific differences of palps and epigyna are probably in most cases effective final barriers.

In the formation of species, display may prove of more importance. As Mayr emphasizes (1947), the growth of geographic isolation is doubtless the essential factor in all species formation. Granting this precedence, it seems likely that cumulative slight differences in display, as in other behavior, often pave the way for final morphological breeding isolation. No one who has been struck, in other animal groups, by display distinctions within a species or subspecies in different parts of its range can doubt that functional change tends to precede structural differentiation. To give examples from my own experience, a crab and a bird may be mentioned. The waving rhythm of the fiddler, Uca pugnax rapax (Smith), varies from Porto Rico down through the islands to Trinidad and British Guiana, and on west through Venezuela to reach a peak of complexity in Cartagena, Colombia. Similarly, the choruses of chachalacas, Ortalis ruficauda (Jard.), when heard in Tobago and Caracas, sound as distinct as the calls of ducks and turkeys in a barnyard. The apparent display differences in Maevia vittata in Wisconsin and Connecticut (Peckham, 1889 , p. 53; Painter, 1913 , p. 634) hint at similar geographic distinctions, of obvious evolutionary interest, among salticid spiders.

\section{SUMMARY.}

(See also sectional summaries on pp. 184, $185,187,190,192$ and 196-199).

1. A study was made of the epigamic display behavior of fifteen species of salticid spiders distributed through seven subfamilies. All observations and experiments were made at Rancho Grande, Parque Nacional de Aragua, Venezuela.

2. The factors comprising the innate releasing mechanisms prove to be similar throughout the family, but their relative importance varies from genus to genus even within the same subfamily, and in minor sign stimuli, from species to species. 
3. The principal controlling factors of the internal releasing mechanism appear to be age, fluctuating epigamic rhythm, hunger, thirst, fatigue, overstimulation and attention.

4. The epigamic rhythm plays an especially important part in daily responses. Only spiders of the highest tone (i.e., lowest epigamic threshold) usually carry courtship to completion in either field or laboratory. No regular periodicity, however, was observed.

5. The controlling factors of the external releasing and directive mechanisms are divided into those of the physical enviroment and of the configurational stimulus situation (sign stimuli).

6. Temperature, humidity and light are recognized as the principal environmental variables. Display may be released throughout a wide range of these factors.

7. Tactile, chemical and visual stimuli are regarded as the major components of the configurational stimulus situation.

8. Display cannot be released through touch, although it plays an important role in the final stages of courtship.

9. Neither is display released through chemical stimuli alone although, in the presence of certain visual stimuli, they are important secondary releasers of courtship. They appear to stimulate two overlapping senses, contact chemoperception (chemotaxis) and distance or airborne chemoperception (apparently akin to odor). The importance of each type, both in comparison with each other and with visual stimuli, depends on the degree of visual dominance of the genus; in the more primitive genera, although they too are visually dominated, greater dependence is placed on chemical senses than in more advanced forms. Absence of chemical stimuli sometimes changes courtship to threat display or actual fighting.

10. Visual stimuli alone are sufficient to release display. The principal factors of the visual stimulus situation appear to be motion, distance, size, form, pattern, intensity and color. The relative importance as well as the characteristics of these factors varies throughout the family, and no single one ever proved to be an essential, primary releaser.

11. In general, motion, form and apparent size are the most important factors, and the sign stimuli among these categories in each genus or species may vary within fairly wide limits. Pattern, intensity (except for visibility contrast) and color, on the other hand, have little releasing value. Sometimes, however, a special contrasting or colored marking does act as a definite releaser or director for display. An example is the yellow clypeal band of $C$. xanthopa, which, in combination with an adequate supporting visual configuration, is a releaser for inter-male threat display. An undoubted director is the white sub-basal abdominal band of many females, which acts as a copulation guide. Most clypeal and palp markings, iridescent patches, leg fringes, etc., have no high releasing value, since complete display readily takes place in their absence without strengthening of other elements in the stimulus configuration.

12. This apparent uselessness of epigamic "decorations" does not, of course, mean that they are necessarily lacking in adaptive value for display or that selection has not been acting upon them toward that end. It is merely a further instance of the unequal value of sign stimuli, and of the lack of a lock-key releasing formula: the effective configuration is made up of many small bits; together, they have cumulative releasing, directive or merely excitatory value, but a number may be missing from an individual situation without noticeable effect. To only one dynamic compound element can the term "primary releaser" be applied: this is a unit composed of any of several adequate visual stimuli; very few releasers and directors are of even secondary importance.

13. Evidence is presented that color perception occurs at least in the yellow region; the two tested genera, Corythalia and Phiale, appear to be insensitive to the red end of the spectrum.

14. All of the components - external and internal-of the innate releasing and directive mechanism form a closely woven, mutually dependent, dynamic whole. When one important part of the normal configuration is weak or absent, reinforcement of another part-including especially high tone in the receptor spider-can bring a complete response: the concept of heterogeneous summation is as important in salticids as in other animal groups.

15. Nevertheless, in the field courtships are usually incomplete when the stimulus configuration is weak in any particular.

16. Although individual spiders, particularly females, sometimes showed slight, temporary idiosyncrasies, display patterns are fixed and instinctive. No evidence at all was found of display learning, imprinting or copying of other species' patterns.

17. Displacement behavior is confined to actions which normally occur in the sexual field.

18. Little evidence has been found of dominance relationships in the vertebrate sense; temporary dominance seems to be due to fluctuating epigamic rhythms.

19. Sociality and home range concepts apply in some species on a primitive level; no defended territories were observed.

20. The functions of courtship in this family are held to be stimulatory with a simultaneous blocking of hunger drives; the concept of "recognition" does not seem to be necessary. 
21. The explanations and functions of threat display depend on the phylogenetic position of the genus in reference to chemical dependence. In the apparently most primitive groups, the males take little or no notice of one another; there is neither fighting nor threat display, nor even inter-male courtship; mirror display does not normally occur. In intermediate genera, with greater visual dependence but strong reliance on airborne chemical stimuli, courtship and threat are similar, usually identical in the first stage, and appear to result from the mistaking of males for females, as suggested by Bristowe. When the mistake is "discovered," fighting often results. In the genera with the least dependence on chemical stimuli, however, courtship and threat are distinct, fighting does not occur and mirror display is readily induced. In these forms, and to some extent in the intermediate group, threat display seems clearly to have a stimulatory function which is totally apart from any direct competition for mates, and which is not concerned in territorial defense.

22. A tentative hypothetical phylogeny is presented, in which the studied genera and some northern relations are placed according to dependence on chemical stimuli, display criteria and method of locomotion. The correlation with morphological characters, to be specially treated in a subsequent paper, are indicated. The evolutionary trend within all the subfamilies appears to be similar in various major characteristics.

23. The origins of most display movements appear to be in accordance with the principle of economical permutation, since the majority probably developed from ordinary motions connected with daily activity.

24. Atavistic behavior was noted in which low-tone, overstimulated or senile individuals of advanced genera resorted to inappropriate aggression and chemotaxis; this was strikingly similar to the normal behavior of more primitive groups.

25. It is held that in salticids, the display motions probably preceded most morphological secondary sexual characteristics, and that the latter often persist vestigially after they have ceased to function as part of the display stimulus configuration.

26. In salticids, as in other groups, sexual dimorphism may occur in all degrees within a closely related group, even within the same genus, and appears to hold little phylogenetic significance. In species having both sexes strongly and similarly marked, the females are often more aggressive than usual and tend to perform definite reciprocal or mutual displays.

27. It is suggested that tropical salticids may differ in behavior from northern forms because of the prolonged breeding season, which necessitates less close correlation of breeding rhythms between the sexes.

28. Although it is agreed that geographic isolation is the prime essential of species formation, it appears that growing display differences may be a strong secondary factor in salticid speciation. As a barrier between species already established, however, display seems to be an effective, but usually supernumerary, isolating mechanism.

\section{REFERENCES.}

Armstrong, E. A.

1947. Bird display and behavior. $431 \mathrm{pp}$. Oxford University Press, New York.

BeEBE, W.

1928. Beneath Tropic Seas. 234 pp. G. P. Putnam's Sons, New York.

1938. Zaca Venture. 308 pp. Harcourt Brace \& Co., New York.

1947. Notes on the Hercules beetle, Dynastes hercules (Linn.), at Rancho Grande, Venezuela, with special reference to combat behavior. Zoologica, Vol. 32, pp. 109-116.

BEEBE, W. \& CRANE, J.

1947. Ecology of Rancho Grande, a subtropical cloud forest in northern Venezuela. Zoologica, Vol. 32, No. 5, pp. 43-60.

BERLAND, L.

1914. Nouvelles observations d'accouplements d'Araignées. Arch. Zool. Exp. et Gen., Vol. 54, Notes et Revue, No. 5, pp. 109-119.

1923. Contributions a l'étude de la biologie des Arachnides (1er Memoire). Ann. Soc. Ent. France, Vol. 91, pp. 193-208.

1927. Contributions a l'étude de la biologie des Arachnides (2e Memoire). Arch. Zool. Exp. et Gen., Vol. 66, Notes et Revue, No. 2, pp. 7-29.

BIRREN, F.

1938. Monument to color. Warde, McFarlane, New York.

BONNET, P.

1933. Cycle vital de Philaeus chrysops Poda. Arch. zool. exper., Vol. 75, pp. 129-144.

1945. Bibliographia araneorum. Analyse methodique de toute la litterature araneologique jusqu'en 1939. Vol. I. Les Frères Douladoure. Toulouse.

BRIstowe, W. S.

1929. The mating habits of spiders, with special reference to the problems surrounding sex dimorphism. Proc. Zool. Soc. London, 1929. pp. 309-358.

1931. The mating habits of spiders: a second supplement. Proc. Zool. Soc. London, 1931, pp. 1401-1412.

1941. The Comity of Spiders. Vol. II. pp. 219560 . Printed for the Ray Society, London.

Bristowe, W. S. \& LOCKeT, G. H.

1926. Courtship of British Lycosid Spiders. Proc. Zool. Soc. London, 1926, pp. 317347. 
Bur', W. H.

1943. Territoriality and home range concepts as applied to mammals. Jour. Mamm., Vol. 24, pp. 346-352.

CHICKERING, A. M.

1946. The Salticidae (Spiders) of Panama. Bull. Mus. Comp. Zool., Harvard, Vol. 97, pp. 1-474.

Crane, J.

1941. Eastern Pacific Expeditions of the New York Zoological Society. XXVI. Crabs of the genus Uca from the west coast of Central America. Zoologica, Vol. 26, pp. 145-208.

1948.1. Comparative biology of salticid spiders at Rancho Grande, Venezuela. Part I. Systematics and life histories in Corythalia. Zoologica, Vol. 33, pp. 1-38.

1948.2. Comparative biology of salticid spiders at Rancho Grande, Venezuela. Part II. Methods of collection, culture, observation and experiment. Zoologica, Vol. 33, pp. 139-145.

1949. Comparative biology of salticid spiders at Rancho Grande, Venezuela. Part III. Systematics and behavior in representative new species. Zoologica, Vol. 34, pp. 31-52.

EHLERS, M.

1939. Untersuchungen uber formen akitiver lokomotien bei spinnen. Zool. Jahrb. (Abt. f. Syst.), Vol. 72, pp. 373-499.

EMERTON, J. H.

1909. Suppl. to the New England Spiders. Trans. Acad. Arts Sci., Vol. 14, pp. $173-236$

Evans, L. T.

1938. Cuban field studies on territoriality of the lizard Anolis sagrei. Jour. Comp. Psych., Vol. 25, pp. 97-127.

Frisch, K. voN.

1949. Die polarisation des himmelslichtes als orientierender factor bei den tanzen der bienen. Experientia, Vol. V/4, pp. 142-148.

GerhardT, U.

1921. Vergleichende studien uber die morphologie der mannlichen tasters und die biologie der kopulation der spinnen. Arch. f. Nautrageschichte, Vol. 87, Abt. A, Heft 4, pp. 125-137.

HARTRIDGE, $\mathrm{H}$.

1945. Acoustic control in the flight of bats. Nature, Vol. 156 (3965); pp. 490-494.

HEIL, K. H.

1936. Beitrage zur physiologie und psychologie der springspinnen. Zeitschr. Verg. Physiol., Vol. 23, pp. 1-25.

HOMANN, H,

1928. Beitrage zur physiologie der spinnenaugen. Zeitschr. Verg. Physiol., Vol. 7, pp. 201-268.

\section{KAESTNGR, A.}

1949. Uber den farbsinn der spinnen. Die Naturwissenschaften, Vol. 36, Part 2, pp. 58-59.
KASTON, B. J.

1936. The senses involved in the courtship of some vagabond spiders. Entomologica americana, Vol. 16, pp. 97-166.

1948. Spiders of Connecticut. State of Conn., State Geol. \& Nat. Hist. Survey, Bull. No. 70 .

Kettienell, H. B. D.

1946. Female assembling scents with reference to an important paper on the subject. Entomologist, Vol. 79, pp. 8-14.

KORZYBSKI, A.

1948. Science and sanity. Third Edition. International Non-Aristotelian Library Publishing Co.

LACK, D.

1943. The life of the robin. H. F. \& G. Witherby Ltd., London.

I.ORENZ, K.

1935. Der kumpan in der umwelt des vogels. Jour. f. Ornith., Vol. 83, pp. 137-213, $289-413$.

1941. Vergleichende bewegungsstudien an Anatinen. Jour. f. Ornith., Vol. 84, pp. 194-294.

MAYR, E.

1947. Ecological factors in speciation. Evolution, Vol. 1, pp. 263-288.

Menninger, K. A.

1945. The human mind. Third Edition. Alfred A. Knopf, N. Y.

Monterosso, B.

1924. Osservazioni ed experimenti intorno alla vita sessuale dei ragni (Salticus). Atti accad. sci. nat. Catania, (5), Vol. 14, No. 7, pp. 1-31.

Montgomery, H., JR.

1910. Significance of the courtship and secondary sexual characters of Araneads. Amer. Nat., Vol. 44, pp. 151-177.

PAINTER, T. S.

1913. On the dimorphism of the males of Maevia vittata. Zool. Jahrb., Abt. $f$. Syst., Vol. 35, pp. 625-636.

Peскнам, G. W. \& E. G.

1887. Some observations on the mental powers of spiders. Jour. Morph., Vol. 1, pp. 383-419.

1889. Observations on sexual selection in spiders of the family Attidae. Occ. Papers Wisconsin Nat. Hist. Soc., Vol. 1, pp. 3-60.

1890. Additional observations on sexual selection in spiders of the family Attidae. Occ. Papers Wisconsin Nat. Hist. Soc., Vol. 1, pp. 117-151.

1894. The sense of sight in spiders with some observations on the color sense. Trans. Wisc. Acad. Sci. Arts \& Letters, Vol. 10, pp. 231-261.

Petrunkevitch, A.

1910. Courtship in Dysdera crocata. Biol. Bull., Vol. 19, pp. 127-219.

1911.1. Sense of sight, courtship and mating in Dugesiella hentzi (Girard) a Thera- 
phosid Spider from Texas. Zool. Jahr., Syst., Vol. 31, pp. 355-376.

1911.2. Courtship in Tarantulas. Entomological News, Vol. 22, p. 127.

1926. The value of instinct as a taxonomic character in spiders. Biol. Bull., vol. 50, pp. 427-432.

1928. Systema Araneorum. Trans. Conn. Acad. Arts \& Sci., Vol. 29, pp. 1-270.

1939. Catalogue of American spiders. Part One. Trans. Conn. Acad. Arts \& Sci. Vol. 33, pp. 133-338.

SAVORY, T. H.

1928. The biology of spiders. $376 \mathrm{pp}$. Sidgwick \& Jackson, London.

THOMAS, M.

1929. L'instinct chez les Araignées (suite). XIII. À propos de l'adaptabilité de l'instinct. XIV. Observations sur Philaeus chrysops. X (suite). Observa- tions sur Ocyale (Pisaura) mirabilis Clerck. Bull. Ann. Soc. Ent. Belg., Vol. 69 , pp. 253-272.

THORPE, W. H.

1949. Orientation and methods of communication of the honey bee and its sensitivity to the polarization of the light. Nature, Vol. 164 (4157), pp. 11-14.

TINBERGEN, N.

1948. Social releasers and the experimental method required for their study. Wilson Bull., Vol. 60, pp. 6-51.

Wallace, A.

1878. Tropical Nature. London.

1889. Darwinism. London.

ZIPF, C. K.

1949. Human behavior and the principle of least effort. Addison-Wesley Press, Cambridge, Mass.

\section{EXPLANATION OF THE PLATE.}

\section{Plate I.}

FIG. 1. Plexippus paykullii. Courtship, Stage II. Typical of Stage II courtship in the Salticidae. In this family, specialization of display occurs principally in the earlier phases.

FIG. 2. Observation table at Rancho Grande, showing presentation of a dried spider to a test salticid. The spider is mounted on an L-shaped strip of pasteboard. The table is covered with oilcloth ruled in concentric circles for distance observations. When chemotaxis was to be eliminated, fresh sheets of paper were used in each test. 


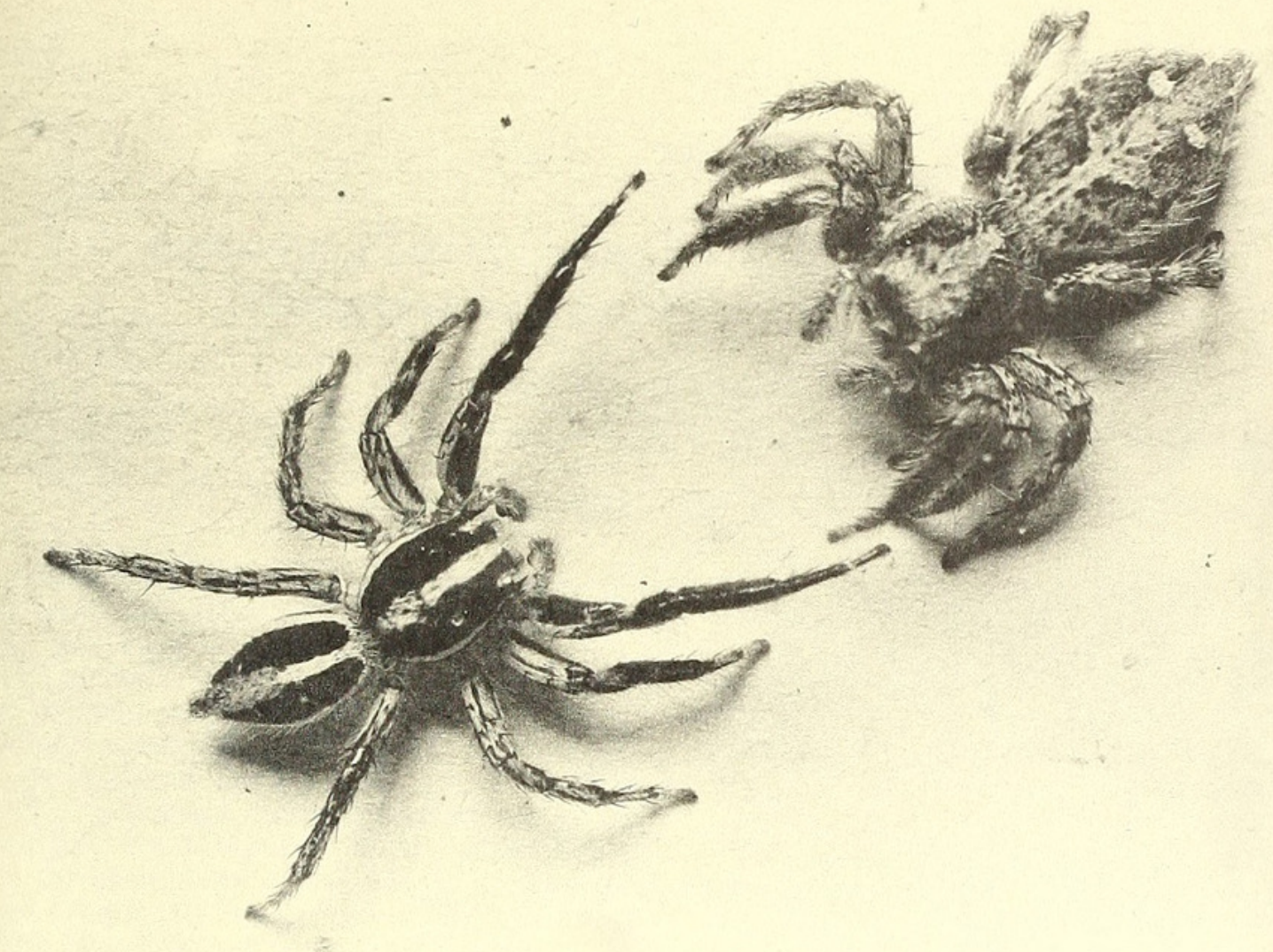

FIG. 1.

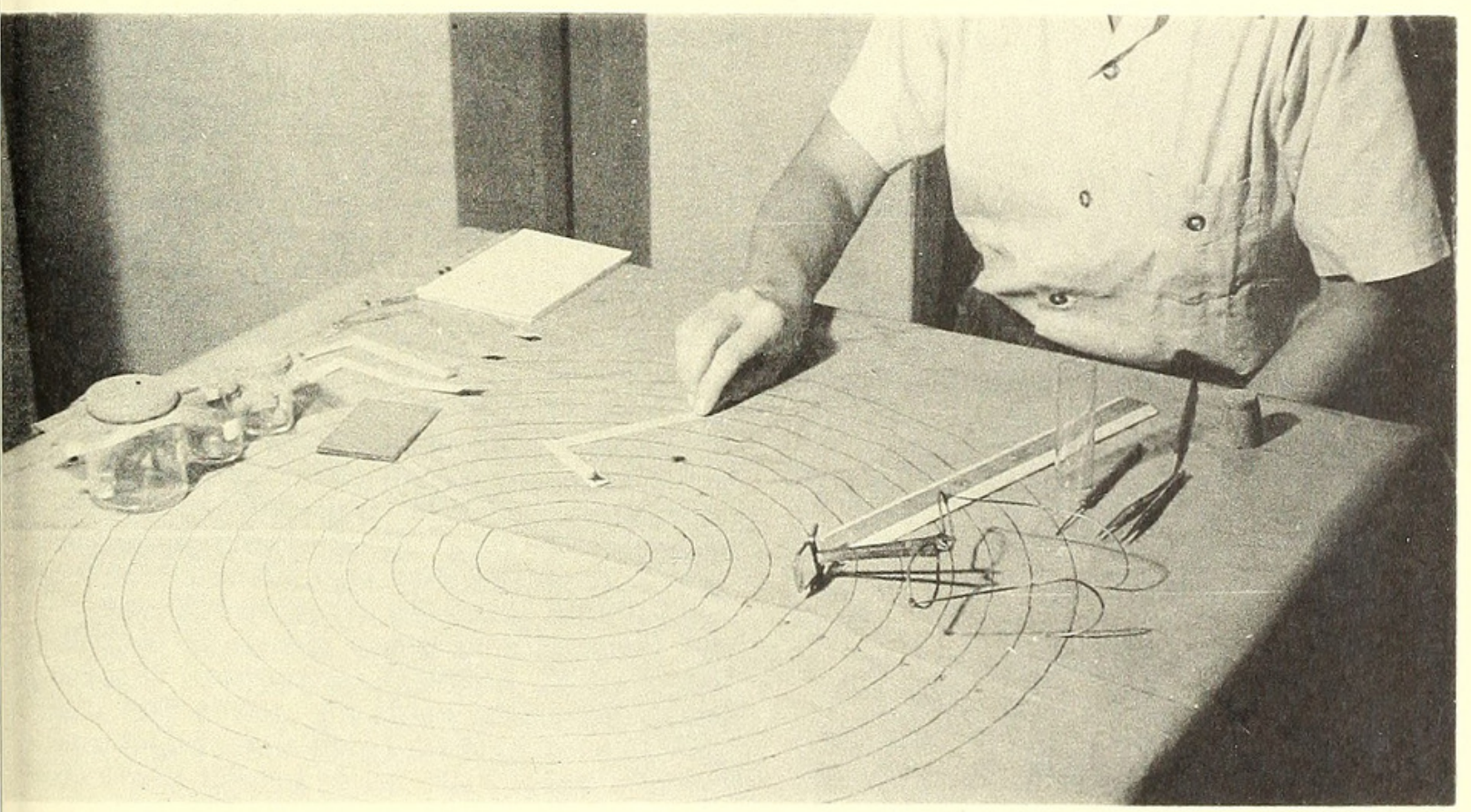

FIG. 2.

COMPARATIVE BIOLOGY OF SALTICID SPIDERS AT RANCHO GRANDE, VENEZUELA. PART IV. AN ANALYSIS OF DISPLAY. 


\section{$2 \mathrm{BHL}$ Biodiversity Heritage Library}

Crane, Jocelyn. 1949. "Comparative biology of salticid spiders at Rancho Grande, Venezuela. Part IV. An analysis of display." Zoologica : scientific contributions of the New York Zoological Society 34(17), 159-214. https://doi.org/10.5962/p.203518.

View This Item Online: https://www.biodiversitylibrary.org/item/207467

DOI: https://doi.org/10.5962/p.203518

Permalink: https://www.biodiversitylibrary.org/partpdf/203518

\section{Holding Institution}

Smithsonian Libraries

\section{Sponsored by}

Biodiversity Heritage Library

\section{Copyright \& Reuse}

Copyright Status: In Copyright. Digitized with the permission of the rights holder

Rights Holder: Wildlife Conservation Society

License: http://creativecommons.org/licenses/by-nc/3.0/

Rights: https://www.biodiversitylibrary.org/permissions/

This document was created from content at the Biodiversity Heritage Library, the world's largest open access digital library for biodiversity literature and archives. Visit BHL at https://www.biodiversitylibrary.org. 